\title{
A Post-PKS Oxidation of the Amphotericin B Skeleton Predicted to be Critical for Channel Formation is Not Required for Potent Antifungal Activity
}

\author{
Daniel S. Palacios, Thomas M. Anderson and Martin D. Burke \\ Roger Adams Lab, Department of Chemistry, University of Illinois at Urbana-Champaign, \\ Urbana IL 61801
}

\section{Supporting Information}

Part A

I. General methods

$\mathrm{S} 1-\mathrm{S} 3$

II. Synthesis of AmB derivatives

$\mathrm{S} 3-\mathrm{S} 36$

III. 2D-NMR acquisition and data processing

S37-S42

IV. Energy minimization calculations

$\mathrm{S} 42-\mathrm{S} 49$

V. Antifungal assays

S50-S52

VI. Liposome studies

S52-S53

Part B

VII. NMR spectra

S54-S113

\section{Complete Versions of Truncated References}

(4e) Zumbuehl, A.; Jeannerat, D.; Martin, S.E.; Sohrmann, M.; Stano, P.; Vigassy, T.; Clark, D.D.; Hussey, S.L.; Peter, M.; Peterson, B.R.; Pretsch, E.; Walde, P.; Carreira, E.M. Angew. Chem. Int. Ed. 2004, 43, 5181-5185.

(7b) Baginski, M.; Resat, H.; McCammon, J.A. Mol. Pharmacol. 1997, 52, 560-570.

(8) (a) McNamara, C.M.; Box, S.; Crawforth, J.M.; Hickman, B.S.; Norwood, T.J.; Rawlings, B.J. J. Chem. Soc. Perkin Trans. 1 1998, 83-87. (b) Caffrey, P.; Lynch, S.; Flood, E. Finnan, S.; Oliynyk, M. Chem. Biol. 2001, 8, 713723.

(10) (a) Chéron, M.; Cybulska, B.; Mazerski, J.; Grzybowska, J.; Czerwinski, A.; Borowski, E. Biochem. Pharmacol. 1988, 37, 827-836. (b) Matsumori, N.; Yamaji, N.; Matsuoka, S.; Oishi, T.; Murata, M. J. Am. Chem. Soc. 2002, 124, 4180-4181. (e) Umegawa, Y.; Matsumori, N.; Oishi, T.; Murata, M. Tetrahedron Lett. 2007, 48, 3393-3396.

(13) (a) Nicolaou, K.C.; Chakraborty, T.K.; Ogawa, Y.; Daines, R.A.; Simpkins, N.S.; Furst, G.T. J. Am. Chem. Soc. 1988, 110, 4660-4672. (b) A degradative synthesis of 4 is described in the patent literature: Driver, M.J.; Greenless, A.R.; and MacPherson, D.T. U.S. Patent \# 5,204,330, 1993. (c) MacPherson, D.T.; Corbett, D.F.; Costello, B.C.; Driver, M.J.; Greenless, A.R.; Maclachlan, W.S.; Shanks, C.T.; Taylor, A.W. Adventures in Polyene Macrolide Chemistry :The Derivatisation of Amphotericin B. In Recent Advances in the Chemistry of Anti-Infective Agents; Bently P.H. and Ponsford, R. Eds.; Royal Society of Chemistry : Cambridge, 1993; Special Publication No. 119, pp 205-222. (d) An impure sample of 4 was prepared via genetic engineering of the producer: Carmody, M.; Murphy, B.; Byrne, B.; Power, P.; Rai, D.; Rawlings, B.; Caffrey, P. J. Biol. Chem. 2005, 280, 34420-34426.

(15) Garegg, P.J.; Samuelsson, B.; J. Chem. Soc., Perkin Trans. I 1980, 2866-2869.

(18) Hutchins, R.O.; Kandasamy, D.; Dux, F.; Maryanoff, C.A.; Rotstein, D.; Goldsmith, B.; Burgoyne, W.; Cistone, F.; Dalessandro, J.; Puglis, J. J. Org. Chem. 1978, 43, 2259-2267.

(19) (a) Sowinski, P.; Pawlak, J.; Borowski, E.; Gariboldi, P. Magn. Res. Chem. 1992, 30, 275-279.

(24) Fujii, G.; Chang, J.-E.; Coley, T.; Steere, B. Biochemistry 1997, 36, 4959-4968.

\section{General Methods}

Materials. Commercially available materials were purchased from Aldrich Chemical Co. (Milwaukee, WI), Fisher Scientific (Hampton, NH), Lipoid (Luwigshafen, Germany) and Silicycle (Quebec, Canada) and used without further purification unless noted otherwise. 
Amphotericin B was a generous gift from Bristol-Myers Squibb Company. All solvents were dispensed from a solvent purification system that passes solvents through packed columns according to the method of Pangborn and coworkers ${ }^{1}$ (THF, $\mathrm{Et}_{2} \mathrm{O}, \mathrm{CH}_{2} \mathrm{Cl}_{2}$ : dry neutral alumina; DMSO, DMF, $\mathrm{CH}_{3} \mathrm{OH}$ : activated molecular sieves). Hexanes, 2,6-lutidine, triethylamine, and pyridine were freshly distilled under nitrogen from $\mathrm{CaH}_{2}$. Camphorsulfonic acid was recrystallized from ethyl acetate. Water was doubly distilled or obtained from a Millipore (Billerica, MA) MilliQ water purification system.

Reactions. Due to the light and air sensitivity of amphotericin B, all manipulations were carried out under low light conditions and compounds were stored under an anaerobic atmosphere. All reactions were performed in oven- or flame-dried glassware under an atmosphere of argon unless otherwise indicated. Reactions were monitored by analytical thin layer chromatography performed using the indicated solvent on E. Merck silica gel $60 \mathrm{~F}_{254}$ plates $(0.25 \mathrm{~mm})$. Compounds were visualized using a UV $\left(\lambda_{254}\right)$ lamp or stained by an acidic solution of $p$ anisaldehyde. Alternatively, reactions were monitored by RP-HPLC using an Agilent 1100 Series HPLC system equipped with a Sunfire ${ }^{\mathrm{TM}} \mathrm{C}_{18} 5$ micron 10 × $250 \mathrm{~mm}$ column (Waters Corp. Milford, MA) with UV detection at $406 \mathrm{~nm}$ and the indicated eluent and flow rate.

Purification and Analysis. Flash chromatography was performed as described by Still and coworkers $^{2}$ using the indicated solvent on E. Merck silica gel $60230-400$ mesh or on Silicycle $17 \%$ carbon $\mathrm{C}_{18} 230-400$ mesh reverse phase silica gel. ${ }^{1} \mathrm{H}$ NMR spectra were recorded at $23{ }^{\circ} \mathrm{C}$ on a Varian Unity Inova Narrow Bore spectrometer operating at a ${ }^{1} \mathrm{H}$ frequency of $500 \mathrm{MHz}$ with a Varian $5 \mathrm{~mm}{ }^{1} \mathrm{H}\left\{{ }^{13} \mathrm{C} /{ }^{15} \mathrm{~N}\right\}$ pulsed-field gradient $\mathrm{Z}$ probe or a Varian Unity Inova spectrometer operating at a ${ }^{1} \mathrm{H}$ frequency of $600 \mathrm{MHz}$ with a Varian $5 \mathrm{~mm}{ }^{1} \mathrm{H}\left\{{ }^{13} \mathrm{C} /{ }^{15} \mathrm{~N}\right\}$ pulsedfield gradient X,Y,Z probe. Chemical shifts $(\delta)$ are reported in parts per million (ppm) downfield from tetramethylsilane and referenced internally to the residual protium in the NMR solvent $\left(\mathrm{CHD}_{2} \mathrm{OD}, \delta=3.31\right.$, center line, $\mathrm{CD}_{3} \mathrm{C}(\mathrm{O}) \mathrm{CHD}_{2}, \delta=2.05$, center line) or to added tetramethylsilane. Data are reported as follows: chemical shift, multiplicity ( $\mathrm{s}=$ singlet, $\mathrm{d}=$ doublet, $\mathrm{t}=$ triplet, $\mathrm{dd}=$ doublet of doublets, $\mathrm{m}=$ multiplet, $\mathrm{b}=$ broad, app = apparent), coupling constant $(J)$ in Hertz $(\mathrm{Hz})$ and integration. For compounds $\mathbf{1 7}$ (a more soluble derivative of $\mathbf{1}$ ), $\mathbf{2}$, 21 (a more soluble derivative of 3), and 23 (a more soluble derivative of 4), proton and coupling constant assigments were made using a variety of two-dimensional NMR techniques including phase-sensitive COSY experiments combined with amplitude constrained multiplet evaluation $(\mathrm{ACME})^{3}$ (see Section III for a detailed discussion). ${ }^{13} \mathrm{C}$ spectra were recorded at $23{ }^{\circ} \mathrm{C}$ with a Varian Unity Inova spectrometer operating at a ${ }^{13} \mathrm{C}$ frequency of $125 \mathrm{MHz}$ with a $5 \mathrm{~mm}$ Nalorac gradient $\left\{{ }^{13} \mathrm{C} /{ }^{15} \mathrm{~N}\right\}{ }^{1} \mathrm{H}$ quad probe or a Varian Unity Inova spectrometer operating at a ${ }^{13} \mathrm{C}$ frequency of $150 \mathrm{MHz}$ and equipped with a Varian $5 \mathrm{~mm} 600 \mathrm{DB}$ Auto X probe. Chemical shifts $(\delta)$ are reported downfield of tetramethylsilane and are referenced to the carbon resonances in the NMR solvent $\left(\mathrm{CD}_{3} \mathrm{OD}, \delta=49.0\right.$, center line, $\mathrm{CD}_{3} \mathrm{C}(\mathrm{O}) \mathrm{CD}_{3}, \delta=29.8$, center line $)$ or to added tetramethylsilane $(\delta=0.00)$. MS analysis was performed with an Applied Biosystems Micromass Ultima system with ESI ionization. High resolution mass spectra (HRMS) were obtained at the University of Illinois mass spectrometry facility. All synthesized compounds (2-4 and 7-23)

\footnotetext{
${ }^{1}$ Pangborn, A.B.; Giardello, M.A.; Grubbs, R.H.; Rosen, R.K.; Timmers, F.J. Organometallics 1996, 15, 15181520.

${ }^{2}$ Still, W.C.; Kahn, M.; Mitra, A. J. Org. Chem. 1978, 43, 2923-2925.

${ }^{3}$ Delaglio, F.; Wu, Z.; Bax, A. J. Magn. Reson. 2001, 149, 276-281.
} 
gave HRMS within $5 \mathrm{ppm}$ of the calculated values. The purity of amphotericin $\mathrm{B}$ and its derivatives was determined by HPLC analysis using a Waters SunFire Prep $\mathrm{C}_{18}$ OBD 5 micron $30 \times 150 \mathrm{~mm}$ Lot \# 168I161701 column with detection at $406 \mathrm{~nm}$ and an eluent of acetonitrile and aqueous ammonium acetate unless otherwise indicated.

\section{Synthesis of AmB derivatives}
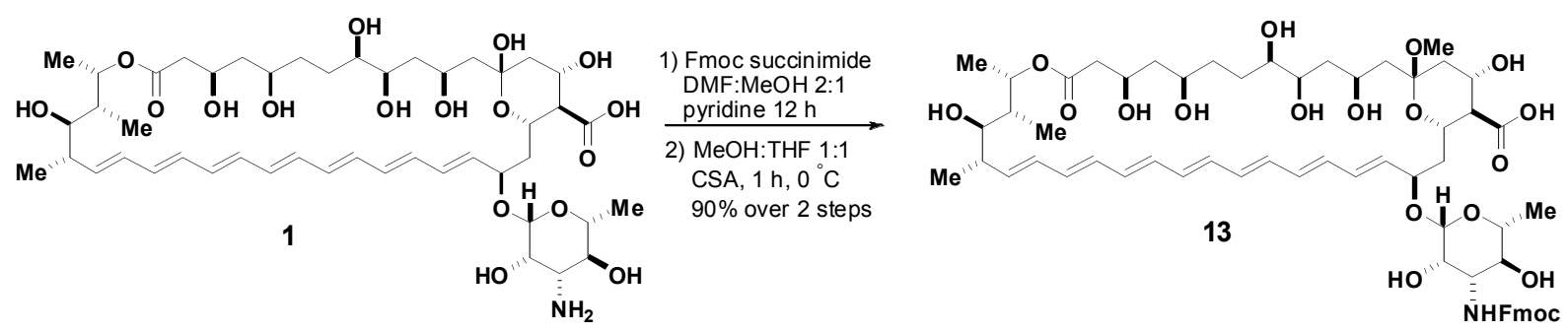

\section{Methyl ketal 13}

A round bottom flask was charged with amphotericin B $(1.5 \mathrm{~g}, \sim 55 \%$ pure, ca. $0.891 \mathrm{mmol}, 1$ eq) and Fmoc-succinimide $(0.840 \mathrm{~g}, 2.48 \mathrm{mmol}, 2.8 \mathrm{eq})$ which were dissolved in a mixture of DMF:MeOH 2:1 (105 mL) at $23{ }^{\circ} \mathrm{C}$. Pyridine (0.84 mL, $\left.10.22 \mathrm{mmol}, 11.5 \mathrm{eq}\right)$ was subsequently added and the reaction was stirred for 12 hours. The reaction mixture was then poured into diethyl ether $(1.8 \mathrm{~L})$ stirring at $0{ }^{\circ} \mathrm{C}$. After stirring for 30 minutes at $0{ }^{\circ} \mathrm{C}$ the resulting yellow precipitate was isolated via Büchner filtration using Whatman 50 filter paper to afford a yellow solid. The residual solvent was removed by coevaporating with acetonitrile $(3 \times 20 \mathrm{~mL})$ and storing under vacuum for one hour. The resulting powder $(1.69 \mathrm{~g}, \mathrm{ca} .0 .8 \mathrm{mmol})$ was dissolved in THF:MeOH 1:1 (50 mL) and cooled to $0{ }^{\circ} \mathrm{C}$. To this solution was added camphorsulfonic acid $(0.100 \mathrm{~g}, 0.438 \mathrm{mmol}, 0.55 \mathrm{eq})$ and the resulting mixture was stirred for 1 hour at $0{ }^{\circ} \mathrm{C}$. The reaction was then quenched at $0{ }^{\circ} \mathrm{C}$ with triethylamine $(0.06 \mathrm{~mL}, 0.438 \mathrm{mmol}, 0.55 \mathrm{eq})$ and gravity filtered. The filtrate was concentrated in vacuo until a yellow solid began to precipitate. The resulting supersaturated solution was poured into hexanes:diethyl ether 1:1 $(800 \mathrm{~mL})$ and the yellow precipitate was collected via Büchner filtration and washed with ethyl acetate:diethyl ether 1:1 (200 mL) to yield 13 as a yellow solid (1.33 g, 70\% purity, ca. $0.80 \mathrm{mmol}, c a .90 \%$ over two steps). This material was carried forward without further purification.

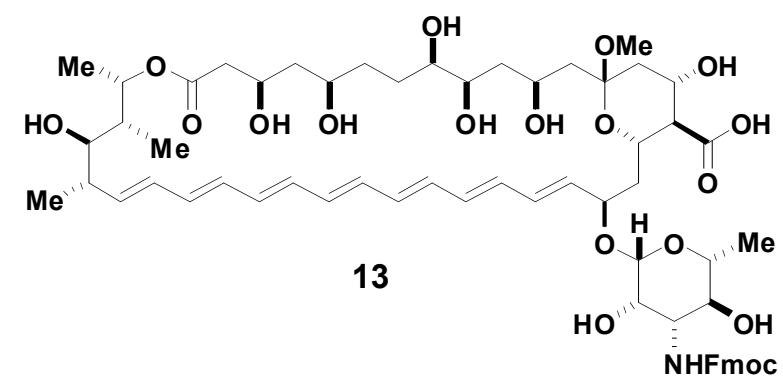

TLC $\left(\mathrm{CH}_{2} \mathrm{Cl}_{2}: \mathrm{MeOH} 5: 1\right)$

$\mathrm{R}_{\mathrm{f}}=0.15$, stained by anisaldehyde

HPLC

$\mathrm{tR}=13.2 \mathrm{~min}$; flow rate $=4 \mathrm{~mL} / \mathrm{min}$, gradient of $5 \rightarrow 95 \% \mathrm{MeCN}$ in $5 \mathrm{mM}$ ammonium acetate over $15 \mathrm{~min}$. 
${ }^{1} \mathrm{H}$ NMR (500 MHz, pyridine $\left.d-5: \mathrm{CD}_{3} \mathrm{OD} 10: 1\right)$

$\delta 7.86(\mathrm{~d}, J=7.5 \mathrm{~Hz}, 2 \mathrm{H}), 7.73(\mathrm{t}, J=8 \mathrm{~Hz}, 2 \mathrm{H}), 7.43(\mathrm{t}, J=7.5 \mathrm{~Hz}, 2 \mathrm{H}), 7.28(\mathrm{dd}, J=2$, $8 \mathrm{~Hz}, 2 \mathrm{H}), 6.59-6.34(\mathrm{~m}, 12 \mathrm{H}), 6.23(\mathrm{dd}, J=6.5,14 \mathrm{~Hz}, 1 \mathrm{H}), 5.66(\mathrm{dd}, J=10,15 \mathrm{~Hz}$, $1 \mathrm{H}), 4.97$ (bs, 1H), 4.92 (bs, 1H), 4.69 (bs, 1H), 4.54 (app t, $J=9.5 \mathrm{~Hz}, 1 \mathrm{H}), 4.52-4.31$ $(\mathrm{m}, 4 \mathrm{H}) 4.31(\mathrm{bs}, 1 \mathrm{H}), 4.26-4.20(\mathrm{~m}, 3 \mathrm{H}), 4.07-4.01(\mathrm{~m}, 2 \mathrm{H}), 3.87$ (app dd, $J=7.5,16.5$ $\mathrm{Hz}, 2 \mathrm{H}), 3.67-3.63(\mathrm{~m}, 2 \mathrm{H}), 3.58(\operatorname{app~d}, 10.5 \mathrm{~Hz}, 1 \mathrm{H}) 3.48$ (app d, $J=8.5 \mathrm{~Hz}, 1 \mathrm{H}), 3.28$ $(\mathrm{s}, 3 \mathrm{H}), 2.77-2.54(\mathrm{~m}, 5 \mathrm{H}), 2.45(\mathrm{dd}, J=3.5,16.5 \mathrm{~Hz}, 1 \mathrm{H}), 2.08-2.00(\mathrm{~m}, 4 \mathrm{H}), 1.88-1.72$ $(\mathrm{m}, 7 \mathrm{H}), 1.68-1.64(\operatorname{app} \mathrm{d}, J=14 \mathrm{~Hz}, 1 \mathrm{H}), 1.52(\mathrm{~d}, J=6 \mathrm{~Hz}, 3 \mathrm{H}), 1.39$ (d, $J=6.5 \mathrm{~Hz}$, $3 \mathrm{H}), 1.29(\mathrm{~d}, J=6.5 \mathrm{~Hz}, 3 \mathrm{H}), 1.20(\mathrm{~d}, J=7 \mathrm{~Hz}, 3 \mathrm{H})$.

${ }^{13} \mathrm{C}$ NMR (125 MHz, pyridine $\left.d-5: \mathrm{CD}_{3} \mathrm{OD} 10: 1\right)$

$\delta 171.7,158.0,144.8,144.7,141.8,137.3,134.6,134.5,134.3,134.0,133.4,133.3$, $133.2,133.1,132.8,132.5,132.2,128.2,127.6,125.9,125.8,120.4,101.9,99.1,78.1$, 75.4, 74.6, 74.5, 71.8, 71.6, 71.1, 70.7, 68.2, 67.7, 67.2, 66.8, 58.1, 46.3, 44.6, 43.5, 43.1, $42.7,42.5,41.5,41.3,39.3,36.1,34.1,30.8,30.5,30.1,29.7,29.3,24.9,24.2,23.3,18.7$, $18.4,17.4,14.1,14.0,12.2,11.0$.

HRMS (ESI)

calculated for $\mathrm{C}_{63} \mathrm{H}_{85} \mathrm{NO}_{19}(\mathrm{M}+\mathrm{Na})^{+}: \quad 1182.5614$

found:

1182.5608
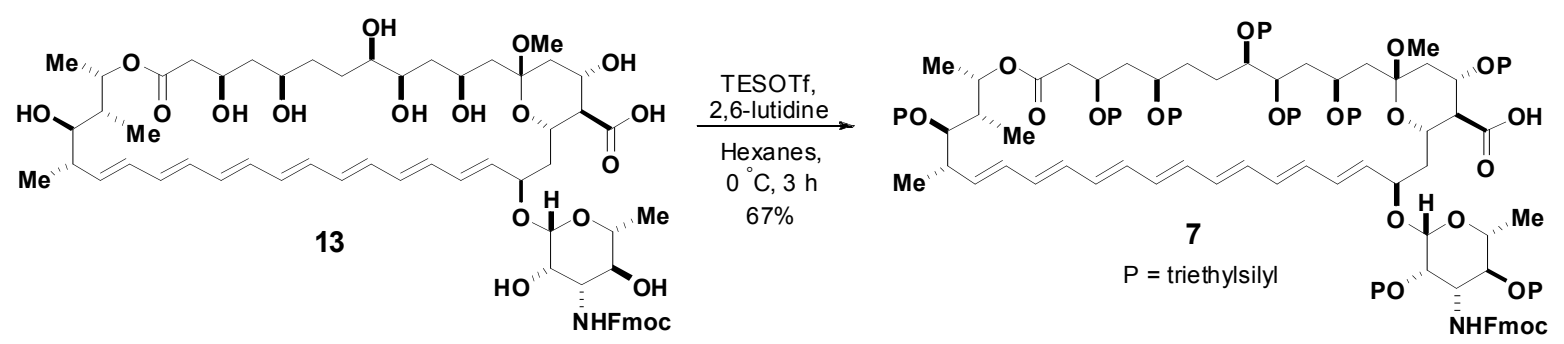

\section{Nonatriethylsilyl ether 7}

Prior to the reaction $\mathbf{1 3}$, was azeotropically dried via coevaporation with acetonitrile $(3 \times 20 \mathrm{~mL})$ and was left under vacuum for a minimum of eight hours. The resulting yellow powder (3.9 $\mathrm{g}, \sim$ $70 \%$ purity, ca. $2.35 \mathrm{mmol}, 1 \mathrm{eq})$ was suspended in hexanes $(110 \mathrm{~mL}) .2,6$-lutidine $(7.0 \mathrm{~mL}, 60.5$ mmol, $26 \mathrm{eq}$ ) was added and the resulting suspension was then cooled to $0{ }^{\circ} \mathrm{C}$. Triethylsilyl triflate $(10.6 \mathrm{~mL}, 47.0 \mathrm{mmol}, 20 \mathrm{eq})$ was added dropwise over 10 minutes and the resulting yellow suspension was stirred for 2 hours at $0{ }^{\circ} \mathrm{C}$. Additional 2,6-lutidine $(1.8 \mathrm{~mL}, 18.3 \mathrm{mmol}$, $6.5 \mathrm{eq})$ was then added followed by additional triethylsilyl triflate $(2.5 \mathrm{~mL}, 11.1 \mathrm{mmol}, 5 \mathrm{eq})$ dropwise over 5 minutes. After 15 minutes of stirring additional 2,6-lutidine $(1.8 \mathrm{~mL}, 18.3$ mmol, $6.5 \mathrm{eq})$ was added followed by additional triethylsilyl triflate $(2.5 \mathrm{~mL}, 11.1 \mathrm{mmol}, 5 \mathrm{eq})$ dropwise over 5 minutes. The mixture was stirred at $0{ }^{\circ} \mathrm{C}$ for 1 hour following completion of the final addition and was then quenched at $0{ }^{\circ} \mathrm{C}$ with saturated aqueous sodium bicarbonate $(250$ $\mathrm{mL})$. The resulting emulsion was diluted with diethyl ether $(500 \mathrm{~mL})$ and the layers were separated. The organic phase was washed with saturated aqueous sodium bicarbonate $(1 \times 100$ $\mathrm{mL})$ and water $(3 \times 50 \mathrm{~mL})$, and the combined aqueous washings were back-extracted with diethyl ether $(3 \times 100 \mathrm{~mL})$. The combined organic phases were then washed with $1 \mathrm{M}$ aqueous 
copper sulfate $(10 \times 25 \mathrm{~mL})$. The combined copper sulfate layers were then back-extracted with diethyl ether $(5 \times 50 \mathrm{~mL})$. The combined organic layers were washed with water $(3 \times 50 \mathrm{~mL})$ and brine $(1 \times 50 \mathrm{~mL})$. This second set of aqueous washings was back extracted with diethyl ether $(3 \times 50 \mathrm{~mL})$ and the combined organic layers were dried over sodium sulfate and concentrated in vacuo. Purification of the crude yellow oil by flash chromatography $\left(\mathrm{SiO}_{2}\right.$; hexanes:diethyl ether 20:1 $\rightarrow$ 7:1) furnished 7 as an orange solid (4.94 g, $2.26 \mathrm{mmol}, 96 \%$ ).

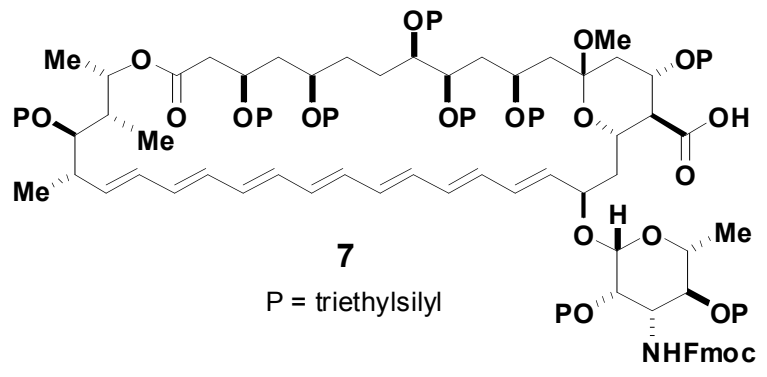

TLC (hexanes:diethyl ether 2:1)

$\mathrm{R}_{\mathrm{f}}=0.38$, visualized by $\mathrm{UV}$

${ }^{1} \mathrm{H}$ NMR (500 MHz, acetone $\left.d-6\right)$

$\delta 7.90(\mathrm{~d}, J=7.5 \mathrm{~Hz}, 2 \mathrm{H}), 7.72(\mathrm{~d}, J=7 \mathrm{~Hz}, 2 \mathrm{H}), 7.45(\mathrm{t}, J=7.5 \mathrm{~Hz}, 2 \mathrm{H}), 7.37(\mathrm{t}, J=7.5$ $\mathrm{Hz}, 2 \mathrm{H}) 6.63-6.56(\mathrm{~m}, 3 \mathrm{H}), 6.49-6.14(\mathrm{~m}, 9 \mathrm{H}) 5.98(\mathrm{dd}, J=5.5,15.5 \mathrm{~Hz}, 1 \mathrm{H}), 5.52(\mathrm{dd}, J$ $=10,15 \mathrm{~Hz}, 1 \mathrm{H}), 5.42(\mathrm{~d}, J=10 \mathrm{~Hz}, 1 \mathrm{H}), 4.74(\mathrm{bs}, 1 \mathrm{H}), 4.67(\mathrm{bs}, 1 \mathrm{H}), 4.57(\mathrm{~s}, 1 \mathrm{H})$, 4.54-4.45 (m, 2H), 4.37 (dd, $J=6.5,10 \mathrm{~Hz}, 1 \mathrm{H}), 4.28$ (app t, $J=6 \mathrm{~Hz}, 2 \mathrm{H}), 4.17$ (t, $J=$ $10 \mathrm{~Hz}, 1 \mathrm{H}), 4.02(\operatorname{app~t}, J=9 \mathrm{~Hz}, 2 \mathrm{H}), 3.92(\mathrm{~d}, J=2.5 \mathrm{~Hz}, 1 \mathrm{H}), 3.89(\operatorname{app~d}, J=8.5 \mathrm{~Hz}$, $1 \mathrm{H}), 3.73(\mathrm{bs}, 1 \mathrm{H}), 3.65-3.60(\mathrm{~m}, 2 \mathrm{H}), 3.48(\operatorname{app~t}, J=9 \mathrm{~Hz}, 2 \mathrm{H}), 3.33(\mathrm{dd}, J=6.5,8.5$ $\mathrm{Hz}, 1 \mathrm{H}), 3.16(\mathrm{~s}, 4 \mathrm{H}), 2.62(\mathrm{~d}, J=7 \mathrm{~Hz}, 1 \mathrm{H}) 2.51-2.46(\mathrm{~m}, 2 \mathrm{H}), 2.35(\mathrm{t}, J=10.5 \mathrm{~Hz}, 1 \mathrm{H})$ 2.17 (dd, $J=7,15 \mathrm{~Hz}, 1 \mathrm{H}), 2.04(\mathrm{dd}, 7.5,15.5 \mathrm{~Hz}, 1 \mathrm{H}), 1.97-1.62(\mathrm{~m}, 10 \mathrm{H}), 1.56-1.52$ $(\mathrm{m}, 1 \mathrm{H}) 1.27(\mathrm{~d}, J=6.5 \mathrm{~Hz}, 3 \mathrm{H}), 1.20(\mathrm{~d}, J=6 \mathrm{~Hz}, 3 \mathrm{H}), 1.11-0.92$ (m, 87H), 0.82-0.59 $(\mathrm{m}, 54 \mathrm{H})$.

${ }^{13} \mathrm{C}$ NMR (125 MHz, acetone $\left.d-6\right)$

$\delta 174.3,170.5,158.2,156.4,145.0,142.2,139.5,137.2,135.8,135.6,135.2,134.5$, $134.2,134.0,132.4,132.3,132.1,132.0,131.2,130.6,128.5,127.9,127.8,125.8,125.7$, $120.8,120.6,101.5,98.0,76.8,75.0,74.5,74.1,73.5,73.4,71.1,68.9,67.5,67.3,67.2$, 58.1, 57.5, 48.1, 48.0, 44.3, 43.4, 42.2, 41.5, 40.7, 35.6, 27.6, 24.4, 20.0, 19.3, 18.9, 11.1, $7.65,7.61,7.51,7.49,7.34,7.30,7.27,7.15,6.37,6.18,5.88,5.87,5.83,5.78,5.76,5.63$.

HRMS (ESI)

calculated for $\mathrm{C}_{117} \mathrm{H}_{211} \mathrm{NO}_{19} \mathrm{Si}_{9}(\mathrm{M}+\mathrm{Na})^{+}: \quad 2209.3397$

found:

2209.3303 


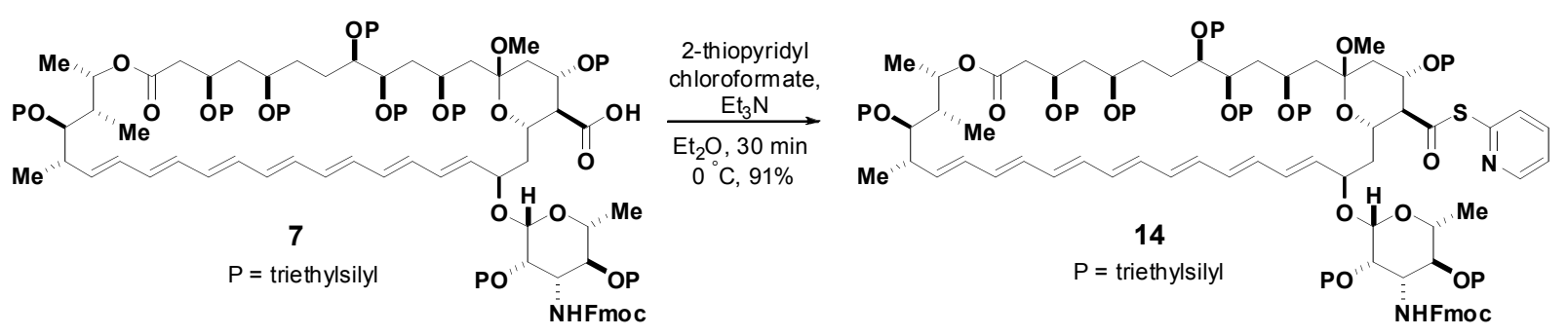

\section{2-pyridylthioester 14}

To a stirred solution of $7(4.9 \mathrm{~g}, 2.24 \mathrm{mmol}, 1 \mathrm{eq})$ in diethyl ether $(90 \mathrm{~mL})$ at $0{ }^{\circ} \mathrm{C}$ was added triethylamine $(0.40 \mathrm{~mL}, 2.91 \mathrm{mmol}, 1.3 \mathrm{eq})$. 2-thiopyridyl chloroformate $(4 \mathrm{~mL}, 4 \mathrm{mmol}, 1.8 \mathrm{eq}$, $1 \mathrm{M}$ in $\mathrm{CH}_{2} \mathrm{Cl}_{2}$ ) was added and the solution was stirred for 30 minutes at $0{ }^{\circ} \mathrm{C}$. The formation of a precipitate was observed as the reaction progressed. The mixture was then diluted with diethyl ether $(200 \mathrm{~mL})$ and the solids were removed via Büchner filtration using Whatman 50 filter paper. The filtrate was concentrated in vacuo to give crude $\mathbf{1 4}$ as a yellow solid. Purification by flash chromatography $\left(\mathrm{SiO}_{2}\right.$; hexanes:diethyl ether 10:1 $\left.\rightarrow 3: 1\right)$ afforded 14 as an orange solid (4.65 g, $2.04 \mathrm{mmol}, 91 \%)$.

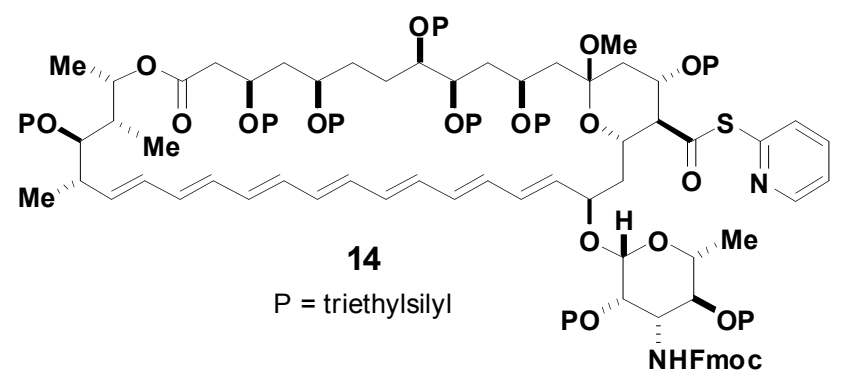

TLC (hexanes:diethyl ether 2:1)

$\mathrm{R}_{\mathrm{f}}=0.76$, visualized by $\mathrm{UV}$

${ }^{1} \mathrm{H}$ NMR (500 MHz, acetone $\left.d-6\right)$

$\delta 8.71(\mathrm{~d}, J=3.5 \mathrm{~Hz}, 1 \mathrm{H}), 7.94(\mathrm{dt}, J=1.5,7.5 \mathrm{~Hz}, 1 \mathrm{H}), 7.86(\mathrm{~d}, J=7.5 \mathrm{~Hz}, 2 \mathrm{H}), 7.73-$ $7.68(\mathrm{~m}, 3 \mathrm{H}), 7.43-7.31(\mathrm{~m}, 5 \mathrm{H}), 6.59-6.52(\mathrm{~m}, 3 \mathrm{H}), 6.46-6.11(\mathrm{~m}, 9 \mathrm{H}) 5.97(\mathrm{dd}, J=5.5$, $16 \mathrm{~Hz}, 1 \mathrm{H}), 5.49(\mathrm{dd}, J=9.5,15 \mathrm{~Hz}, 1 \mathrm{H}), 5.28(\mathrm{~d}, J=10 \mathrm{~Hz}, 1 \mathrm{H}), 4.78(\mathrm{bs}, 1 \mathrm{H}), 4.65$ (bs, 1H), $4.62(\mathrm{~s}, 1 \mathrm{H}), 4.52-4.43(\mathrm{~m}, 3 \mathrm{H}), 4.33(\mathrm{dd}, J=7,10.5 \mathrm{~Hz}, 1 \mathrm{H}), 4.23$ (app t, $J$ $=6.5 \mathrm{~Hz}, 2 \mathrm{H}), 4.14(\mathrm{t}, J=10 \mathrm{~Hz}, 1 \mathrm{H}), 4.06(\mathrm{t}, J=9.0 \mathrm{~Hz}, 1 \mathrm{H}), 4.00(\mathrm{bs}, 1 \mathrm{H}), 3.91(\mathrm{~d}, J=$ $2.5 \mathrm{~Hz}, 1 \mathrm{H}), 3.85(\mathrm{dd}, J=2,8.5 \mathrm{~Hz}, 1 \mathrm{H}), 3.70-3.66(\mathrm{~m}, 3 \mathrm{H}), 3.61(\mathrm{dd}, J=4,10.5 \mathrm{~Hz}$, $1 \mathrm{H}), 3.44-3.37(\mathrm{~m}, 2 \mathrm{H}), 3.13(\mathrm{~s}, 3 \mathrm{H}), 2.71(\mathrm{t}, J=10 \mathrm{~Hz}, 1 \mathrm{H}), 2.58(\mathrm{~d}, J=6.5 \mathrm{~Hz}, 1 \mathrm{H})$, 2.43 (app dd, $J=7,9 \mathrm{~Hz}, 1 \mathrm{H}), 2.32$ (dd, $J=6.5,15 \mathrm{~Hz}, 1 \mathrm{H}) 2.12-2.08(\mathrm{~m}, 2 \mathrm{H}), 1.93-$ $1.83(\mathrm{~m}, 3 \mathrm{H}), 1.79-1.62(\mathrm{~m}, 7 \mathrm{H}), 1.53-1.50(\mathrm{~m}, 1 \mathrm{H}), 1.22(\mathrm{~d}, J=5.5 \mathrm{~Hz}, 3 \mathrm{H}), 1.17(\mathrm{~d}, J=$ $6 \mathrm{~Hz}, 3 \mathrm{H}), 1.10-0.90(\mathrm{~m}, 87 \mathrm{H}), 0.81-0.56(\mathrm{~m}, 54 \mathrm{H})$. 
${ }^{13} \mathrm{C}$ NMR (125 MHz, acetone $\left.d-6\right)$

$\delta 197.5,169.9,163.5,155.6,151.5,151.0,144.5,141.6,138.3,137.8,135.1,135.0$, $134.5,133.7,133.3,131.9,131.8,131.6,131.3,130.7,130.0,129.5,127.8,127.2,127.1$, $125.2,125.1,124.1,120.1,100.7,97.2,76.0,74.0,73.7,73.6,73.4,72.8,72.7,70.5,68.5$, $67.2,66.8,66.7,66.6,64.8,57.2,47.6,47.4,43.5,42.7,42.0,40.9,40.1,35.0,34.7,26.9$, $19.3,18.7,18.3,10.5,7.01,6.89,6.88,6.72,6.68,6.65,6.59,5.80,5.56,5.29,5.28,5.24$, $5.21,5.16,5.02$.

HRMS (ESI)

calculated for $\mathrm{C}_{122} \mathrm{H}_{214} \mathrm{~N}_{2} \mathrm{O}_{18} \mathrm{SSi}_{9}(\mathrm{M}+\mathrm{Na})^{+}$: $\quad 2302.3424$

found:

2302.3328
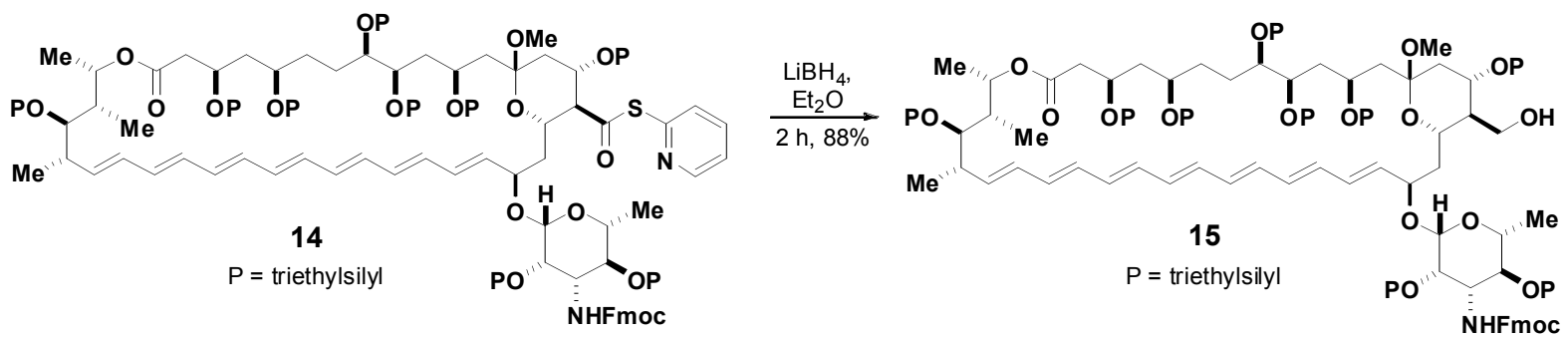

\section{Hydroxymethyl derivative 15}

To a stirred solution of $\mathbf{1 4}(4.6 \mathrm{~g}, 2.02 \mathrm{mmol}, 1 \mathrm{eq})$ in diethyl ether $(100 \mathrm{~mL})$ at $23{ }^{\circ} \mathrm{C}$ was added dropwise a solution of lithium borohydride in THF (2M, $10 \mathrm{~mL}, 20 \mathrm{mmol}, 10 \mathrm{eq})$. The solution was stirred for 2 hours and then cooled to $0{ }^{\circ} \mathrm{C}$ and quenched by addition over 5 minutes of saturated aqueous ammonium chloride $(100 \mathrm{~mL})$. The two layers were separated and the organic phase was diluted with diethyl ether $(100 \mathrm{~mL})$. The organic phase was washed with saturated ammonium chloride $(1 \times 20 \mathrm{~mL})$, water $(3 \times 20 \mathrm{~mL})$ and brine $(1 \times 20 \mathrm{~mL})$. The combined aqueous washings were back-extracted with diethyl ether $(1 \times 50 \mathrm{~mL})$ and the combined organic layers were dried over sodium sulfate and concentrated in vacuo. Purification of the resulting residue by flash chromatography $\left(\mathrm{SiO}_{2}\right.$; hexanes:diethyl ether 20:1 $\left.\rightarrow 5: 1\right)$ furnished 15 as a yellow solid (3.87 g, $1.78 \mathrm{mmol}, 88 \%)$.

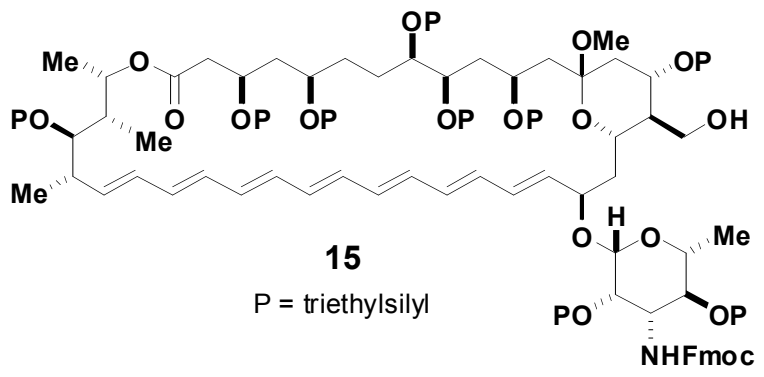

TLC (hexanes:diethyl ether $1: 1$ )

$$
\mathrm{R}_{\mathrm{f}}=0.67 \text {, visualized by } \mathrm{UV}
$$


${ }^{1} \mathrm{H}$ NMR (500 MHz, acetone $\left.d-6\right)$

$\delta 7.86(\mathrm{~d}, J=8 \mathrm{~Hz}, 2 \mathrm{H}), 7.69(\mathrm{~d}, J=7.5 \mathrm{~Hz}, 2 \mathrm{H}), 7.42(\mathrm{t}, J=7.5 \mathrm{~Hz}, 2 \mathrm{H}), 7.33(\mathrm{t}, J=7.5$ $\mathrm{Hz}, 2 \mathrm{H}), 6.53-6.10(\mathrm{~m}, 12 \mathrm{H}), 6.05(\mathrm{dd}, J=6.5,15.5 \mathrm{~Hz}, 1 \mathrm{H}), 5.50(\mathrm{dd}, J=9.5,15 \mathrm{~Hz}$, $1 \mathrm{H}), 5.32(\mathrm{~d}, J=10 \mathrm{~Hz}, 1 \mathrm{H}) 4.77(\mathrm{~s}, 1 \mathrm{H}), 4.68(\operatorname{app~t}, J=6 \mathrm{~Hz}, 2 \mathrm{H}), 4.46(\mathrm{dd}, J=6.5$, $10.5 \mathrm{~Hz}, 1 \mathrm{H}), 4.32(\mathrm{dd}, J=6.5,10.5 \mathrm{~Hz}, 1 \mathrm{H}), 4.23$ (app t, $J=6.5 \mathrm{~Hz}, 2 \mathrm{H}), 4.18$ (dt, $J=$ $5,10.5 \mathrm{~Hz}, 1 \mathrm{H}), 4.11(\mathrm{t}, J=10.5 \mathrm{~Hz}, 1 \mathrm{H}), 3.99(\mathrm{~m}, 1 \mathrm{H}), 3.91(\mathrm{~d}, J=3 \mathrm{~Hz}, 2 \mathrm{H}), 3.86-380$ $(\mathrm{m}, 4 \mathrm{H}), 3.70-3.67(\mathrm{~m}, 2 \mathrm{H}), 3.65-3.59(\mathrm{~m}, 3 \mathrm{H}), 3.46(\mathrm{t}, J=9 \mathrm{~Hz}, 1 \mathrm{H}), 3.34$ (app dd, $J=$ $6.5,8.5 \mathrm{~Hz}, 1 \mathrm{H}), 3.11(\mathrm{~s}, 3 \mathrm{H}), 2.56-2.54(\mathrm{~m}, 2 \mathrm{H}), 2.45-2.38(\mathrm{~m}, 2 \mathrm{H}), 2.10(\mathrm{dd}, J=4.5$, $12.5 \mathrm{~Hz}, 1 \mathrm{H}), 2.02-2.00(\mathrm{~m}, 1 \mathrm{H}), 1.94-1.61(\mathrm{~m}, 10 \mathrm{H}), 1.52-1.49(\mathrm{~m}, 1 \mathrm{H}), 1.24(\mathrm{~d}, J=6.5$ $\mathrm{Hz}, 3 \mathrm{H}), 1.17$ (d, $J=6 \mathrm{~Hz}, 3 \mathrm{H}), 1.06-0.890(\mathrm{~m}, 87 \mathrm{H}), 0.77-0.57$ (m, 54H).

${ }^{13} \mathrm{C}$ NMR $(125 \mathrm{MHz}$, acetone $d-6)$

$\delta 170.0,155.8,144.4,141.6,138.6,135.2,134.7,134.1,133.3,132.5,132.4,132.2$, $131.9,130.8,130.4,130.1,127.9,127.3,127.2,125.2,125.1,120.2,100.4,97.3,92.4$, 76.1, 75.0, 73.8, 73.4, 72.8, 70.4, 67.4, 66.9, 66.7, 66.6, 66.1, 58.4, 57.5, 49.6, 47.3, 47.1, $44.0,43.4,42.7,40.8,35.1,26.8,19.3,18.3,7.01,6.88,6.72,6.68,5.72,5.51,5.23,5.16$, $5.12,4.99$.

HRMS (ESI)

calculated for $\mathrm{C}_{117} \mathrm{H}_{213} \mathrm{NO}_{18} \mathrm{Si}_{9}(\mathrm{M}+\mathrm{Na})^{+}: \quad 2195.3604$

found:

2195.3503

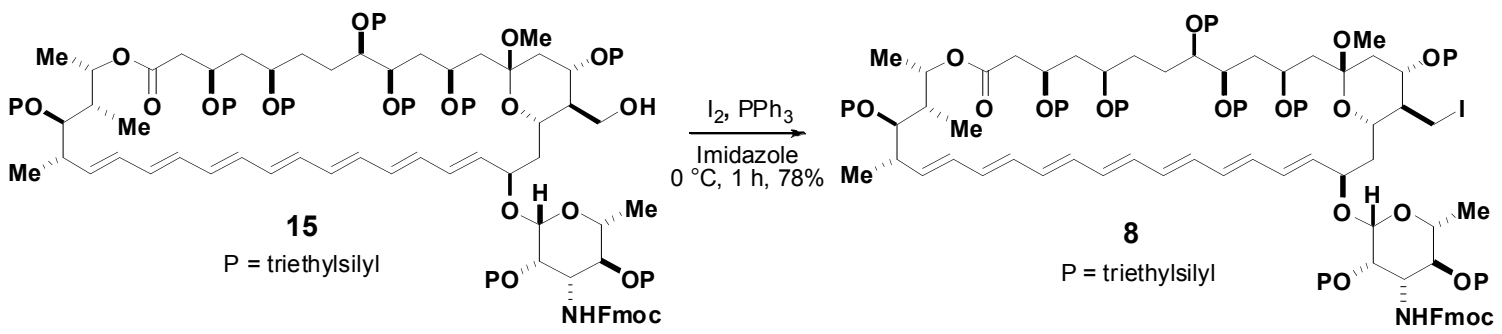

\section{Iodomethyl derivative 8}

Prior to the reaction, $\mathbf{1 5}$ was azeotropically dried via coevaporation with benzene $(3 \times 25 \mathrm{~mL})$ and left under vacuum for a minimum of eight hours. The resulting yellow solid (3.8 $\mathrm{g}, 1.74$ mmol, 1 eq) was dissolved in THF $(60 \mathrm{~mL})$ and cooled $0{ }^{\circ} \mathrm{C}$. To this solution was added imidazole $(0.355 \mathrm{~g}, 5.22 \mathrm{mmol}, 3 \mathrm{eq})$, triphenyl phosphine $(0.912 \mathrm{~g}, 3.48 \mathrm{mmol}, 2 \mathrm{eq})$, and iodine $(0.880 \mathrm{~g}, 3.48 \mathrm{mmol}, 2 \mathrm{eq})$. The resulting brown solution was stirred for 1 hour at $0{ }^{\circ} \mathrm{C}$ and then quenched with the addition of saturated aqueous sodium bisulfite $(50 \mathrm{~mL})$. The two phases were separated and the organic layer was diluted with diethyl ether $(50 \mathrm{~mL})$. The organic layer was washed with saturated aqueous sodium bisulfite $(1 \times 20 \mathrm{~mL})$, water $(3 \times 20 \mathrm{~mL})$, and brine $(1 \mathrm{x}$ $20 \mathrm{~mL})$. The combined aqueous washings were back-extracted with diethyl ether $(1 \mathrm{x} 20 \mathrm{~mL})$. The combined organic layers were dried over sodium sulfate and concentrated in vacuo. Purification of the resulting residue by flash chromatography $\left(\mathrm{SiO}_{2}\right.$; hexanes:diethyl ether 20:1 $\rightarrow 7: 1)$ furnished 8 as an orange solid $(3.10 \mathrm{~g}, 1.36 \mathrm{mmol}, 78 \%)$ and recovered 15 as a yellow solid (0.545 g, $0.251 \mathrm{mmol}, 14 \%)$. 


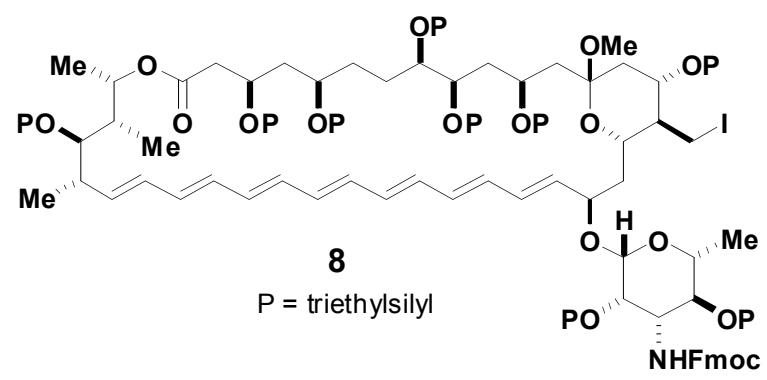

TLC (hexanes:diethyl ether 2:1)

$\mathrm{R}_{\mathrm{f}}=0.79$, visualized by $\mathrm{UV}$

${ }^{1} \mathrm{H}$ NMR (500 MHz, acetone $\left.d-6\right)$

$\delta 7.86(\mathrm{~d}, J=7.5 \mathrm{~Hz}, 2 \mathrm{H}), 7.69(\mathrm{~d}, J=6.5 \mathrm{~Hz}, 2 \mathrm{H}), 7.41(\mathrm{t}, J=7 \mathrm{~Hz}, 2 \mathrm{H}), 7.32$ (t, $J=$ $7.5 \mathrm{~Hz}, 2 \mathrm{H}), 6.54-6.10(\mathrm{~m}, 12 \mathrm{H}), 6.04(\mathrm{dd}, J=6,15.5 \mathrm{~Hz}, 1 \mathrm{H}), 5.50$ (dd, $J=9.5,14.5$ $\mathrm{Hz}, 1 \mathrm{H}), 5.30$ (d, $J=10 \mathrm{~Hz}, 1 \mathrm{H}), 4.87$ (s, 1H) 4.72 (bs, 1H), 4.67 (bs, 1H), 4.46 (dd, $J=$ $6.5,10.5 \mathrm{~Hz}, 1 \mathrm{H}), 4.34(\mathrm{dd}, J=6.5,10.5 \mathrm{~Hz}, 1 \mathrm{H}), 4.22$ (app t, $J=6 \mathrm{~Hz}, 2 \mathrm{H}), 4.14-4.04$ $(\mathrm{m}, 3 \mathrm{H}), 4.00(\mathrm{bs}, 1 \mathrm{H}) 3.84(\mathrm{app} \mathrm{d}, J=7 \mathrm{~Hz}, 1 \mathrm{H}), 3.76(\mathrm{t}, J=9 \mathrm{~Hz}, 1 \mathrm{H}), 3.72-3.69(\mathrm{~m}$, $3 \mathrm{H}) 3.63-3.61(\mathrm{~m}, 2 \mathrm{H}), 3.50(\mathrm{app} \mathrm{d}, J=8 \mathrm{~Hz}, 1 \mathrm{H}), 3.46(\mathrm{t}, 9.5 \mathrm{~Hz}, 1 \mathrm{H}), 3.41-3.37$ (m, 2H), 3.14 (s, 3H), 2.57 (bs, 2H), 2.43 (app dd, $J=9,15 \mathrm{~Hz}, 1 \mathrm{H}), 2.27$ (dd, $J=7.5,14.5$ $\mathrm{Hz}, 1 \mathrm{H}), 2.16(\mathrm{dd}, J=5,12.5 \mathrm{~Hz}, 1 \mathrm{H}), 1.93-1.86(\mathrm{~m}, 3 \mathrm{H}), 1.81-1.74(\mathrm{~m}, 6 \mathrm{H}) 1.65-1.61$ $(\mathrm{m}, 2 \mathrm{H}), 1.49$ (bs, 1H), 1.25 (d, $J=6 \mathrm{~Hz}, 3 \mathrm{H}), 1.16$ (d, $J=6 \mathrm{~Hz}, 3 \mathrm{H}), 1.06-0.86$ (m, $87 \mathrm{H}), 0.77-0.55(\mathrm{~m}, 54 \mathrm{H})$.

${ }^{13} \mathrm{C}$ NMR (125 MHz, acetone $\left.d-6\right)$

$\delta 170.0,155.7,144.7,144.4,141.6,138.5,135.1,134.6,134.5,134.0,133.2,132.4$, $132.3,132.0,130.9,130.2,127.9,127.2,125.2,125.1,120.2,100.4,97.3,76.1,74.0$, $73.4,72.8,70.5,69.9,68.3,66.9,66.7,66.5,57.5,47.4,47.2,45.9,43.8,42.8,42.0,40.6$, $40.3,35.1,33.5,26.8,19.3,18.6,18.3,10.7,9.23,7.04,7.03,6.92,6.91,6.79,6.77,6.73$, $6.69,5.80,5.55,5.48,5.31,5.28,5.24,5.20,5.17$.

HRMS (ESI)

calculated for $\mathrm{C}_{117} \mathrm{H}_{212} \mathrm{INO}_{17} \mathrm{Si}_{9}(\mathrm{M}+\mathrm{Na})^{+}: 2305.2621$

found:

2305.2617 

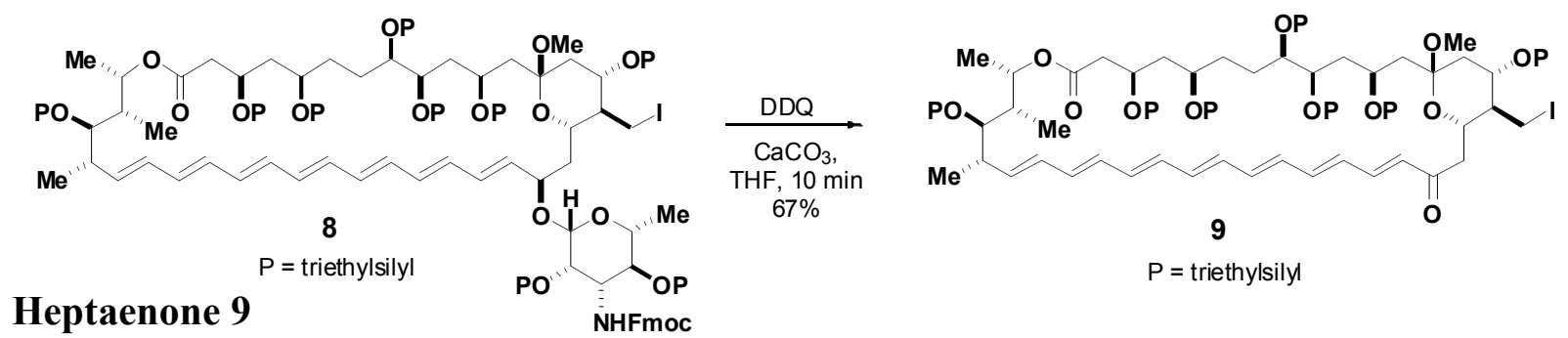

Prior to the reaction, calcium carbonate was dried via storage under vacuum for a minimum of eight hours in the presence phosphorus pentoxide desiccant. Also, 8 was azeotropically dried via coevaporation with benzene $(3 \times 25 \mathrm{~mL})$ and left under vacuum for a minimum of eight hours. The resulting orange solid $(2.45 \mathrm{~g}, 1.07 \mathrm{mmol}, 1 \mathrm{eq})$ was dissolved in THF $(50 \mathrm{~mL})$ at $23{ }^{\circ} \mathrm{C}$ and calcium carbonate $(1.07 \mathrm{~g}, 10.7 \mathrm{mmol}, 10 \mathrm{eq})$ was added. DDQ $(0.364 \mathrm{~g}, 1.61 \mathrm{mmol}, 1.5 \mathrm{eq})$ was added and the reaction mixture immediately transitioned to a dark red color. The mixture was stirred for 10 minutes and then quenched with saturated aqueous sodium bicarbonate $(250 \mathrm{~mL})$. The resulting red emulsion was extracted with dichloromethane $(10 \times 100 \mathrm{~mL})$. The combined organic extracts were washed with brine $(1 \mathrm{x} 100 \mathrm{~mL})$, dried over sodium sulfate, and concentrated in vacuo. Purification of the resulting residue by flash chromatography $\left(\mathrm{SiO}_{2}\right.$; hexanes:diethyl ether 20:1 $\rightarrow$ 9:1) afforded 9 as a deep red solid $(1.21 \mathrm{~g}, 0.717 \mathrm{mmol}, 67 \%)$.

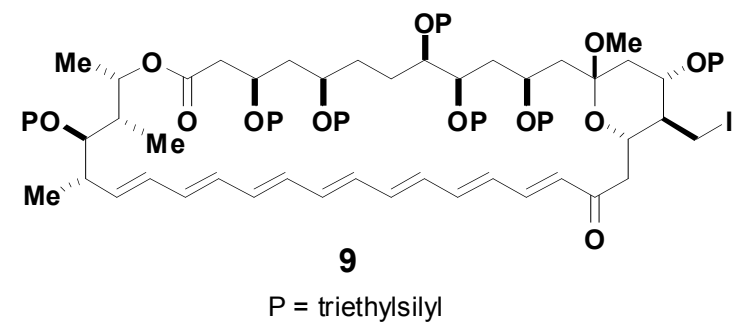

TLC (hexanes:diethyl ether 2:1)

$\mathrm{R}_{\mathrm{f}}=0.48$, visualized by eye

${ }^{1} \mathrm{H}$ NMR (500 MHz, acetone $\left.d-6\right)$

$\delta 7.84(\mathrm{dd}, J=11.5,16 \mathrm{~Hz}, 1 \mathrm{H}), 7.11(\mathrm{dd}, J=11.5,14.5 \mathrm{~Hz}, 1 \mathrm{H}), 6.80(\mathrm{dd}, J=11,15$ $\mathrm{Hz}, 1 \mathrm{H}), 6.61-6.54(\mathrm{~m}, 2 \mathrm{H}), 6.49-6.14(\mathrm{~m}, 7 \mathrm{H}), 6.08(\mathrm{~d}, J=15.5 \mathrm{~Hz}, 1 \mathrm{H}), 5.52(\mathrm{dd}, J=$ 9.5, $15 \mathrm{~Hz}, 1 \mathrm{H}), 4.47-4.44(\mathrm{~m}, 1 \mathrm{H}), 4.27$ (app t, $J=10.5 \mathrm{~Hz}, 1 \mathrm{H}), 4.16-4.07(\mathrm{~m}, 3 \mathrm{H})$, $3.96(\mathrm{dd}, J=3,9 \mathrm{~Hz}, 1 \mathrm{H}), 3.75-3.63(\mathrm{~m}, 4 \mathrm{H}), 3.46(\mathrm{dd}, J=3,10.5 \mathrm{~Hz}, 1 \mathrm{H}), 3.01(\mathrm{dd}, J=$ $10.5,12 \mathrm{~Hz}, 1 \mathrm{H}), 2.90(\mathrm{~s}, 3 \mathrm{H}), 2.66(\mathrm{dd}, J=4,18 \mathrm{~Hz}, 1 \mathrm{H}), 2.60(\mathrm{dd}, J=9.5,18 \mathrm{~Hz}, 1 \mathrm{H})$ 2.47-2.42 (m, 2H), $2.26($ app t, $J=10.5 \mathrm{~Hz}, 1 \mathrm{H}), 2.10(\mathrm{dd}, J=5,12 \mathrm{~Hz}, 1 \mathrm{H}), 2.00$ (app t, $J=10.5 \mathrm{~Hz}, 1 \mathrm{H}), 1.93-1.72(\mathrm{~m}, 8 \mathrm{H}), 1.65(\operatorname{app~d}, J=12.5 \mathrm{~Hz}, 1 \mathrm{H}), 1.47$ (app t, $J=10.5$ $\mathrm{Hz}, 1 \mathrm{H}), 1.15$ (d, $J=6 \mathrm{~Hz}, 3 \mathrm{H}), 1.11(\mathrm{t}, J=8 \mathrm{~Hz}, 10 \mathrm{H}), 1.05-0.96(\mathrm{~m}, 51 \mathrm{H}), 0.89$ (t, $J=$ $7.5 \mathrm{~Hz}, 9 \mathrm{H}), 0.84$ (q, $J=8 \mathrm{~Hz}, 6 \mathrm{H}), 0.76-0.51(\mathrm{~m}, 36 \mathrm{H})$.

${ }^{13} \mathrm{C}$ NMR (125 MHz, acetone $\left.d-6\right)$

$\delta 199.4,169.4,148.1,142.8,140.2,139.4,138.6,137.6,136.5,131.5,131.1,130.9$, $130.4,130.3,130.2,129.6,100.4,76.1,73.5,73.0,72.9,70.9,68.2,67.2,66.4,47.8,46.5$, $46.4,43.2,42.7,42.6,40.7,40.3,36.5,34.6,27.2,24.6,23.2,19.5,19.1,7.11,6.90,6.84$, $6.67,6.62,5.94,5.50,5.38,5.23,5.21,5.08,4.97$. 
HRMS (ESI)

calculated for $\mathrm{C}_{84} \mathrm{H}_{161} \mathrm{O}_{12} \mathrm{ISi}_{7}(\mathrm{M}+\mathrm{Na})^{+}: \quad 1707.9316$

found:

1707.9270
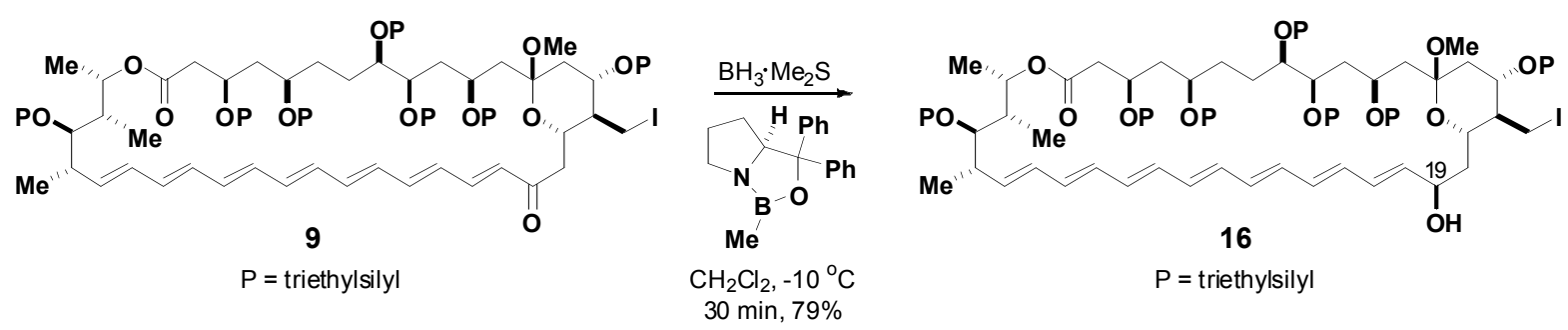

\section{Allylic alcohol 16}

Prior to the reaction, 9 was azeotropically dried via coevaporation with benzene $(3 \times 10 \mathrm{~mL})$ and was left under vacuum for a minimum of eight hours. To a stirred solution of borane dimethyl sulfide complex (27 $\mu \mathrm{L}, 0.270 \mathrm{mmol}, 1.2 \mathrm{eq})$, and $(S)$-2-methyl-CBS-oxazaborolidine $(0.225$ $\mathrm{mL}, 0.225 \mathrm{mmol}, 1 \mathrm{eq}, 1 \mathrm{M}$ in toluene) in dichloromethane $(1 \mathrm{~mL})$ at $-10^{\circ} \mathrm{C}$ was added 9 (380 $\mathrm{mg}, 0.225 \mathrm{mmol}, 1 \mathrm{eq})$ dropwise as a solution in dichloromethane $(6.5 \mathrm{~mL})$. The resulting solution was stirred for 30 minutes at $-10{ }^{\circ} \mathrm{C}$ and during this time a color change from deep red to pale orange was observed. The reaction was quenched at $-10{ }^{\circ} \mathrm{C}$ with saturated aqueous ammonium chloride $(10 \mathrm{~mL})$ and diluted with dichloromethane $(50 \mathrm{~mL})$. The two layers were separated and the organic layer was washed with saturated aqueous ammonium chloride $(1 \times 20$ $\mathrm{mL})$, water $(3 \times 20 \mathrm{~mL})$, and brine $(1 \times 20 \mathrm{~mL})$. The combined aqueous washings were backextracted with dichloromethane $(1 \times 50 \mathrm{~mL})$. The combined organic extracts were dried over sodium sulfate and concentrated in vacuo. Purification of the resulting residue by flash chromatography $\left(\mathrm{SiO}_{2}\right.$; hexanes:diethyl ether 19:1 $\rightarrow$ 6:1) furnished $16(300 \mathrm{mg}, 0.177 \mathrm{mmol}$, 6:1 d.r., 79\%). The major diastereomer was assigned as having the $(R)$ configuration at C-19 based on extensive NMR characterization of final product $\mathbf{2}$ as described in detail on pages S19S21.

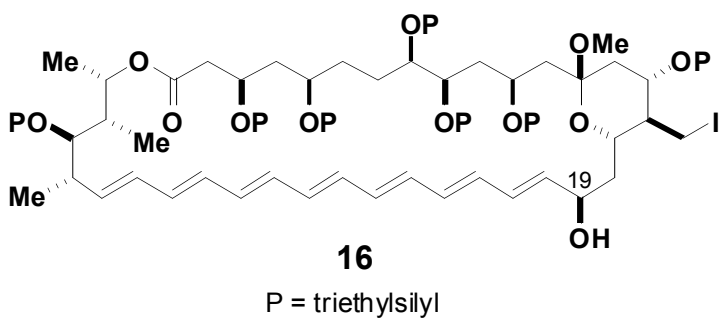

TLC (hexanes:diethyl ether 2:1)

$\mathrm{R}_{\mathrm{f}}=0.35$, stained by anisaldehyde

${ }^{1} \mathrm{H}$ NMR $(500 \mathrm{MHz}$, acetone $d-6)$

$\delta$ 6.48-6.10 (m, 13H), $5.53(\mathrm{dd}, J=9.5,15 \mathrm{~Hz}, 1 \mathrm{H}), 4.71(\mathrm{bs}, 1 \mathrm{H}), 4.52(\mathrm{bs}, 1 \mathrm{H}), 4.25$ (bs, $1 \mathrm{H}), 4.10$ (t, $J=10 \mathrm{~Hz}, 1 \mathrm{H}), 4.06-3.98(\mathrm{~m}, 2 \mathrm{H}), 3.88$ (app d, $J=1.5,1 \mathrm{H}) 3.80$ (app t, $J=9 \mathrm{~Hz}, 2 \mathrm{H}), 3.68-3.61(\mathrm{~m}, 4 \mathrm{H}), 3.37$ (app d, $J=10 \mathrm{~Hz}, 1 \mathrm{H}), 3.13$ (s, 3H), 2.55 (t, $J=6$ $\mathrm{Hz}, 2 \mathrm{H}$ ), 2.42 (app dd, $J=7,14 \mathrm{~Hz}, 1 \mathrm{H}$ ), 2.17 (dd, $J=5,10.5 \mathrm{~Hz}, 1 \mathrm{H}), 1.99-1.84$ (m, 
5H), 1.78-1.69 (m, 5H), 1.62-1.61 (m, 3H), 1.53-1.47 (m, 1H), $1.17(\mathrm{~d}, J=6 \mathrm{~Hz}, 3 \mathrm{H})$, $1.06-0.95(\mathrm{~m}, 69 \mathrm{H}), 0.75-0.62(\mathrm{~m}, 42 \mathrm{H})$.

${ }^{13} \mathrm{C}$ NMR (125 MHz, acetone $\left.d-6\right)$

$\delta 173.6,142.7,141.7,137.9,137.7,136.9,136.3,136.0,135.9,135.6,135.5,134.5$, $134.4,133.8,130.7,104.0,79.6,77.0,76.1,73.9,73.4,72.0,71.9,70.4,70.3,50.9,50.8$, $50.6,49.1,47.5,46.4,45.9,44.2,43.9,42.4,40.1,38.6,30.3,28.2,22.7,22.0,14.2,12.5$, $10.6,10.4,10.2,9.32,9.09,9.03,8.82,8.75,8.73$.

HRMS (ESI)

calculated for $\mathrm{C}_{84} \mathrm{H}_{163} \mathrm{O}_{12} \mathrm{ISi}_{7}(\mathrm{M}+\mathrm{Na})^{+}: \quad 1709.9472$

found:

1709.9456
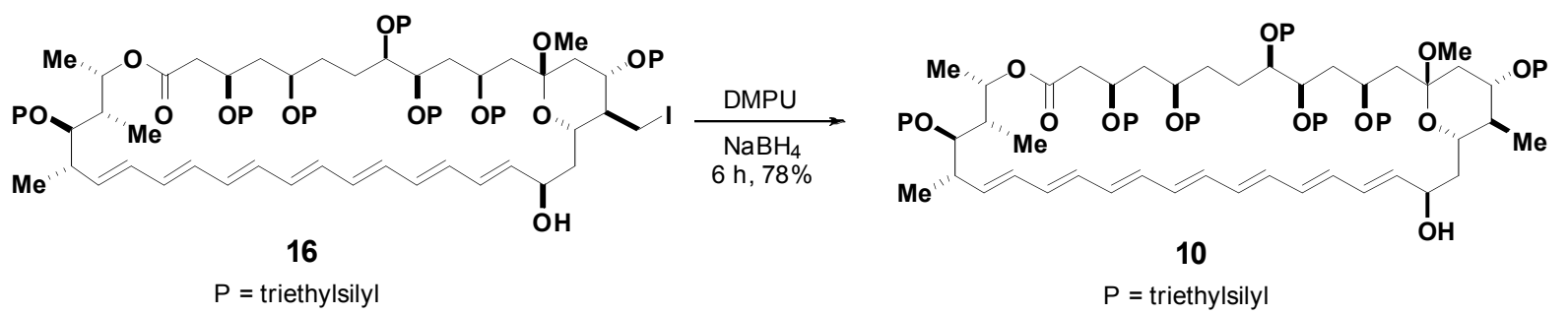

\section{C(41)-methyl derivative 10}

Prior to the reaction, 16 was azeotropically dried via coevaporation with benzene $(3 \mathrm{x} 25 \mathrm{~mL})$ and left under vacuum for a minimum of eight hours. The resulting orange solid $(775 \mathrm{mg}, 0.459$ mmol, $1 \mathrm{eq})$ was dissolved in DMPU $(15 \mathrm{~mL})$ at $23{ }^{\circ} \mathrm{C}$ and sodium borohydride $(87 \mathrm{mg}, 2.3$ mmol, 5 eq) was added. The solution was stirred for 6 hours and was then quenched with saturated aqueous ammonium chloride $(5 \mathrm{~mL})$. The resulting yellow emulsion was diluted with hexanes $(50 \mathrm{~mL})$ and the mixture washed with water $(5 \times 10 \mathrm{~mL})$ and brine $(1 \mathrm{x} 10 \mathrm{~mL})$. The combined aqueous washings were back-extracted with hexanes $(25 \mathrm{~mL})$. The combined organic extracts were dried over sodium sulfate and concentrated in vacuo. Purification of the resulting residue by flash chromatography $\left(\mathrm{SiO}_{2}\right.$; hexanes:diethyl ether 20:1 $\left.\rightarrow 10: 1\right)$ yielded $\mathbf{1 0}$ as an orange solid (557 mg, $0.356 \mathrm{mmol}, 78 \%$ ).

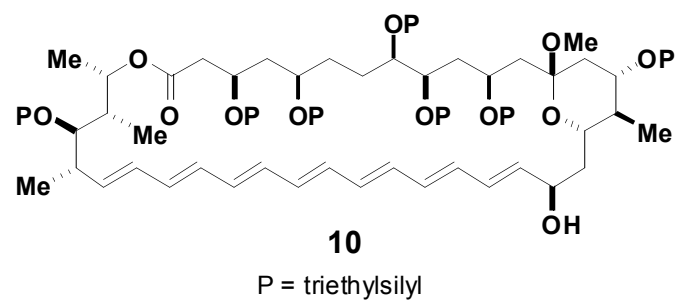

TLC (hexanes:diethyl ether, 2:1)

$$
\mathrm{R}_{\mathrm{f}}=0.28 \text {, stained by anisaldehyde }
$$

${ }^{1} \mathrm{H}$ NMR (500 MHz, acetone $\left.d-6\right)$

$\delta$ 6.49-6.10 (m, 13H), $5.52(\mathrm{dd}, J=9.5,15 \mathrm{~Hz}, 1 \mathrm{H}), 4.71(\operatorname{app~t}, J=6.5 \mathrm{~Hz}, 1 \mathrm{H}), 4.47$ (bs, 1H), 4.28-4.24 (m, 1H), $4.10(\mathrm{t}, J=10 \mathrm{~Hz}, 1 \mathrm{H}), 4.00-3.97(\mathrm{~m}, 1 \mathrm{H}), 3.85(\mathrm{~d}, J=4 \mathrm{~Hz}$, $1 \mathrm{H}), 3.82(\mathrm{dd}, J=2.5,9 \mathrm{~Hz}, 1 \mathrm{H}) 3.76-3.67(\mathrm{~m}, 3 \mathrm{H}), 3.62(\mathrm{dd}, J=4.5,10.5 \mathrm{~Hz}, 1 \mathrm{H}), 3.56$ 
(app t, $J=8.5 \mathrm{~Hz}, 1 \mathrm{H}), 3.10(\mathrm{~s}, 3 \mathrm{H}), 2.55(\mathrm{t}, J=6.5 \mathrm{~Hz}, 2 \mathrm{H}), 2.42(\operatorname{app} \mathrm{dd}, J=9,16 \mathrm{~Hz}$, $1 \mathrm{H}), 2.01-1.97(\mathrm{~m}, 2 \mathrm{H}), 1.93-1.84(\mathrm{~m}, 3 \mathrm{H}), 1.80-1.74(\mathrm{~m}, 3 \mathrm{H}), 1.73-1.70(\mathrm{~m}, 2 \mathrm{H}) 1.68-$ $1.62(\mathrm{~m}, 3 \mathrm{H}), 1.53-1.50(\mathrm{~m}, 1 \mathrm{H}), 1.36-1.27(\mathrm{~m}, 2 \mathrm{H}) 1.17(\mathrm{~d}, J=6 \mathrm{~Hz}, 3 \mathrm{H}), 1.06-0.94(\mathrm{~m}$, $72 \mathrm{H}), 0.75-0.61(\mathrm{~m}, 42 \mathrm{H})$.

${ }^{13} \mathrm{C}$ NMR (125 MHz, acetone $\left.d-6\right)$ $\delta 170.1,139.1,138.2,134.3,134.2,133.4,132.7,132.5,132.4,132.1,132.0,131.0$, $130.9,130.2,128.5,127.2,100.5,76.1,73.5,72.6,71.6,70.7,70.4,68.7,68.5,67.0,66.8$, 47.2 , 47.1, 44.1, 42.9, 42.8, 40.8, 40.4, 39.5, 35.1, 26.8, 19.2, 18.5, 13.3, 10.7, 10.6, 7.04, $7.01,6.90,6.71,6.69,5.78,5.57,5.31,5.27,5.24,5.22$.

HRMS (ESI)

calculated for $\mathrm{C}_{84} \mathrm{H}_{164} \mathrm{O}_{12} \mathrm{Si}_{7}(\mathrm{M}+\mathrm{Na})^{+}: \quad 1584.0506$

found:

1584.0481 


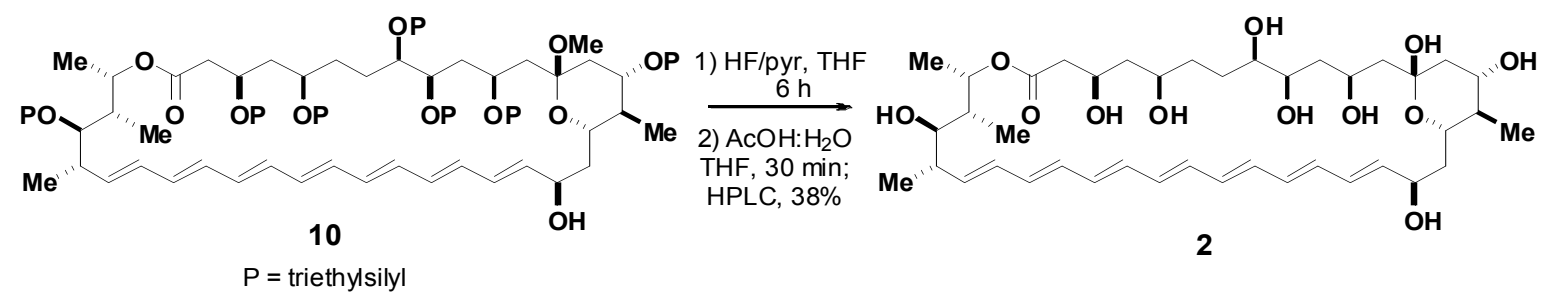

\section{C41-Methyl amphoteronolide B (2)}

To a stirred solution of $\mathbf{1 0}(50 \mathrm{mg}, 0.032 \mathrm{mmol})$ in THF:pyridine $3: 2(5 \mathrm{~mL})$ at $0{ }^{\circ} \mathrm{C}$ was added dropwise $70 \% \mathrm{HF} /$ pyridine complex $(320 \mu \mathrm{L})$. The solution was stirred for 6 hours at $0{ }^{\circ} \mathrm{C}$ and was then quenched with the addition of trimethylsilyl ethoxide $(2 \mathrm{~mL})$. The solution was concentrated in vacuo and the resulting residue was dissolved in THF $(1 \mathrm{~mL})$ and $\mathrm{AcOH}: \mathrm{H}_{2} \mathrm{O}$ 1:1 $(1 \mathrm{~mL})$. The solution was stirred for 30 minutes and was then concentrated in vacuo. The resulting orange solid was immediately dissolved in DMSO $(1.5 \mathrm{~mL})$ and purified by preparative RP-HPLC (Waters SunFire Prep C 18 OBD 5 micron 30 x $150 \mathrm{~mm}$ Lot \# 168I161701 $300 \mu \mathrm{L}$ injection volume, $25 \mathrm{~mL} / \mathrm{min}$ flow rate, $\mathrm{MeCN}: \mathrm{H}_{2} \mathrm{O} 1: 19 \rightarrow 19: 1$, over 25 minutes) to yield C(41)-methyl amphoteronolide B (2) as a yellow solid ( $9 \mathrm{mg}, 0.012 \mathrm{mmol}, 38 \%$ over two steps).

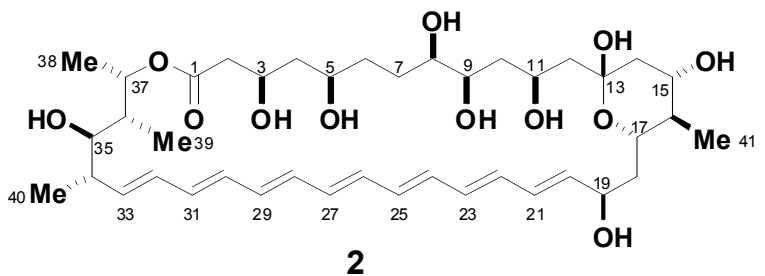

HPLC

$\mathrm{tR}=24.9 \mathrm{~min}$, flow rate $=25 \mathrm{~mL} / \mathrm{min}$, gradient of $5 \rightarrow 95 \% \mathrm{MeCN}$ in $\mathrm{H}_{2} \mathrm{O}$ over $25 \mathrm{~min}$.

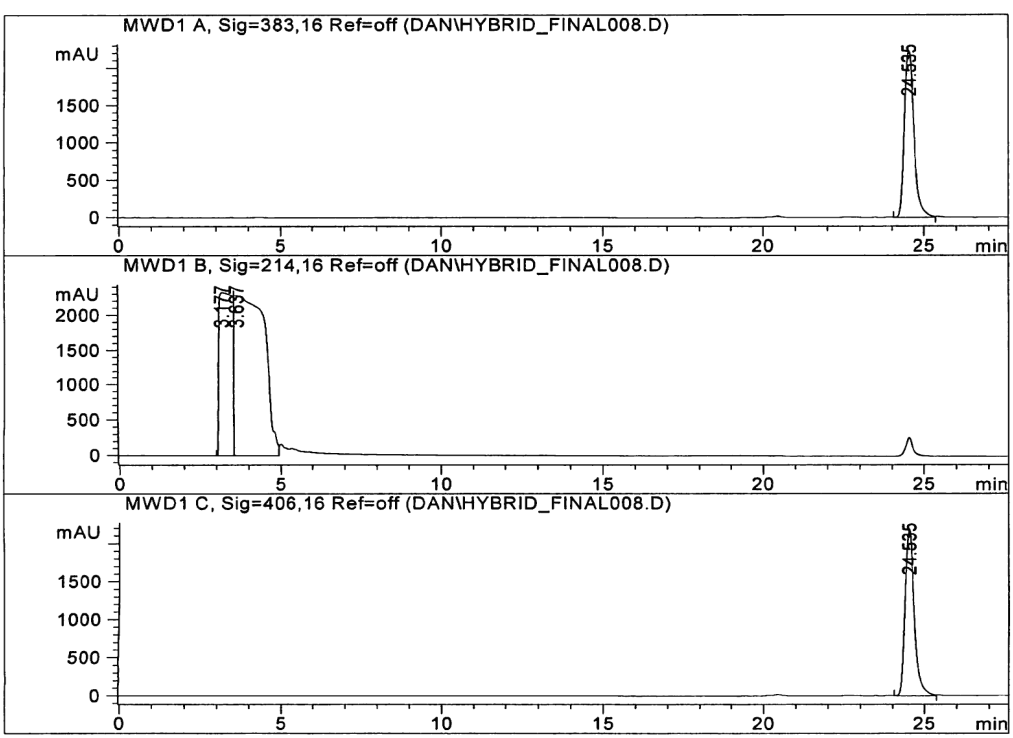


As described in detail in Section III, proton and coupling constant assignments were made using a variety of twodimensional NMR techniques including phase-sensitive COSY experiments combined with amplitude constrained multiplet evaluation (ACME). ${ }^{3}$ Briefly, as demonstrated in section III, the polyene macrolide skeletons of 1-4 are quite rigid and hydrogen atoms can be assigned as having pseudoequatorial (e) and pseudoaxial (a) orientations. ${ }^{4}$ The labeling scheme used herein is consistent with that utilized

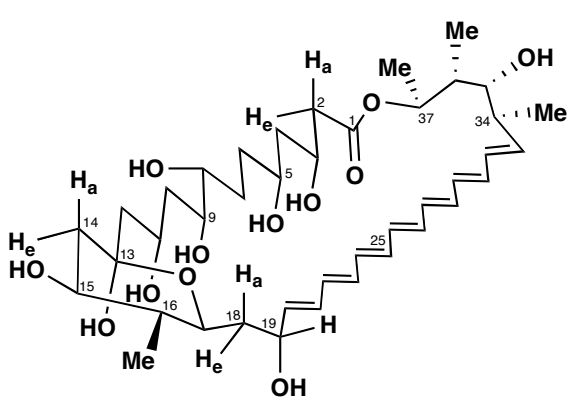
in Ref $19 \mathrm{a}$ of the text.

${ }^{1} \mathrm{H}$ NMR (600 MHz, pyridine $d-5, \mathrm{CD}_{3} \mathrm{OD} 10: 1$ )

$\delta 6.83(\mathrm{dd}, J=10.8,14.7 \mathrm{~Hz}, 1 \mathrm{H}, \mathbf{H - 2 2}), 6.77$ (dd, $J=10.8,15 \mathrm{~Hz}, 1 \mathrm{H}, \mathbf{H - 2 4}), 6.70$ (dd, $\left.J_{19,20}=8.9 \mathrm{~Hz}, J_{20,21}=15 \mathrm{~Hz}, 1 \mathrm{H}, \mathbf{H - 2 0}\right), 6.60(\mathrm{dd}, J=11.4,14.4 \mathrm{~Hz}, 1 \mathrm{H}, \mathbf{H - 2 3}), 6.55-$ $6.35(\mathrm{~m}, 9 \mathrm{H}), 5.79\left(\operatorname{app~d}, J_{36,37}=3.1 \mathrm{~Hz}, 1 \mathrm{H}, \mathbf{H}-37\right), 5.55\left(\mathrm{dd}, J_{32,33}=15.6, J_{33,34}=9.9\right.$ $\mathrm{Hz}, 1 \mathrm{H}, \mathbf{H - 3 3}), 4.87\left(\operatorname{app~t}, J_{10 \mathrm{a}, 11}=1.3 \mathrm{~Hz}, J_{10 \mathrm{e}, 11}=10.9 \mathrm{~Hz}, J_{11,12 \mathrm{a}}=1.2 \mathrm{~Hz}, J_{11,12 \mathrm{e}}=10.7\right.$ $\mathrm{Hz}, 1 \mathrm{H}, \mathbf{H - 1 1}), 4.77\left(\mathrm{~m}, J_{18 \mathrm{a}, 19}=3.9, J_{18 \mathrm{e}, 19}=5.5 \mathrm{~Hz}, J_{19,20}=8.9 \mathrm{~Hz}, 1 \mathrm{H}, \mathbf{H}-19\right), 4.65$ (m, $\left.J_{2 \mathrm{e}, 3}=9.2 \mathrm{~Hz}, J_{3,4 \mathrm{a}}=4.3, J_{3,4 \mathrm{e}}=10.9 \mathrm{~Hz}, J_{16,17}=10.8 \mathrm{~Hz}, J_{17,18 \mathrm{a}}=8.1 \mathrm{~Hz}, 2 \mathrm{H}, \mathbf{H}-3, \mathbf{H}-17\right)$, 4.20 (app dt, $\left.J_{14 \mathrm{e}, 15}=2.1, J_{14 \mathrm{a}, 15}=11.5 \mathrm{~Hz}, J_{15,16}=10.8 \mathrm{~Hz}, 1 \mathrm{H}, \mathbf{H - 1 5}\right), 4.12\left(\operatorname{app~t}, J_{4 \mathrm{a}, 5}=\right.$ $\left.1.8, J_{4 \mathrm{e}, 5}=10.3 \mathrm{~Hz}, J_{5,6 \mathrm{a}}=1.1, J_{5,6 \mathrm{e}}=11.5 \mathrm{~Hz}, 1 \mathrm{H}, \mathbf{H - 5}\right), 4.03\left(\operatorname{app} \mathrm{dd}, J_{8,9}=3.2 \mathrm{~Hz}, J_{9,10 \mathrm{a}}\right.$ $\left.=2.3, J_{9,10 \mathrm{e}}=11.7 \mathrm{~Hz}, 1 \mathrm{H}, \mathbf{H}-9\right), 3.60\left(\operatorname{app} \mathrm{dd}, J_{7 \mathrm{e}, 8}=2.4, J_{7 \mathrm{a}, 8}=11.3 \mathrm{~Hz}, J_{8,9}=3.2 \mathrm{~Hz}\right.$, $1 \mathrm{H}, \mathbf{H - 8}), 3.44\left(\operatorname{app} \mathrm{d}, J_{34,35}=10.0 \mathrm{~Hz}, J_{35,36}=2.6 \mathrm{~Hz}, 1 \mathrm{H}, \mathbf{H}-35\right), 2.68\left(\mathrm{~m}, J_{33,34}=9.9 \mathrm{~Hz}\right.$, $\left.J_{34,35}=10.0 \mathrm{~Hz}, 1 \mathrm{H}, \mathbf{H}-34\right), 2.62\left(\mathrm{dd}, J_{2 \mathrm{a}, 2 \mathrm{e}}=16.2 \mathrm{~Hz}, J_{2 \mathrm{e}, 3}=9.2 \mathrm{~Hz}, 1 \mathrm{H}, \mathbf{H}-2 \mathrm{e}\right), 2.49-2.44$ $\left(\mathrm{m}, J_{14 \mathrm{e}, 15}=2.1 \mathrm{~Hz}, J_{18 \mathrm{e}, 19}=5.5 \mathrm{~Hz}, 3 \mathrm{H}, \mathbf{H - 2 a}, \mathbf{H - 1 4 e}, \mathbf{H}-18 \mathrm{e}\right), 2.37-2.34\left(\mathrm{~m}, J_{6 \mathrm{a}, 7 \mathrm{a}}=10.6\right.$ $\left.\mathrm{Hz}, J_{6 \mathrm{e}, 7 \mathrm{a}}=5.7 \mathrm{~Hz}, J_{7 \mathrm{a}, 8}=11.3,1 \mathrm{H}, \mathbf{H}-7 \mathbf{a}\right), 2.19-2.15\left(\mathrm{~m}, J_{9,10 \mathrm{e}}=11.7 \mathrm{~Hz}, J_{10 \mathrm{e}, 11}=10.9 \mathrm{~Hz}\right.$, $1 \mathrm{H}, \mathbf{H - 1 0 e}) 2.13-2.10\left(\mathrm{~m}, J_{35,36}=2.6 \mathrm{~Hz}, J_{36,37}=3.1 \mathrm{~Hz}, 1 \mathrm{H}, \mathbf{H}-36\right), 2.02\left(\mathrm{ddd}, J_{17,18 \mathrm{a}}=8.1\right.$ $\left.\mathrm{Hz}, J_{18 \mathrm{a}, 18 \mathrm{e}}=14.4 \mathrm{~Hz}, J_{18 \mathrm{a}, 19}=3.9 \mathrm{~Hz}, 1 \mathrm{H}, \mathbf{H}-18 \mathrm{a}\right), 1.99-1.95\left(\mathrm{~m}, J_{5,6 \mathrm{e}}=11.5 \mathrm{~Hz}, J_{6 \mathrm{e}, 7 \mathrm{a}}=\right.$ $\left.5.7 \mathrm{~Hz}, J_{6 \mathrm{e}, 7 \mathrm{e}}=13.5 \mathrm{~Hz}, J_{11,12 \mathrm{e}}=10.7 \mathrm{~Hz}, 2 \mathrm{H}, \mathbf{H - 6 e}, \mathbf{H - 1 2 e}\right), 1.85-1.74\left(\mathrm{~m}, J_{3,4 \mathrm{e}}=10.9 \mathrm{~Hz}\right.$, $J_{4 \mathrm{e}, 5}=10.3 \mathrm{~Hz}, J_{6 \mathrm{e}, 7 \mathrm{e}}=13.5 \mathrm{~Hz}, J_{7 \mathrm{e}, 8}=2.4 \mathrm{~Hz}, J_{11,12 \mathrm{a}}=1.2 \mathrm{~Hz}, J_{14 \mathrm{a}, 15}=11.5 \mathrm{~Hz}, 4 \mathrm{H}, \mathbf{H}-4 \mathbf{e}$, H-7e, H-12a, H-14a), $1.72-1.66\left(\mathrm{~m}, J_{5,6 \mathrm{a}}=1.1 \mathrm{~Hz}, J_{6 \mathrm{a}, 7 \mathrm{a}}=10.6 \mathrm{~Hz}, J_{15,16}=10.8 \mathrm{~Hz}, 2 \mathrm{H}\right.$, H-6a, H-16), 1.63 (app dt, $\left.J_{3,4 \mathrm{a}}=4.3 \mathrm{~Hz}, J_{4 \mathrm{a}, 4 \mathrm{e}}=14.1 \mathrm{~Hz}, J_{4 \mathrm{a}, 5}=1.8 \mathrm{~Hz}, 1 \mathrm{H}, \mathbf{H - 4 a}\right), 1.56$ $\left(\operatorname{app~dd}, J_{9,10 \mathrm{a}}=2.3 \mathrm{~Hz}, J_{10 \mathrm{a}, 10 \mathrm{e}}=14.4 \mathrm{~Hz}, J_{10 \mathrm{a}, 11}=1.3 \mathrm{~Hz}, 1 \mathrm{H}, \mathbf{H - 1 0 a}\right), 1.45\left(\mathrm{~d}, J_{37,38}=6.6\right.$ $\mathrm{Hz}, 3 \mathrm{H}, \mathbf{H - 3 8}), 1.34$ (d, $\left.J_{16,41}=6 \mathrm{~Hz}, 3 \mathrm{H}, \mathbf{H}-41\right), 1.31$ (d, $\left.J_{34,40}=6 \mathrm{~Hz}, 3 \mathrm{H}, \mathbf{H}-40\right), 1.24$ (d, $\left.J_{36,39}=7.2 \mathrm{~Hz}, 3 \mathrm{H}, \mathbf{H}-39\right)$.

${ }^{13} \mathrm{C}$ NMR (150 MHz, pyridine $\left.d-5: \mathrm{CD}_{3} \mathrm{OD}, 10: 1\right)$ $\delta 172.1,141.4,137.5,135.1,134.8,134.2,133.6,133.4,133.1,132.8,132.7,129.1,98.3$, $78.7,76.3,75.3,75.2,72.2,71.4,70.4,69.7,68.5,48.2,46.7,45.1,44.4,43.8,43.0,41.5$, $41.2,41.0,36.6,31.9,30.2,29.8,19.1,17.4,14.1,12.8$.

HRMS (ESI)

calculated for $\mathrm{C}_{41} \mathrm{H}_{64} \mathrm{O}_{12}(\mathrm{M}+\mathrm{Na})^{+}: 771.4295$

found:

771.4268

${ }^{4}$ Ganis, P.; Avitabile, G.; Mechlinski, W.; Schaffner, C.P. J. Am. Chem. Soc. 1971, 93, 4560-4564. 
The following data are consistent with the assignment of the C19 stereocenter of MeAmdeB (2) as 19-(R):

1. The 19-(R) assignment is consistent with preference for peripheral hydride attack precedented by Nicolaou and coworkers and the matched/mismatched relationships observed with the CBS catalysts.

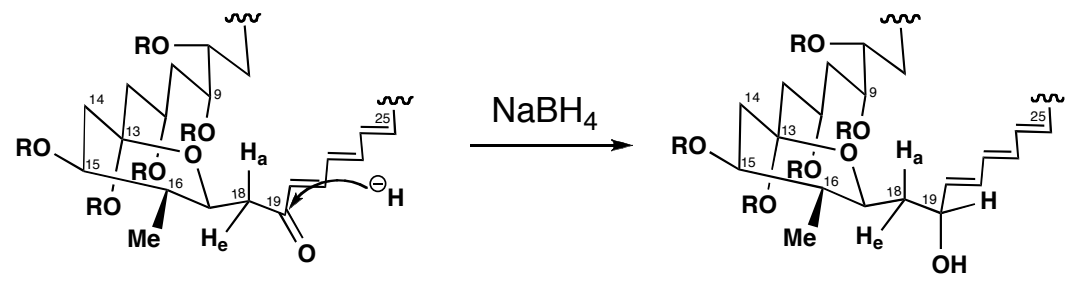

Figure S1. The peripheral mode of hydride attack.

Specifically, in the context of degradative synthetic studies with amphotericin B, ${ }^{5}$ Nicolaou and coworkers performed the following transformation of $\mathbf{S 1}$ into $\mathbf{S 2}$ :

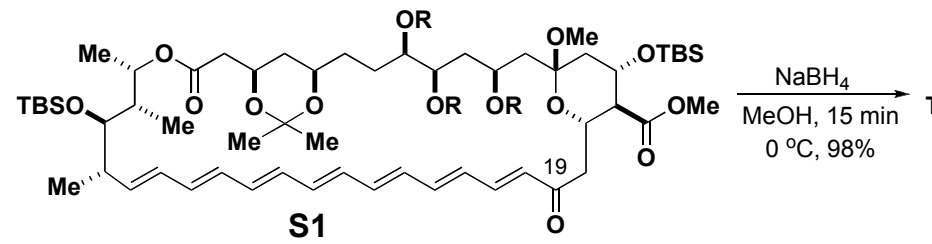

$\mathrm{R}=$ acetonide or $t$-butyldimethylsilyl

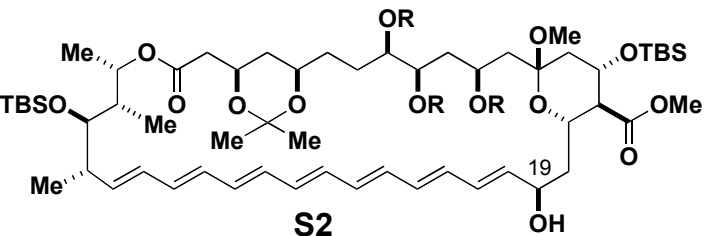

$\mathrm{R}=$ acetonide or $t$-butyldimethylsilyl

A single stereoisomer at $\mathrm{C}(19)$ was observed, consistent with a predicted strong preference for peripheral hydride attack as shown in Fig. S1. The assignment of this stereocenter as the 19- $(R)$ isomer was ultimately confirmed unambiguously via total synthesis of amphotericin B. ${ }^{6}$ Nicolaou and coworkers also demonstrated that the protective groups can be changed without altering the observed diastereomeric outcome. ${ }^{5}$ For example, octatrimethylsilyl ether derivative $\mathbf{S 3}$ was reduced to allylic alcohol $\mathbf{S 4}$ as the only reduction product. ${ }^{5}$
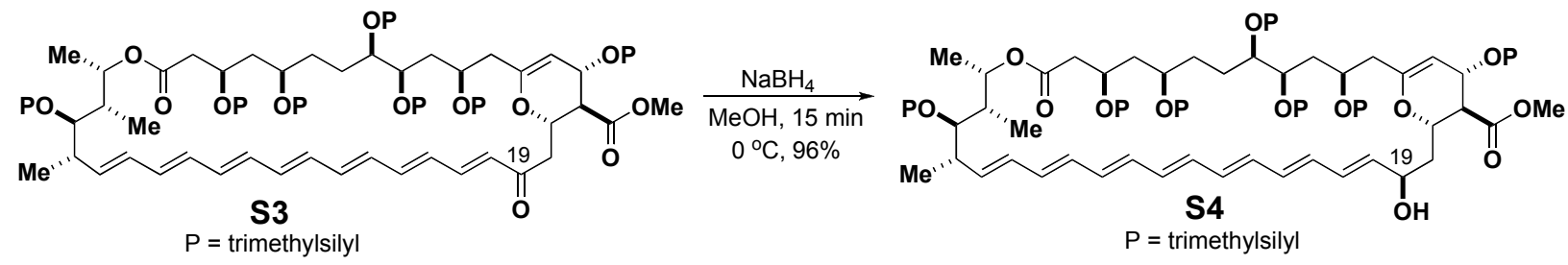

We observed the same result (a single diastereomer) for the reduction of enone $\mathbf{1 9}$ to allylic alcohol 11 using $\mathrm{NaBH}_{4}$ in the context of our alternative synthesis of amphoteronolide B 3 (see S23-S24). However, the $\mathrm{NaBH}_{4}$-mediated reduction of enone $\mathbf{9}$ to allylic alcohol $\mathbf{1 6}$ en route to

\footnotetext{
${ }^{5}$ Nicolaou, K.C.; Chakraborty, T.K.; Ogawa, Y.; Daines, R.A.; Simpskins, N.S.; Furst, G.T. J. Am. Chem. Soc. 1988, 110, 4660-4672.

${ }^{6}$ a) Nicolaou, K.C.; Daines, R.A.; Chakraborty, T.K.; Ogawa, Y. J. Am. Chem. Soc. 1987, 109, 2821-2822. B)

Nicolaou, K.C.; Daines, R.A.; Chakraborty, T.K. J. Am. Chem. Soc. 1987, 109, 2208-2210.
} 
MeAmdeB (2) was less selective ( 2:1 mixture of diastereomers). Based on the precedent described above, we tentatively assigned the major isomer as 19- $(R)$. Consistent with this, when we performed this same reduction of 9 to 16 with $(S)$-2-methyl-CBS-oxazaborolidine, the catalyst enantiomer predicted to deliver the desired $19(R)$ isomer (the matched case), we obtained a significant enhancement in diastereoselectivity with the same major diastereomer being formed with a d.r. of 6:1. Alternative use of the $(R)$-2-methyl-CBS-oxazaborolidine (the predicted mismatched case) led to a 1:1 mixture of diastereomeric products.

2. The observed $J_{18 \mathrm{a}, 19}$ and $J_{18 \mathrm{e}, 19}$ coupling constants for MeAmdeB (2) are consistent with those calculated for the 19- $(R)$ configuration and with those observed for AmB derivatives known to have the 19- $(R)$ configuration.

As described in detail in Section III, we have determined the skeletons of 1-4 to be quite rigid, making it possible to calculate predicted coupling constants using the Altona Karplus equation. Moreover, we have utilized phase-sensitive COSY (COSYPS) techniques and amplitude constrained multiplet evaluation ${ }^{3}$ to unambiguously assign the $J_{18 \mathrm{a}, 19}$ and $J_{18 \mathrm{e}, 19}$ coupling constants. As shown in Fig. S2A, for the 19- $(R)$ isomer, it is predicted that both $J_{18 \mathrm{a}, 19}$ and $J_{18 \mathrm{e}, 19}$ will be $<8 \mathrm{~Hz}$. This is not the case for the $19-(S)$ isomer $\left(J_{18 \mathrm{a}, 19}\right.$ is predicted to be $\left.>8 \mathrm{~Hz}\right)$. As shown in Fig. S2B, the observed $J_{18 \mathrm{a}, 19}$ and $J_{18 \mathrm{e}, 19}$ couplings for MeAmdeB (2) are consistent only with the calculated values for the 19- $(R)$ isomer. Moreover, these values are consistent with those observed for AmB derivatives $\mathbf{1 7 ^ { 8 }}$ and $\mathbf{2 3}$ for which the $C(19)$ stereocenter was not altered.

A

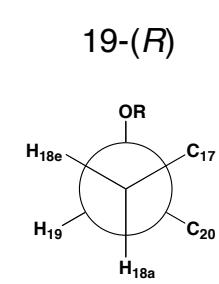

Calculated coupling constants $(\mathrm{Hz})$

\begin{tabular}{lll}
\hline$J_{18 \mathrm{a}, 19}<7$ & $>8$ \\
$J_{18 \mathrm{e}, 19}<8$ & $<8$
\end{tabular}

B

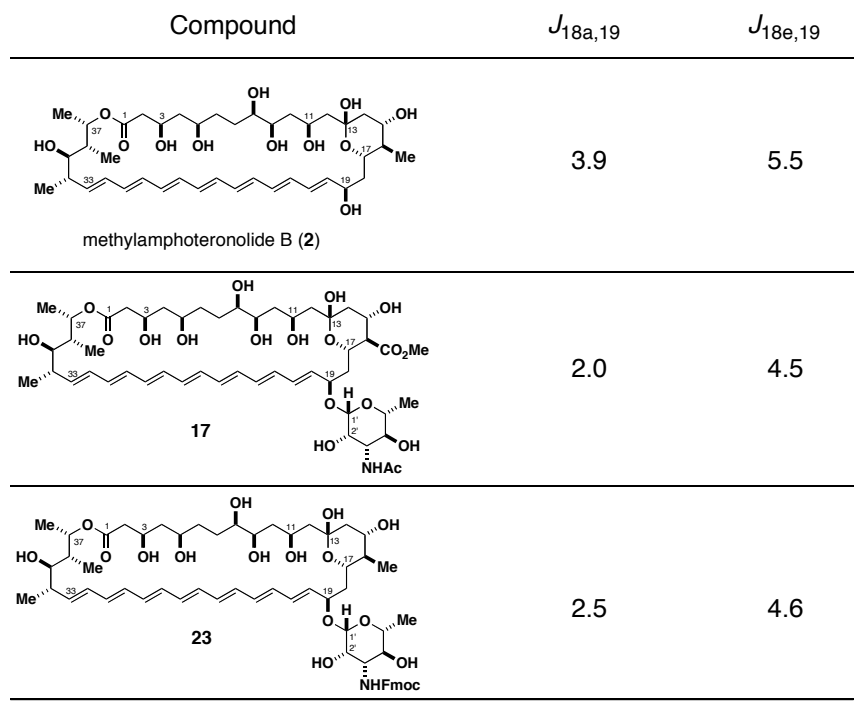

Figure S2. Coupling constants are consistent with the 19- $(R)$ assignment for MeAmdeB (2).

\footnotetext{
${ }^{7}$ Haasnoot, C. A. G.; de Leeuw, F. A. A. M.; Altona, C. Tetrahedron, 1980, 36, 2783-2792.

8 a) Schaffner, C.P.; J. Antibiot. 1972, 25, 256. b) Pandey, R.C.; Rinehart, K.L., Jr. J. Antibiot. 1977, $30,158$.
} 


\section{The 19-(R) assignment for MeAmdeB (2) is consistent with NOEs observed in all four} compounds 17, 2, 21, and 23 (See Section III for details).
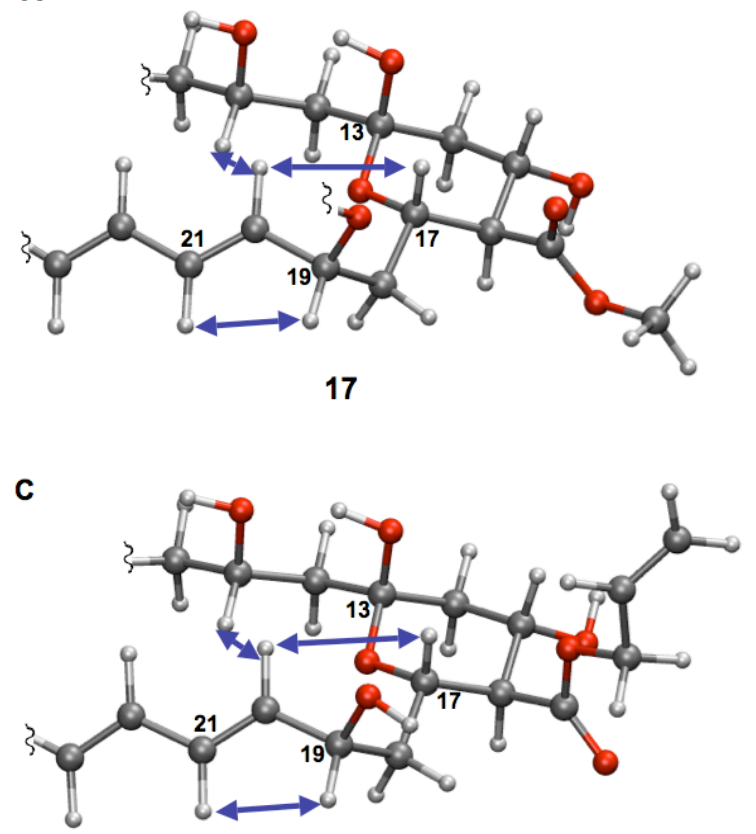

21

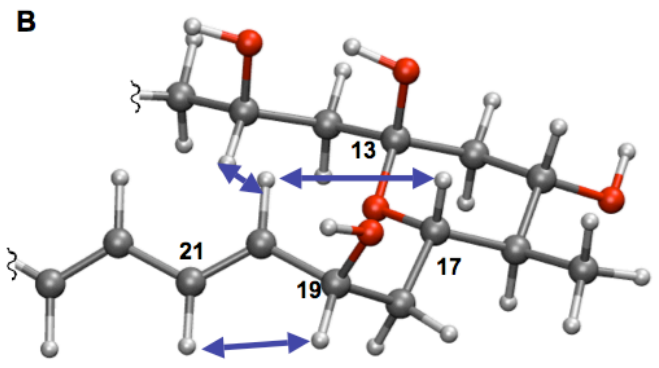

2

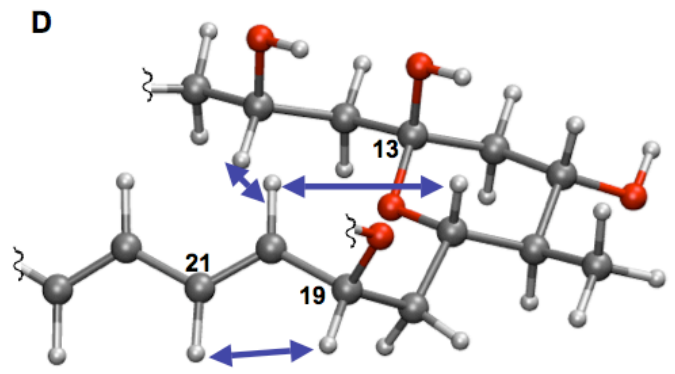

23

Figure S3. Observed NOEs (double-headed arrows) are consistent with the 19- $(R)$ assignment for MeAmdeB (2).

In all four 17, 2, 21, and 23 compounds an NOE correlation between H-19 and H-21 was observed, which is consistent with an $\mathrm{A}_{1,3}$ type interaction between H-19 and H-21 (Figure S3A$D)$. This NOE is expected to be present only with the $19-R$ configuration. 

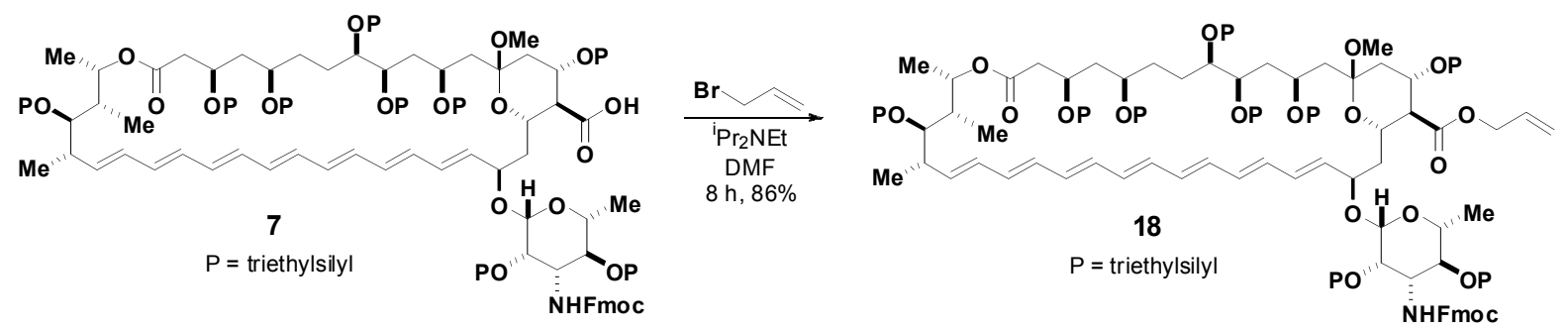

\section{Allyl ester 18}

To a stirred solution of 7 (4.95 g, $2.26 \mathrm{mmol}, 1 \mathrm{eq})$ in DMF:MeOH 10:1 (82.5 mL) at $23{ }^{\circ} \mathrm{C}$ was added allyl bromide $(7.5 \mathrm{~mL}, 85.9 \mathrm{mmol}, 38 \mathrm{eq})$ and diisopropyl ethyl amine $(1.75 \mathrm{~mL}, 9.9$ mmol, $4.4 \mathrm{eq})$. The solution was stirred for 8 hours and then diluted with water:saturated aqueous sodium bicarbonate 1:1 $(250 \mathrm{~mL})$. The aqueous phase was extracted with diethyl ether $(4 \times 100 \mathrm{~mL})$ and the combined organic extracts were washed with brine $(1 \times 50 \mathrm{~mL})$, dried over sodium sulfate and concentrated in vacuo. Purification of the resulting residue by flash chromatography $\left(\mathrm{SiO}_{2}\right.$; hexanes:diethyl ether 20:1 $\left.\rightarrow 10: 1\right)$ yielded $\mathbf{1 8}$ as a yellow solid (4.33 grams, $1.94 \mathrm{mmol}, 86 \%$ ).

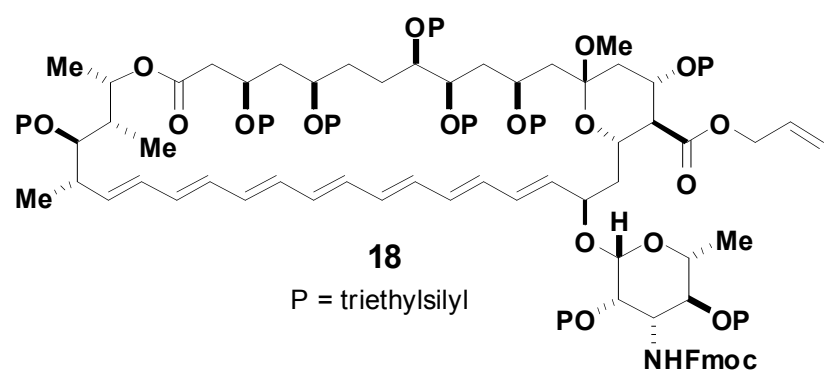

TLC (hexanes:diethyl ether 2:1)

$\mathrm{R}_{\mathrm{f}}=0.85$, visualized by $\mathrm{UV}$

${ }^{1} \mathrm{H}$ NMR (500 MHz, acetone $\left.d-6\right)$

$\delta 7.87(\mathrm{~d}, J=7.5 \mathrm{~Hz}, 2 \mathrm{H}), 7.69(\mathrm{~d}, J=7.5 \mathrm{~Hz}, 2 \mathrm{H}), 7.42(\mathrm{t}, J=7.5 \mathrm{~Hz}, 2 \mathrm{H}), 7.34$ (t, $J=$ $7.5 \mathrm{~Hz}, 2 \mathrm{H}), 6.57-6.50(\mathrm{~m}, 2 \mathrm{H}), 6.48-6.13(\mathrm{~m}, 10 \mathrm{H}), 6.06-5.99(\mathrm{~m}, 1 \mathrm{H}), 5.98(\mathrm{dd}, J=5.5$, $16 \mathrm{~Hz}, 1 \mathrm{H}), 5.49$ (dd, $J=9.5,14.5 \mathrm{~Hz}, 1 \mathrm{H}), 5.43(\mathrm{dd}, J=1.5,17 \mathrm{~Hz}, 1 \mathrm{H}), 5.34(\mathrm{~d}, J=10$ $\mathrm{Hz}, 1 \mathrm{H}), 5.29(\mathrm{~d}, J=10.5 \mathrm{~Hz}, 1 \mathrm{H}), 4.74(\mathrm{dd}, J=6,13.5 \mathrm{~Hz}, 1 \mathrm{H}), 4.63-4.51(\mathrm{~m}, 3 \mathrm{H})$, 4.49-4.41 (m, 3H), 4.33 (dd, $J=6.5,10.5 \mathrm{~Hz}, 1 \mathrm{H}), 4.26-4.23(\mathrm{~m}, 2 \mathrm{H}), 4.12$ (t, $J=10 \mathrm{~Hz}$, $1 \mathrm{H}), 4.02-3.97(\mathrm{~m}, 2 \mathrm{H}), 3.90(\mathrm{~d}, J=3 \mathrm{~Hz}, 1 \mathrm{H}), 3.85$ (dd, $J=2.5,6.5 \mathrm{~Hz}, 1 \mathrm{H}), 3.71-3.67$ $(\mathrm{m}, 2 \mathrm{H}), 3.66-3.62(\mathrm{~m}, 3 \mathrm{H}), 3.45(\mathrm{t}, J=8.5 \mathrm{~Hz}, 1 \mathrm{H}), 3.43-3.30(\mathrm{~m}, 1 \mathrm{H}), 3.13(\mathrm{~s}, 3 \mathrm{H})$, 2.58-2.56 (m, 2H) 2.43 (app dd, $J=9,16 \mathrm{~Hz}, 1 \mathrm{H}), 2.36(\mathrm{t}, J=10.5 \mathrm{~Hz}, 1 \mathrm{H}), 2.00-1.96$ (m, 2H), 1.93-1.90 (m, 2H), 1.84-1.58 (m, 8H), $1.50(\mathrm{bs}, 1 \mathrm{H}), 1.23(\mathrm{~d}, J=6 \mathrm{~Hz}, 3 \mathrm{H})$, $1.17(\mathrm{~d}, J=6 \mathrm{~Hz}, 3 \mathrm{H}), 1.07-0.89(\mathrm{~m}, 87 \mathrm{H}), 0.78-0.56(\mathrm{~m}, 54 \mathrm{H})$. 
${ }^{13} \mathrm{C}$ NMR $(125 \mathrm{MHz}$, acetone $d-6)$ $\delta 172.9,170.5,156.3,145.0,144.9,142.2,142.1,139.3,135.6,135.5,135.0,134.5$, $134.2,133.6,133.4,132.4,132.3,132.1,131.6,131.2,130.6,128.4,127.8,127.7,125.8$, $125.7,120.7,119.0,101.4,98.6,76.6,75.7,74.5,74.0,73.9,73.4,73.2,71.0,68.9,67.6$, $67.4,67.3,67.2,65.9,58.1,57.5,48.1,48.0,47.8,44.2,43.3,42.2,41.4,40.7,36.2,35.6$, $27.4,22.9,19.9,19.2,18.8,15.5,11.1,7.58,7.53,7.43,7.42,7.29,7.23,7.20,7.19,7.07$, $6.30,6.11,5.84,5.82,5.81,5.76,5.72,5.70,5.58$.

HRMS (ESI)

calculated for $\mathrm{C}_{120} \mathrm{H}_{215} \mathrm{NO}_{19} \mathrm{Si}_{9}(\mathrm{M}+\mathrm{Na})^{+}: \quad 2249.3710$

found:

2249.3630 

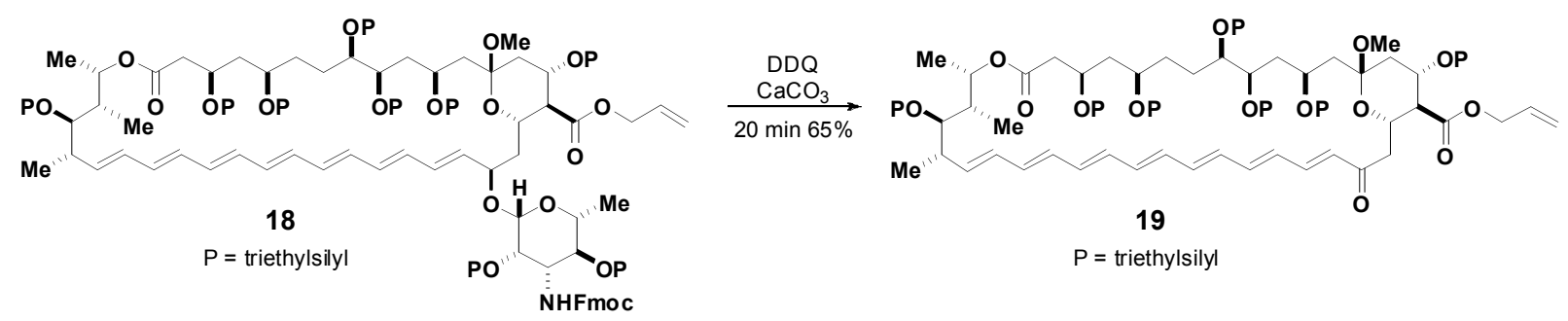

\section{Heptaenone 19}

Prior to the reaction, calcium carbonate was dried via storage under vacuum for a minimum of eight hours in the presence of phosphorus pentoxide desiccant. Also, $\mathbf{1 8}$ was azeotropically dried via coevaporation with benzene $(3 \times 25 \mathrm{~mL})$ and left under vacuum for a minimum of eight hours. The resulting yellow solid (4.33 g, $1.94 \mathrm{mmol}, 1 \mathrm{eq})$ was dissolved in THF (100 mL) at 23 ${ }^{\circ} \mathrm{C}$ and calcium carbonate (1.94 g, $\left.19.4 \mathrm{mmol}, 10 \mathrm{eq}\right)$ was added. DDQ (0.660 g, $2.91 \mathrm{mmol}, 1.5$ eq) was added and an immediate color change to dark red was observed. This mixture was stirred for 20 minutes and then quenched with the addition of $100 \mathrm{~mL}$ saturated aqueous sodium bicarbonate. The resulting emulsion was diluted with water $(300 \mathrm{~mL})$ and extracted with dichloromethane $(10 \times 250 \mathrm{~mL})$. The combined organic extracts were washed with brine $(1 \mathrm{x}$ $150 \mathrm{~mL}$ ) and concentrated in vacuo. Purification of the resulting residue by flash chromatography $\left(\mathrm{SiO}_{2}\right.$; hexanes: $\left.\mathrm{Et}_{2} \mathrm{O} 20: 1 \rightarrow 6: 1\right)$ yielded 19 as a dark orange solid $(2.06 \mathrm{~g}, 1.26$ mmol, 65\%).

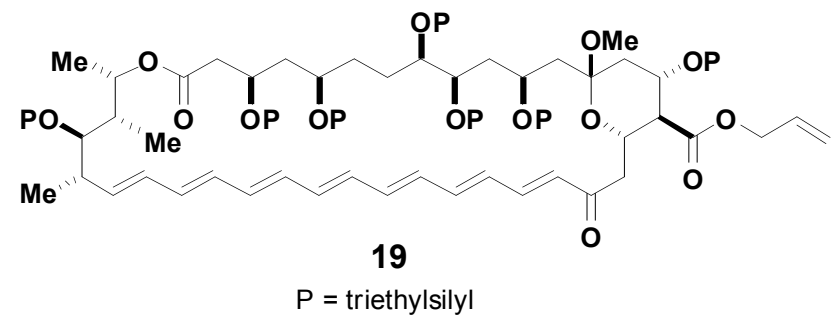

TLC (hexanes: $\mathrm{Et}_{2} \mathrm{O} 2: 1$ )

$\mathrm{R}_{\mathrm{f}}=0.44$, visualized by eye

${ }^{1} \mathrm{H}$ NMR (500 MHz, acetone $\left.d-6\right)$

$\delta 7.84(\mathrm{dd}, J=11,15.5 \mathrm{~Hz}, 1 \mathrm{H}), 7.13(\mathrm{dd}, J=11.5,14.5 \mathrm{~Hz}, 1 \mathrm{H}), 6.81(\mathrm{dd}, J=11,14.5$ $\mathrm{Hz}, 1 \mathrm{H}), 6.62-6.55(\mathrm{~m}, 2 \mathrm{H}), 6.49-6.14(\mathrm{~m}, 7 \mathrm{H}), 6.05(\mathrm{~d}, J=15.5 \mathrm{~Hz}, 1 \mathrm{H}), 6.01$ (app ddd, $J=6,10,16 \mathrm{~Hz}, 1 \mathrm{H}), 5.51(\mathrm{dd}, J=10,15 \mathrm{~Hz}, 1 \mathrm{H}), 5.42(\mathrm{dd}, J=1.5,17.5 \mathrm{~Hz}, 1 \mathrm{H}), 5.27$ $(\mathrm{dd}, J=1.5,10.5 \mathrm{~Hz}, 1 \mathrm{H}), 4.68(\operatorname{app~d}, J=5.5 \mathrm{~Hz}, 2 \mathrm{H}), 4.50(\mathrm{dd}, J=5,10.5 \mathrm{~Hz}, 1 \mathrm{H})$, $4.45(\mathrm{dd}, J=5.5,10 \mathrm{~Hz}, 1 \mathrm{H}), 4.28(\operatorname{app~t}, J=10.5 \mathrm{~Hz}, 1 \mathrm{H}), 4.13-4.08(\mathrm{~m}, 2 \mathrm{H}), 3.96(\mathrm{dd}$, $J=3,9.5 \mathrm{~Hz}, 1 \mathrm{H}), 3.77(\mathrm{t}, J=10.5 \mathrm{~Hz}, 1 \mathrm{H}), 3.72-3.64(\mathrm{~m}, 4 \mathrm{H}), 3.20(\mathrm{dd}, J=11,12.5$ $\mathrm{Hz}, 1 \mathrm{H}), 2.92(\mathrm{~s}, 3 \mathrm{H}), 2.70(\mathrm{dd}, J=4,18 \mathrm{~Hz}, 1 \mathrm{H}), 2.62$ (dd, $J=10,18 \mathrm{~Hz}, 1 \mathrm{H}), 2.46$ (app $\mathrm{dd}, J=9,16 \mathrm{~Hz}, 1 \mathrm{H}), 2.40(\mathrm{t}, J=10.5 \mathrm{~Hz}, 1 \mathrm{H}), 2.30(\operatorname{app~t}, J=11 \mathrm{~Hz}, 1 \mathrm{H}), 2.13(\mathrm{~d}, J=$ $12 \mathrm{~Hz}, 1 \mathrm{H}), 1.96-1.86(\mathrm{~m}, 4 \mathrm{H}), 1.83-1.76(\mathrm{~m}, 4 \mathrm{H}), 1.67$ (app d, $J=12.5 \mathrm{~Hz}, 1 \mathrm{H}), 1.50$ (app t, $J=10.5 \mathrm{~Hz}, 1 \mathrm{H}), 1.17(\mathrm{~d}, J=6 \mathrm{~Hz}, 3 \mathrm{H}), 1.15$ (t, $J=8 \mathrm{~Hz}, 9 \mathrm{H}), 1.09-0.96$ (m, $60 \mathrm{H}), 0.89(\mathrm{q}, J=8.5 \mathrm{~Hz}, 6 \mathrm{H}), 0.78-0.54(\mathrm{~m}, 36 \mathrm{H})$ 
${ }^{13} \mathrm{C}$ NMR (125 MHz, acetone $\left.d-6\right)$ $\delta 199.3,172.1,169.9,149.2,143.7,140.8,140.2,139.2,138.3,137.1,133.2,132.0$, $131.6,131.3,130.7,130.6,130.5,130.1,118.6,101.2,76.7,74.1,73.6,71.5,70.4,68.9$, $67.8,67.0,65.9,57.9,48.4,47.1,44.6,43.5,43.1,40.9,40.7,39.9,35.1,27.7,20.0,19.7$, $10.9,7.66,7.45,7.44,7.39,7.21,7.16,6.98,6.50,6.06,5.80,5.77,5.63,5.54,5.50$.

HRMS (ESI)

calculated for $\mathrm{C}_{87} \mathrm{H}_{164} \mathrm{O}_{14} \mathrm{Si}_{7}(\mathrm{M}+\mathrm{Na})^{+}: \quad 1652.0404$

found:

1652.0461 

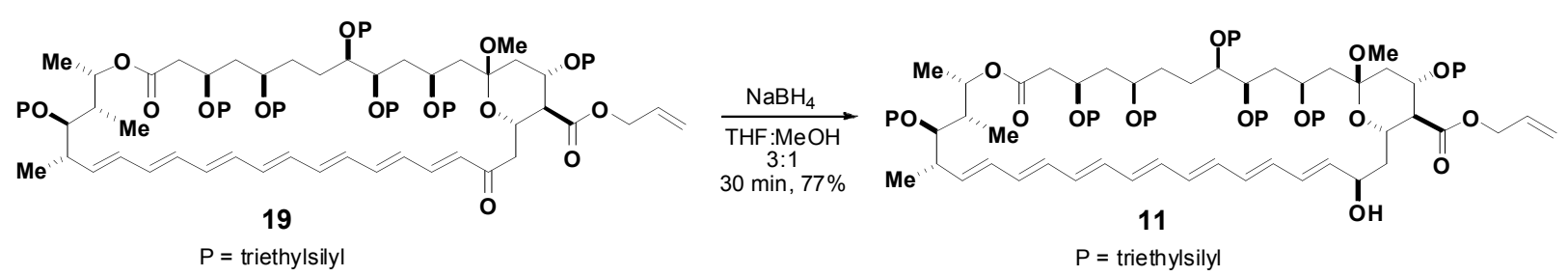

\section{Allylic alcohol 11}

Prior to the reaction 19 was azeotropically dried via coevaporation with benzene $(3 \times 25 \mathrm{~mL})$ and left under vacuum for a minimum of eight hours. The resulting red solid $(2.05 \mathrm{~g}, 1.26 \mathrm{mmol}, 1$ eq) was dissolved in THF:MeOH 3:1 $(12 \mathrm{~mL})$ the resulting solution was cooled to $0{ }^{\circ} \mathrm{C}$ and sodium borohydride $(0.480 \mathrm{~g}, 12.6 \mathrm{mmol}, 10 \mathrm{eq})$ was added. The solution was stirred for 30 minutes and a color change from dark red to light orange was observed during the course of the reaction. The reaction was then quenched at $0{ }^{\circ} \mathrm{C}$ by the addition of saturated aqueous ammonium chloride $(100 \mathrm{~mL})$. The resulting emulsion was diluted with diethyl ether $(250 \mathrm{~mL})$. The two layers were separated and the organic phase was washed with water $(3 \times 50 \mathrm{~mL})$ and brine $(1 \times 50 \mathrm{~mL})$. The combined aqueous washings were back-extracted with diethyl ether $(1 \mathrm{x}$ $100 \mathrm{~mL}$ ) and the combined organic extracts were dried over sodium sulfate and concentrated in vacuo. Purification of the resulting residue by flash chromatography ( $\mathrm{SiO}_{2}$; hexanes:diethyl ether $20: 1 \rightarrow 4: 1)$ furnished 11 as a pale orange solid $(1.59 \mathrm{~g}, 0.974 \mathrm{mmol},>20: 1 \mathrm{dr}, 77 \%)$.

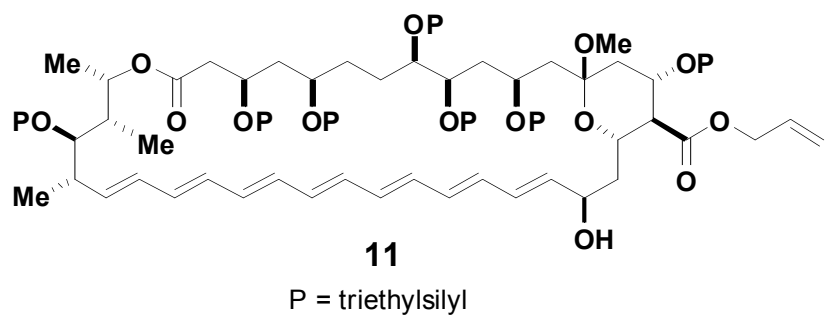

TLC (hexanes:diethyl ether 2:1)

$\mathrm{R}_{\mathrm{f}}=0.25$, stained by anisaldehyde

${ }^{1} \mathrm{H}$ NMR (500 MHz, acetone $\left.d-6\right)$

$\delta$ 6.52-6.13 (m, 13H), 5.98 (app ddd, $J=6,10.5,16.5 \mathrm{~Hz}, 1 \mathrm{H}), 5.55$ (dd, $J=9.5,15 \mathrm{~Hz}$, $1 \mathrm{H}), 5.40(\mathrm{dd}, J=1.5,16 \mathrm{~Hz}, 1 \mathrm{H}), 5.24(\mathrm{dd}, J=1,6.5 \mathrm{~Hz}, 1 \mathrm{H}), 4.70$ (app t, $J=6.5 \mathrm{~Hz}$, $1 \mathrm{H}), 4.63(\operatorname{app~t}, J=5.5 \mathrm{~Hz}, 2 \mathrm{H}), 4.52(\mathrm{bs}, 1 \mathrm{H}), 4.44(\mathrm{dt}, J=4.5,10.5 \mathrm{~Hz}, 1 \mathrm{H}), 4.24(\mathrm{~m}$, $1 \mathrm{H}), 4.14$ (t, $J=9.5 \mathrm{~Hz}, 1 \mathrm{H}), 4.06(\mathrm{dq}, J=3,7.5 \mathrm{~Hz}, 1 \mathrm{H}), 4.04-3.99(\mathrm{~m}, 1 \mathrm{H}), 3.95(\mathrm{~d}, J=$ $3.5 \mathrm{~Hz}, 1 \mathrm{H}), 3.86(\mathrm{dd}, J=2.5,9 \mathrm{~Hz}, 1 \mathrm{H}), 3.73-3.70(\mathrm{~m}, 2 \mathrm{H}), 3.65(\mathrm{dd}, J=4.5,10.5 \mathrm{~Hz}$ $1 \mathrm{H}), 3.17(\mathrm{~s}, 3 \mathrm{H}), 2.58(\operatorname{app~t}, J=2 \mathrm{~Hz}, 1 \mathrm{H}), 2.44(\operatorname{app} \mathrm{dd}, J=9,15.5 \mathrm{~Hz}, 1 \mathrm{H}), 2.34(\mathrm{t}, J$ $=10 \mathrm{~Hz}, 1 \mathrm{H}), 2.12(\mathrm{dd}, J=4.5,12.5 \mathrm{~Hz}, 1 \mathrm{H}) 2.07-2.05(\mathrm{~m}, 2 \mathrm{H}), 2.05-1.99(\mathrm{~m}, 1 \mathrm{H}), 1.97-$ 1.59 (m, 10H), 1.52 (bs, 1H) 1.18 (d, $J=6 \mathrm{~Hz}, 3 \mathrm{H}), 1.08-0.95$ (m, 69H), 0.78-0.59 (m, 42H).

${ }^{13} \mathrm{C}$ NMR (125 MHz, acetone $\left.d-6\right)$

$\delta 172.8,170.6,139.0,135.0,134.9,134.1,133.5,133.1,133.0,132.6,131.8,131.5$, $130.8,128.1,126.0,118.4,101.4,76.7,74.0,71.0,69.0,67.5,67.4,65.6,57.7,48.1,47.8$, $44.4,43.5,42.4,41.3,40.7,35.6,30.7,29.2,27.4,19.8,19.1,7.62,7.59,7.48,7.30,7.27$, $7.12,6.38,6.17,5.89,5.83,5.79,5.64$. 
HRMS (ESI)

calculated for $\mathrm{C}_{87} \mathrm{H}_{166} \mathrm{O}_{14} \mathrm{Si}_{7}(\mathrm{M}+\mathrm{Na})^{+}: \quad 1654.0506$

found:

1654.0493

For a detailed discussion of the 19-(R) stereochemical assignment, see S16-S18.

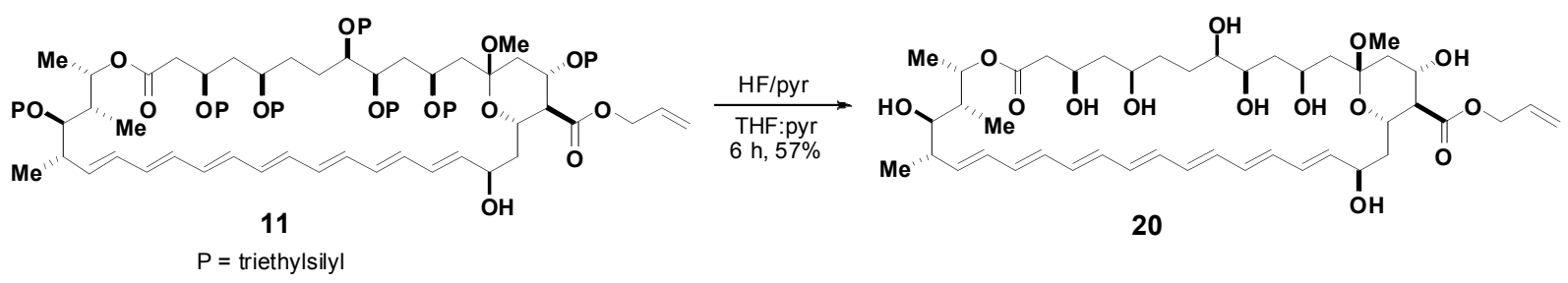

\section{Polyol 20}

To a stirred solution of $\mathbf{1 1}(1.55 \mathrm{~g}, 0.949 \mathrm{mmol}, 1 \mathrm{eq})$ in THF $(7 \mathrm{~mL})$ in a polypropylene vial at 0 ${ }^{\circ} \mathrm{C}$ was added a chilled $\left(0{ }^{\circ} \mathrm{C}\right)$ solution of $70 \% \mathrm{HF} /$ pyridine complex $(10 \mathrm{~mL})$ in THF:pyridine 5:3 $(160 \mathrm{~mL})$. The resulting solution was allowed to warm to $23{ }^{\circ} \mathrm{C}$ and stirred for 6 hours. The reaction was then cooled to $0{ }^{\circ} \mathrm{C}$ and quenched by the addition of saturated aqueous sodium bicarbonate $(500 \mathrm{~mL})$. The resulting yellow emulsion was extracted with $\mathrm{CH}_{2} \mathrm{Cl}_{2}: \mathrm{MeOH}$ 5:1 (5 x $200 \mathrm{~mL})$. The combined organic extracts were washed with brine $(1 \times 100 \mathrm{~mL})$, dried over sodium sulfate and concentrated in vacuo. Purification of the resulting residue by flash chromatography $\left(\mathrm{C}_{18}\right.$ bonded $\left.\mathrm{SiO}_{2} ; \mathrm{MeCN}: \mathrm{H}_{2} \mathrm{O} 1: 1\right)$ furnished 20 as an orange solid $(0.442 \mathrm{~g}$, $0.531 \mathrm{mmol}, 56 \%)$.

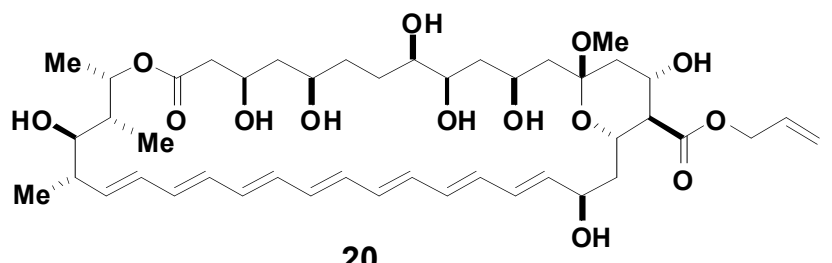

TLC $\left(\mathrm{CH}_{2} \mathrm{Cl}_{2}: \mathrm{MeOH} 10: 1\right)$

$\mathrm{R}_{\mathrm{f}}=0.25$, stained by anisaldehyde

HPLC

$\mathrm{tR}=18.90 \mathrm{~min}$; flow rate $=4 \mathrm{~mL} / \mathrm{min}$, gradient of $5 \rightarrow 95 \% \mathrm{MeCN}$ in $5 \mathrm{mM}$ ammonium acetate over $25 \mathrm{~min}$.

${ }^{1} \mathrm{H}$ NMR $\left(500 \mathrm{MHz}, \mathrm{CD}_{3} \mathrm{OD}\right)$

$\delta$ 6.43-6.13 (m, 12H), 5.98 (app ddd, $J=6,10.5,16 \mathrm{~Hz}, 1 \mathrm{H}), 5.80(\mathrm{dd}, J=7.5,15 \mathrm{~Hz}$, $1 \mathrm{H}), 5.47$ (dd, $J=9.5,14 \mathrm{~Hz}, 1 \mathrm{H}), 5.38(\mathrm{dd}, J=1.5,16 \mathrm{~Hz}, 1 \mathrm{H}), 5.24(\mathrm{dd}, J=1,10.5 \mathrm{~Hz}$, $1 \mathrm{H}), 4.66$ (d, $J=5 \mathrm{~Hz}, 2 \mathrm{H}), 4.48$ (app dd, $J=7,11.5 \mathrm{~Hz}, 1 \mathrm{H}), 4.20-4.12(\mathrm{~m}, 3 \mathrm{H}), 3.99$ (dq, $J=3.5,10.5 \mathrm{~Hz}, 1 \mathrm{H}), 3.91$ (dd, $J=8.5,12.5 \mathrm{~Hz}, 1 \mathrm{H}), 3.71$ (app t, $J=6 \mathrm{~Hz}, 1 \mathrm{H}), 3.53$ (app d, $J=10 \mathrm{~Hz}, 1 \mathrm{H}), 3.26(\mathrm{dd}, J=7.5,9.5 \mathrm{~Hz}, 1 \mathrm{H}), 3.22(\operatorname{app~d}, J=12.5 \mathrm{~Hz}, 1 \mathrm{H}), 3.19$ (s, 3H), 2.39 (app dd, $J=7,9.5 \mathrm{~Hz}, 1 \mathrm{H}), 2.31$ (dd, $J=10.5,15.5 \mathrm{~Hz}, 1 \mathrm{H}), 2.22$ (dd, $J=$ $3.5,16.5 \mathrm{~Hz}, 1 \mathrm{H}), 2.11(\mathrm{dd}, J=5,13 \mathrm{~Hz}, 1 \mathrm{H}), 1.90-1.81(\mathrm{~m}, 4 \mathrm{H}), 1.72-1.61(\mathrm{~m}, 4 \mathrm{H})$, $1.51-1.26(\mathrm{~m}, 8 \mathrm{H}), 1.19$ (d, $J=6.5 \mathrm{~Hz}, 3 \mathrm{H}), 1.11(\mathrm{~d}, J=6.5 \mathrm{~Hz}, 3 \mathrm{H}), 1.00(\mathrm{~d}, J=7.5 \mathrm{~Hz}$, $3 \mathrm{H})$. 
${ }^{13} \mathrm{C}$ NMR (125 MHz, pyridine $\left.d-5: \mathrm{CD}_{3} \mathrm{OD} 10: 1\right)$

$\delta 173.0,171.4,140.1,135.4,134.4,134.2,134.1,133.6,133.2,133.1,132.9,132.8$, $132.7,132.4,131.8,128.5,101.7,77.7,75.2,74.5,71.5,70.5,67.9,67.7,67.6,67.4,66.7$, $66.5,65.1,57.0,44.6,43.5,43.1,42.9,42.3,41.3,41.2,38.9,36.0,33.9,32.1,30.5,29.0$, $24.7,23.9,23.1,18.6,18.5,17.5,13.9,12.2,10.9$.

HRMS (ESI)

calculated for $\mathrm{C}_{45} \mathrm{H}_{68} \mathrm{O}_{12}(\mathrm{M}+\mathrm{Na})^{+}: 855.4507$

found:

855.4482
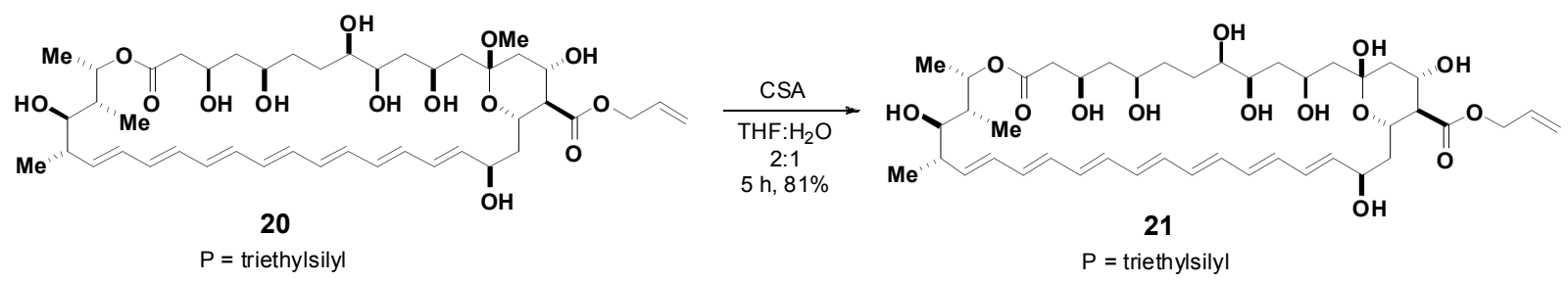

\section{Amphoteronolide B allyl ester 21}

To a stirred solution of 20 (10 mg, $0.012 \mathrm{mmol}, 1 \mathrm{eq})$ in THF: $\mathrm{H}_{2} \mathrm{O} 2: 1(1.2 \mathrm{~mL})$ at $23{ }^{\circ} \mathrm{C}$ was added camphorsulfonic acid $(0.6 \mathrm{mg}, 0.003 \mathrm{mmol}, 0.25 \mathrm{eq})$. The solution was stirred for 5 hours and was then diluted with THF $(2 \mathrm{~mL})$ and quenched by addition of solid sodium bicarbonate. The mixture was stirred vigorously for five minutes and the solids were removed by filtration through a pad of Celite. The filtrate was concentrated in vacuo and the resulting yellow solid was dissolved in THF $\left(1.5 \mathrm{~mL}\right.$ ) and purified by prep RP-HPLC (Waters SunFire Prep $\mathrm{C}_{18}$ OBD 5 micron $30 \times 150 \mathrm{~mm} ; 300 \mu \mathrm{L}$ injection volume, $25 \mathrm{~mL} / \mathrm{min}$ flow rate, $\mathrm{MeCN}: \mathrm{H}_{2} \mathrm{O}$ 1:19 $\rightarrow$ 19:1, over 25 minutes) to yield amphoteronolide B allyl ester (21) as a yellow powder $(8 \mathrm{mg}, 0.0098$ mmol, 81\%).

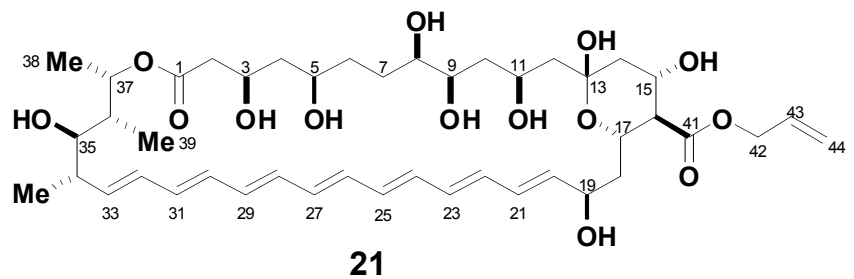

HPLC

$\mathrm{tR}=28.6 \mathrm{~min}$; flow rate $=25 \mathrm{~mL} / \mathrm{min}$, gradient of $5 \rightarrow 95 \% \mathrm{MeCN}$ in $\mathrm{H}_{2} \mathrm{O}$ over $25 \mathrm{~min}$. 
${ }^{1} \mathrm{H}$ NMR (500 MHz, pyridine $\left.d-5: \mathrm{CD}_{3} \mathrm{OD} 10: 1\right)$

$\delta 6.83(\mathrm{dd}, J=11,15 \mathrm{~Hz}, 1 \mathrm{H}, \mathbf{H}-22), 6.77(\mathrm{dd}, J=11,15 \mathrm{~Hz}, 1 \mathrm{H}, \mathbf{H}-24), 6.69$ (dd, $J_{19.20}$ $\left.=9.5 \mathrm{~Hz}, J_{20,21}=15.5 \mathrm{~Hz}, 1 \mathrm{H}, \mathbf{H - 2 0}\right), 6.61$ (dd, $\left.J=14.5,15 \mathrm{~Hz}, 1 \mathrm{H}, \mathbf{H}-26\right), 6.54-6.35$ (m, $9 \mathrm{H}), 6.04-5.96\left(\mathrm{app} \mathrm{ddd}, J_{42,43}=6.5, J_{43,44 \text { cis }}=11 \mathrm{~Hz}, J_{43,44 \text { trans }}=17 \mathrm{~Hz}, 1 \mathrm{H}, \mathbf{H}-43\right), 5.80$ $\left(\right.$ app d, $\left.J_{36,37}=1.9 \mathrm{~Hz}, 1 \mathrm{H}, \mathbf{H}-37\right), 5.55\left(\mathrm{dd}, J_{32,33}=15 \mathrm{~Hz}, J_{33,34}=10.1 \mathrm{~Hz}, 1 \mathrm{H}, \mathbf{H}-33\right)$, $5.42\left(\mathrm{dd}, J_{44 \mathrm{cis}, 44 \text { trans }}=1.5 \mathrm{~Hz}, J_{43,44 \text { trans }}=17.5 \mathrm{~Hz}, 1 \mathrm{H}, \mathbf{H}-44\right.$ trans $), 5.30\left(\right.$ app t, $J_{16,17}=$ $\left.10.6 \mathrm{~Hz}, J_{17,18 \mathrm{e}}=0.9 \mathrm{~Hz}, J_{17,18 \mathrm{a}}=8.7 \mathrm{~Hz}, 1 \mathrm{H}, \mathbf{H - 1 7}\right), 5.14\left(\mathrm{dd}, J_{44 \text { cis }, 44 \text { trans }}=1.5 \mathrm{~Hz}, J_{43,44 \text { cis }}\right.$ $=10.5 \mathrm{~Hz}, 1 \mathrm{H}, \mathbf{H}-44$ cis $), 5.06$ (app dt, $J_{14 \mathrm{e}, 15}=3.5 \mathrm{~Hz}, J_{14 \mathrm{a}, 15}=11.0 \mathrm{~Hz}, J_{15,16}=10.7 \mathrm{~Hz}$, $1 \mathrm{H}, \mathbf{H}-15), 4.87\left(\mathrm{t}, J_{10 \mathrm{a}, 11}=3.1 \mathrm{~Hz}, J_{10 \mathrm{e}, 11}=10.3 \mathrm{~Hz}, J_{11,12 \mathrm{a}}=3.4 \mathrm{~Hz}, J_{11,12 \mathrm{e}}=11.3 \mathrm{~Hz}, 1 \mathrm{H}\right.$, H-11), 4.80-4.73 (m, $\left.J_{18 \mathrm{e}, 19}=6.0 \mathrm{~Hz}, J_{19,20}=8.8 \mathrm{~Hz}, 3 \mathrm{H}, \mathbf{H - 1 9}, \mathbf{H}-42(2)\right), 4.64\left(\operatorname{app~t}, J_{2 \mathrm{a}, 3}\right.$ $\left.=4.7 \mathrm{~Hz}, J_{2 \mathrm{e}, 3}=9.2 \mathrm{~Hz}, J_{3,4 \mathrm{a}}=3.9 \mathrm{~Hz}, J_{3,4 \mathrm{e}}=10.1 \mathrm{~Hz}, 1 \mathrm{H}, \mathbf{H}-3\right), 4.13\left(\right.$ app t, $J_{4 \mathrm{a}, 5}=4.4$ $\left.\mathrm{Hz}, J_{4 \mathrm{e}, 5}=9.5 \mathrm{~Hz}, J_{5,6 \mathrm{a}}=5.4 \mathrm{~Hz}, J_{5,6 \mathrm{e}}=10.3 \mathrm{~Hz}, 1 \mathrm{H}, \mathbf{H}-5\right), 4.04\left(\operatorname{app} \mathrm{d}, J_{8,9}=3.0 \mathrm{~Hz}, J_{9,10 \mathrm{a}}\right.$ $\left.=3.3 \mathrm{~Hz}, J_{9,10 \mathrm{e}}=10.7 \mathrm{~Hz}, 1 \mathrm{H}, \mathbf{H}-9\right), 3.61\left(\operatorname{app~d}, J_{7 \mathrm{e}, 8}=2.8 \mathrm{~Hz}, J_{7 \mathrm{a}, 8}=11.2 \mathrm{~Hz}, J_{8,9}=3.0\right.$ $\mathrm{Hz}, 1 \mathrm{H}, \mathbf{H - 8}), 3.43\left(\operatorname{app} \mathrm{d}, J_{34,35}=9.8 \mathrm{~Hz}, J_{35,36}=2.6 \mathrm{~Hz}, 1 \mathrm{H}, \mathbf{H}-35\right), 2.85\left(\mathrm{t}, J_{15,16}=10.7\right.$ $\left.\mathrm{Hz}, J_{16,17}=10.6 \mathrm{~Hz}, 1 \mathrm{H}, \mathbf{H}-16\right), 2.66\left(\mathrm{~m}, J_{33,34}=10.1 \mathrm{~Hz}, J_{34,35}=9.8 \mathrm{~Hz}, 1 \mathrm{H}, \mathbf{H}-34\right), 2.61$ $\left(\mathrm{dd}, J_{2 \mathrm{a}, 2 \mathrm{e}}=17 \mathrm{~Hz} J_{2 \mathrm{e}, 3}=9.2 \mathrm{~Hz}, 1 \mathrm{H}, \mathbf{H}-2 \mathrm{e}\right), 2.51\left(\mathrm{dd}, J_{14 \mathrm{a}, 14 \mathrm{e}}=12 \mathrm{~Hz} J_{14 \mathrm{e}, 15}=3.5 \mathrm{~Hz}, 1 \mathrm{H}\right.$, H-14e), $2.46\left(\mathrm{dd}, J_{2 \mathrm{a}, 2 \mathrm{e}}=16.5, J_{2 \mathrm{a}, 3}=4.7,1 \mathrm{H}, \mathbf{H - 2 a}\right), 2.41\left(\mathrm{dd}, J_{17,18 \mathrm{e}}=0.9 \mathrm{~Hz}, J_{18 \mathrm{a}, 18 \mathrm{e}}=\right.$ $\left.14 \mathrm{~Hz}, J_{18 \mathrm{e}, 19}=6.0 \mathrm{~Hz}, 1 \mathrm{H}, \mathbf{H - 1 8 e}\right), 2.37\left(\mathrm{~m}, J_{7 \mathrm{e}, 8}=2.8 \mathrm{~Hz}, 1 \mathrm{H}, \mathbf{H}-7 \mathbf{e}\right), 2.19-2.15\left(\mathrm{~m}, J_{9,10 \mathrm{e}}\right.$ $\left.=10.7 \mathrm{~Hz}, J_{10 \mathrm{e}, 11}=10.3 \mathrm{~Hz}, J_{17,18 \mathrm{a}}=8.7 \mathrm{~Hz} .2 \mathrm{H}, \mathbf{H - 1 0 e}, \mathbf{H 1 8 a}\right), 2.10\left(\mathrm{~m}, J_{35,36}=2.6 \mathrm{~Hz}\right.$, $\left.J_{36,37}=1.9 \mathrm{~Hz}, 1 \mathrm{H}, \mathbf{H - 3 6}\right), 2.00-1.95\left(\mathrm{~m}, J_{5,6 \mathrm{e}}=10.3 \mathrm{~Hz}, J_{11,12 \mathrm{e}}=11.3 \mathrm{~Hz}, 2 \mathrm{H}, \mathbf{H - 6 e}, \mathbf{H}-\right.$ 12e), $1.85-1.80\left(\mathrm{~m}, J_{3,4 \mathrm{e}}=10.1 \mathrm{~Hz}, J_{4 \mathrm{e}, 5}=9.5 \mathrm{~Hz}, J_{7 \mathrm{a}, 8}=11.2 \mathrm{~Hz}, J_{14 \mathrm{e}, 15}=3.5 \mathrm{~Hz}, 3 \mathrm{H}, \mathbf{H}-\right.$ 4e, H-7a, H-14e) $, 1.78-1.70\left(\mathrm{~m}, J_{5,6 \mathrm{a}}=5.4 \mathrm{~Hz}, J_{11,12 \mathrm{a}}=3.4 \mathrm{~Hz}, 2 \mathrm{H}, \mathbf{H}-6 \mathbf{a}, \mathbf{H - 1 2 a}\right), 1.61$ $\left(\operatorname{app~t}, J_{3,4 \mathrm{a}}=3.9 \mathrm{~Hz}, J_{4 \mathrm{a}, 5}=4.4 \mathrm{~Hz}, 1 \mathrm{H}, \mathbf{H}-4 \mathbf{a}\right), 1.56\left(\operatorname{app~d}, J_{9,10 \mathrm{a}}=3.3 \mathrm{~Hz}, J_{10 \mathrm{a}, 10 \mathrm{e}}=14.5\right.$ $\left.\mathrm{Hz}, J_{10 \mathrm{a}, 11}=3.1 \mathrm{~Hz}, 1 \mathrm{H}, \mathbf{H - 1 0 a}\right), 1.46\left(\mathrm{~d}, J_{37,38}=6.5 \mathrm{~Hz}, 3 \mathrm{H}, \mathbf{H - 3 8}\right), 1.31\left(\mathrm{~d}, J_{34,40}=6 \mathrm{~Hz}\right.$, $3 \mathrm{H}, \mathbf{H}-40), 1.25$ (d, $\left.J_{36,39}=7 \mathrm{~Hz}, 3 \mathrm{H}, \mathbf{H}-39\right)$.

${ }^{13} \mathrm{C}$ NMR (150 MHz, pyridine $\left.d-5: \mathrm{CD}_{3} \mathrm{OD}, 10: 1\right)$

$\delta 173.5,172.2,140.9,137.5,135.0,134.8,134.7,134.1,133.7,133.5,133.4,133.3$, $133.2,133.1,132.9,132.8,129.1,118.0,98.6,78.8,76.3,75.2,72.2,71.1,70.4,69.7$, $68.5,68.1,67.0,66.7,65.4,59.0,47.6,45.9,45.1,43.8,43.0,42.8,41.1,41.0,39.4,36.6$, $31.8,30.2,29.5,26.0,24.4,23.5,19.1,17.4,12.9$.

HRMS (ESI)

calculated for $\mathrm{C}_{44} \mathrm{H}_{66} \mathrm{O}_{14}(\mathrm{M}+\mathrm{Na})^{+}: \quad 841.4350$

found:

841.4369 


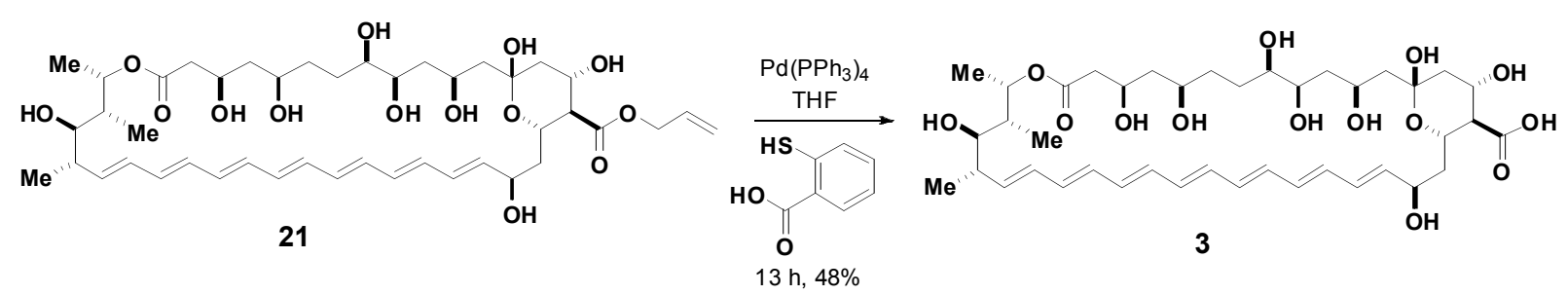

\section{Amphoteronolide B 3}

Prior to the reaction, 21 was azeotropically dried via coevaporation with acetonitrile ( $3 \times 5 \mathrm{~mL})$ and left under vacuum for a minimum of eight hours. The resulting yellow solid $(20 \mathrm{mg}, 0.024$ mmol, 1 eq) was dissolved in THF $(1.5 \mathrm{~mL})$ at $23{ }^{\circ} \mathrm{C}$ and thiosalicylic acid $(20 \mathrm{mg}, 0.12 \mathrm{mmol}, 5$ eq). Palladium tetrakis(triphenylphosphine) $(27 \mathrm{mg}, 0.024 \mathrm{mmol}, 1 \mathrm{eq})$ was added and the solution was stirred for 13 hours, during which time the formation of a precipitate was observed. The reaction was then concentrated in vacuo and the residue was triturated with cold $\left(0{ }^{\circ} \mathrm{C}\right)$ diethyl ether $(5 \times 5 \mathrm{~mL})$. The yellow solid was then dissolved in DMSO $(1.5 \mathrm{~mL})$ and purified by preparative RP-HPLC (Waters SunFire Prep $\mathrm{C}_{18}$ OBD 5 micron $30 \times 150 \mathrm{~mm} ; 250 \mu \mathrm{L}$ injection volume, $25 \mathrm{~mL} / \mathrm{min}$ flow rate, $5 \rightarrow 75 \% \mathrm{MeCN}$ in $10 \mathrm{mM} \mathrm{NH} 4 \mathrm{OAc}$ over 25 minutes) to afford amphoteronolide B (3) $(9 \mathrm{mg}, 0.012 \mathrm{mmol}, 50 \%)$ as a yellow powder.

HPLC

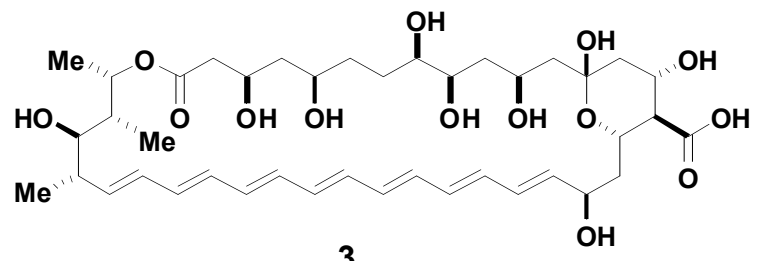

tR: $21.6 \mathrm{~min}$; flow rate $=25 \mathrm{~mL} / \mathrm{min}$, gradient of $5 \rightarrow 75 \% \mathrm{MeCN}$ in $10 \mathrm{mM}$ ammonium acetate over $25 \mathrm{~min}$.

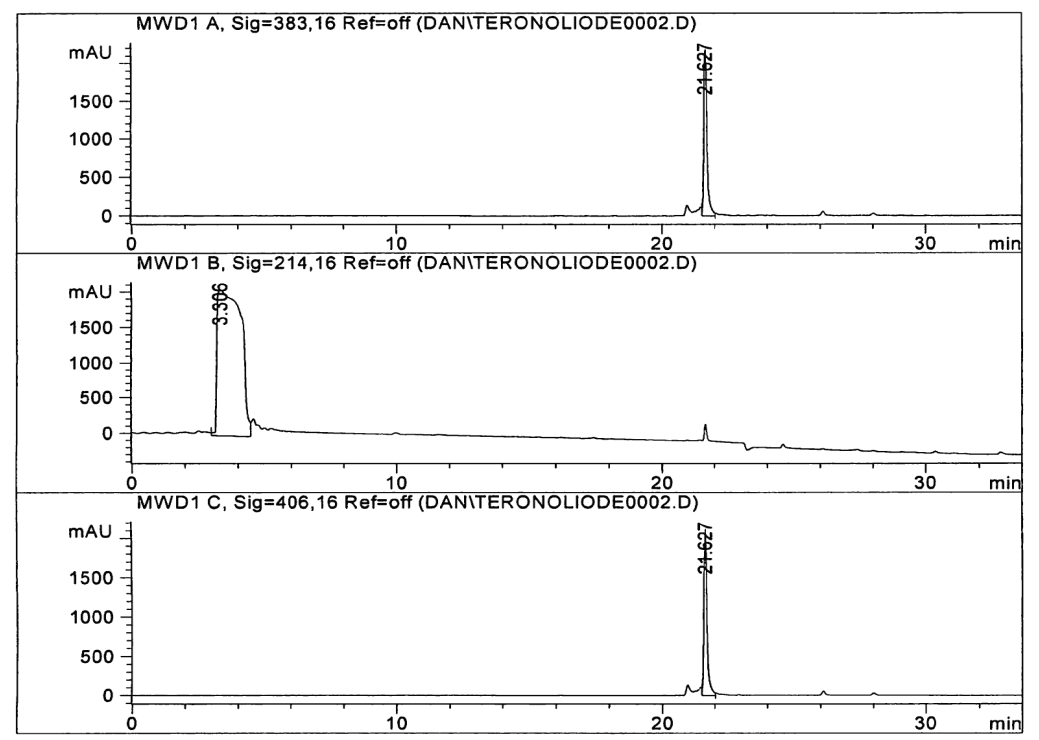


${ }^{1} \mathrm{H}$ NMR (pyridine $d-5: \mathrm{CD}_{3} \mathrm{OD} 10: 1$ )

$\delta$ 6.76-6.67 (m, 2H), 6.59-6.55 (m, 2H), 6.45-6.35 (m, 10H), $5.72(\operatorname{app~d}, J=5 \mathrm{~Hz}, 1 \mathrm{H})$, 5.16 (app t, $J=10 \mathrm{~Hz}, 1 \mathrm{H}), 4.92(\mathrm{bs}, 1 \mathrm{H}), 4.78$ (bs, 2H), 4.57 (app t, $J=10 \mathrm{~Hz}, 1 \mathrm{H}), 4.05$ (app t, $9.5 \mathrm{~Hz}, 1 \mathrm{H}), 3.95(\operatorname{app~d}, J=10.5 \mathrm{~Hz}, 1 \mathrm{H}), 3.65(\operatorname{app~d}, J=4 \mathrm{~Hz}, 1 \mathrm{H}), 3.52$ (app $\mathrm{d}, J=10.5 \mathrm{~Hz}, 1 \mathrm{H}), 3.41(\operatorname{app~d}, J=9 \mathrm{~Hz}, 1 \mathrm{H}), 2.64(\mathrm{bs}, 2 \mathrm{H}), 2.56(\mathrm{dd}, J=10,16.5 \mathrm{~Hz}$, $1 \mathrm{H}), 2.43-2.40(\mathrm{~m}, 2 \mathrm{H}), 2.24$ (bs, 2H), 2.10-2.05 (m, 2H), 1.95-1.90 (m, 2H), 1.79-1.65 $(\mathrm{m}, 5 \mathrm{H}), 1.58(\operatorname{app~d}, J=13.5 \mathrm{~Hz}, 1 \mathrm{H}), 1.51(\operatorname{app~d}, J=11 \mathrm{~Hz}, 1 \mathrm{H}), 1.41(\mathrm{~d}, J=6.5 \mathrm{~Hz}$, $3 \mathrm{H}), 1.28(\mathrm{~d}, J=6.5 \mathrm{~Hz}, 3 \mathrm{H}), 1.21(\mathrm{~d}, J=7 \mathrm{~Hz}, 3 \mathrm{H})$.

\section{HRMS}

Calculated for $\mathrm{C}_{41} \mathrm{H}_{62} \mathrm{O}_{14}(\mathrm{M}+\mathrm{Na})^{+}: 801.4037$

found:

801.4039 

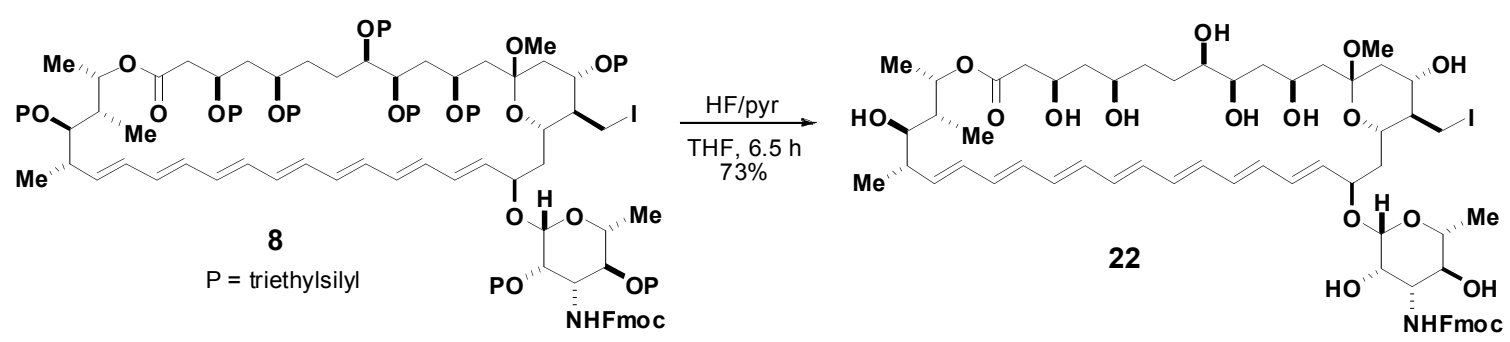

\section{Polyol 22}

To a stirred solution of $8(500 \mathrm{mg}, 0.219 \mathrm{mmol})$ in THF $(7 \mathrm{~mL})$ in a polypropylene vial at $0{ }^{\circ} \mathrm{C}$ was added chilled $\left(0{ }^{\circ} \mathrm{C}\right) 70 \% \mathrm{HF} /$ pyridine complex $(2.2 \mathrm{~mL}, 77 \mathrm{mmol}, 350 \mathrm{eq})$ diluted with THF:pyridine 5:3 (40 mL). The solution was allowed to warm to $25{ }^{\circ} \mathrm{C}$ and stirred for 6.5 hours. The solution was subsequently cooled to $0{ }^{\circ} \mathrm{C}$ and quenched with the addition of saturated aqueous sodium bicarbonate $(100 \mathrm{~mL})$. The resulting yellow emulsion was extracted with $\mathrm{CH}_{2} \mathrm{Cl}_{2}: \mathrm{MeOH}$ 5:1 (5 x $\left.100 \mathrm{~mL}\right)$. The combined organic extracts were washed with brine $(1 \mathrm{x}$ $25 \mathrm{~mL}$ ), dried over sodium sulfate and concentrated in vacuo. Purification of the resulting residue by flash chromatography $\left(\mathrm{SiO}_{2}\right.$; DCM:MeOH 100:1 $\rightarrow$ 15:1) afforded 22 as a yellow solid (202 mg, $0.160 \mathrm{mmol}, 73 \%$ ).

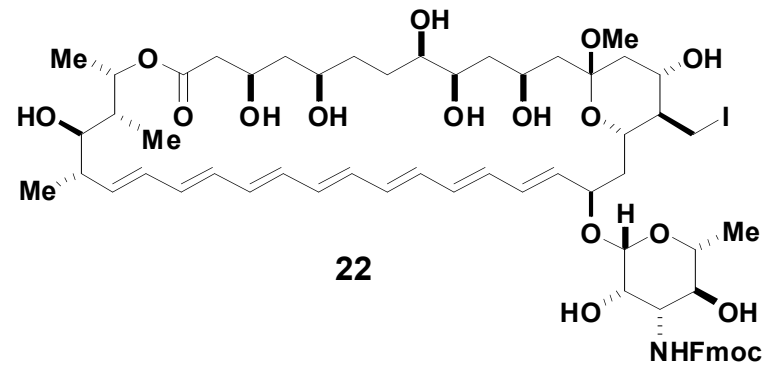

TLC (DCM:MeOH 10:1)

$$
\mathrm{R}_{\mathrm{f}}=0.5 \text {, stained by anisaldehyde }
$$

\section{HPLC}

$\mathrm{tR}=23.40 \mathrm{~min}$; flow rate $=4 \mathrm{~mL} / \mathrm{min}$, gradient of $5 \rightarrow 95 \% \mathrm{MeCN}$ in $5 \mathrm{mM}$ ammonium acetate over 25 min.

\section{${ }^{1} \mathrm{H}$ NMR (500 MHz, $\left.\mathrm{CD}_{3} \mathrm{OD}\right)$}

$\delta 7.79(\mathrm{~d}, J=7.5 \mathrm{~Hz}, 2 \mathrm{H}), 7.68(\mathrm{dd}, J=4.5,7.5 \mathrm{~Hz}, 2 \mathrm{H}), 7.39(\mathrm{t}, J=7 \mathrm{~Hz}, 2 \mathrm{H}), 7.31(\mathrm{t}, J$ $=8 \mathrm{~Hz}, 2 \mathrm{H}), 6.41-6.14(\mathrm{~m}, 12 \mathrm{H}), 5.86(\mathrm{dd}, J=6.5,14 \mathrm{~Hz}, 1 \mathrm{H}), 5.55(\mathrm{dd}, J=9,14 \mathrm{~Hz}$, $1 \mathrm{H}), 5.14(\mathrm{bs}, 1 \mathrm{H}), 4.82(\mathrm{~s}, 1 \mathrm{H}), 4.63(\mathrm{t}, J=7 \mathrm{~Hz}, 1 \mathrm{H}), 4.36(\operatorname{app} \mathrm{d}, J=7 \mathrm{~Hz}, 2 \mathrm{H}), 4.23$ $(\mathrm{t}, J=7 \mathrm{~Hz}, 1 \mathrm{H}), 4.15-4.11(\mathrm{~m}, 1 \mathrm{H}), 3.97-3.93(\mathrm{~m}, 2 \mathrm{H}), 3.86(\mathrm{dt}, J=5.5,10 \mathrm{~Hz}, 1 \mathrm{H})$, $3.80(\mathrm{t}, J=9.5 \mathrm{~Hz}, 1 \mathrm{H}), 3.75(\mathrm{~d}, J=9 \mathrm{~Hz}, 1 \mathrm{H}), 3.72-3.68(\mathrm{~m}, 1 \mathrm{H}), 3.64(\mathrm{dd}, J=2.5,9$ $\mathrm{Hz}, 1 \mathrm{H}), 3.52(\operatorname{app~d}, J=10.5 \mathrm{~Hz}, 1 \mathrm{H}), 3.36-3.31(\mathrm{~m}, 1 \mathrm{H}), 3.23(\operatorname{app} \mathrm{d}, J=9.5 \mathrm{~Hz}, 1 \mathrm{H})$, $3.18(\mathrm{~s}, 3 \mathrm{H}), 2.38(\operatorname{app} \mathrm{dd}, J=7.5,15.5 \mathrm{~Hz}, 1 \mathrm{H}), 2.29$ (dd, $J=9,16.5 \mathrm{~Hz}, 1 \mathrm{H}), 2.23$ (dd, $J=3,16.5 \mathrm{~Hz}, 1 \mathrm{H}), 2.15(\mathrm{dd}, J=5,13 \mathrm{~Hz}, 1 \mathrm{H}), 1.86-1.83(\mathrm{~m}, 1 \mathrm{H}), 1.80-1.75(\mathrm{~m}, 1 \mathrm{H})$, $1.69-1.54(\mathrm{~m}, 8 \mathrm{H}), 1.50-1.39(\mathrm{~m}, 9 \mathrm{H}), 1.30(\mathrm{~d}, J=5.5 \mathrm{~Hz}, 3 \mathrm{H}), 1.20(\mathrm{~d}, J=6.5 \mathrm{~Hz}, 3 \mathrm{H})$, $1.11(\mathrm{~d}, J=6.5 \mathrm{~Hz}, 3 \mathrm{H}), 1.01(\mathrm{~d}, J=7.5,3 \mathrm{H})$. 


\section{${ }^{13} \mathrm{C}$ NMR $\left(125 \mathrm{MHz}, \mathrm{CD}_{3} \mathrm{OD}\right)$} $\delta 172.6,158.7,145.4,145.3,142.6,137.4,135.0,134.5,134.1,134.0,133.9,133.4$, $133.2,132.7,128.8,128.2,126.3,120.9,102.3,98.6,79.0,75.8,75.4,75.1,74.6,72.3$, $71.9,71.5,71.2,68.8,68.3,67.9,66.8,58.3,46.2,44.7,43.3,43.1,41.5,36.0,35.3,30.4$, $18.9,18.3,17.9,12.2$.

HRMS (ESI)

calculated for $\mathrm{C}_{63} \mathrm{H}_{86} \mathrm{INO}_{17}(\mathrm{M}+\mathrm{Na})^{+}: \quad 1278.4838$

found:

1278.4817 

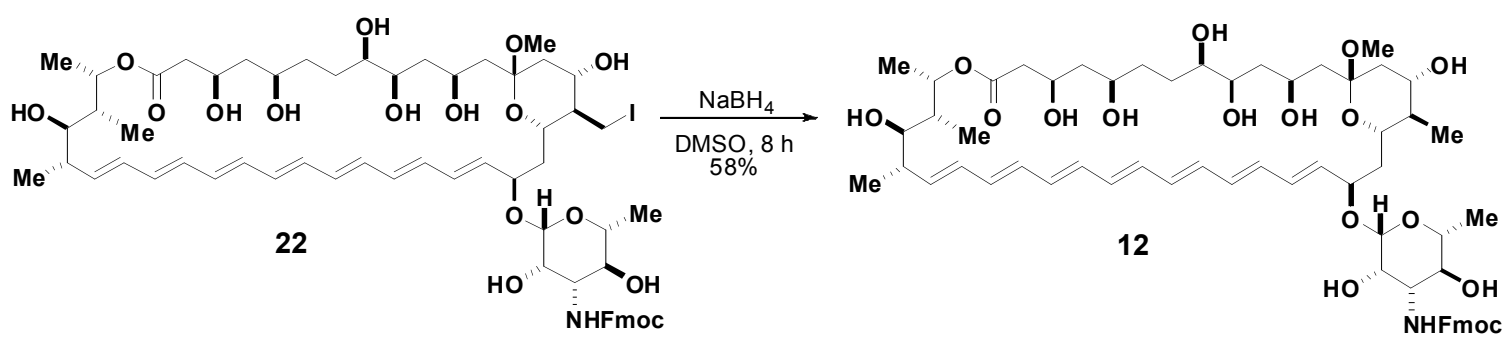

\section{1-Methyl derivative 12}

Prior to the reaction, 22 was azeotropically dried via coevaporation with acetonitrile $(3 \times 10 \mathrm{~mL})$ and left under vacuum for a minimum of eight hours. The resulting yellow solid $(50 \mathrm{mg}, 0.0398$ mmol, 1 eq) was dissolved in DMSO $(1.3 \mathrm{~mL})$ at $23{ }^{\circ} \mathrm{C}$ and sodium borohydride $(7.5 \mathrm{mg}, 0.199$ mmol, 5 eq) was added. The solution was then stirred for 8.5 hours and subsequently quenched with the addition of saturated aqueous sodium bicarbonate $(1 \mathrm{~mL})$. The resulting emulsion was diluted with water $(25 \mathrm{~mL})$ and extracted with $\mathrm{CH}_{2} \mathrm{Cl}_{2}: \mathrm{MeOH}$ 5:1 (5 x $\left.10 \mathrm{~mL}\right)$. The combined organic phases were washed with brine $(1 \times 20 \mathrm{~mL})$, dried over sodium sulfate and concentrated in vacuo. Purification of the residue by flash chromatography $\left(\mathrm{SiO}_{2} ; \mathrm{DCM}: \mathrm{MeOH} 20: 1 \rightarrow 10: 1\right)$ yielded 12 as a yellow solid (26 $\mathrm{mg} 0.023 \mathrm{mmol}, 58 \%)$.

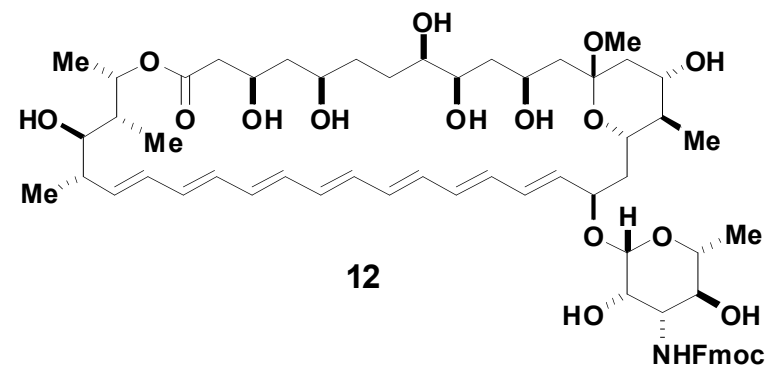

\section{$\operatorname{TLC}\left(\mathrm{CH}_{2} \mathrm{Cl}_{2}: \mathrm{MeOH} 10: 1\right)$}

$\mathrm{R}_{f}=0.5$, stained by anisaldehyde

HPLC

$\mathrm{tR}=22.59 \mathrm{~min}$; flow rate $=4 \mathrm{~mL} / \mathrm{min}$, gradient of $5 \rightarrow 95 \% \mathrm{MeCN}$ in $5 \mathrm{mM}$ ammonium acetate over $25 \mathrm{~min}$.

${ }^{1} \mathrm{H} \mathrm{NMR}\left(500 \mathrm{MHz}, \mathrm{CD}_{3} \mathrm{OD}\right)$

$\delta 7.79(\mathrm{~d}, J=7.5 \mathrm{~Hz}, 2 \mathrm{H}), 7.68(\mathrm{t}, J=6.5 \mathrm{~Hz}, 2 \mathrm{H}), 7.39(\mathrm{t}, J=7 \mathrm{~Hz}, 2 \mathrm{H}), 7.31(\mathrm{t}, 7.5 \mathrm{~Hz}$, 2H), 6.44-6.15 (m, 12H), $5.83(\mathrm{dd}, J=8,15 \mathrm{~Hz}, 1 \mathrm{H}), 5.44(\mathrm{dd}, J=10,14 \mathrm{~Hz}, 1 \mathrm{H}), 5.28$ (bs, $1 \mathrm{H}), 4.61(\mathrm{~s}, 1 \mathrm{H}), 4.49(\mathrm{dt}, J=2.5,8.5 \mathrm{~Hz}, 1 \mathrm{H}), 4.40-4.33(\mathrm{~m}, 2 \mathrm{H}), 4.23(\mathrm{t}, J=7 \mathrm{~Hz}$, $1 \mathrm{H}), 4.18-4.13(\mathrm{~m}, 1 \mathrm{H}), 3.94-3.89(\mathrm{~m}, 3 \mathrm{H}), 3.81(\mathrm{~d}, J=3 \mathrm{~Hz}, 1 \mathrm{H}), 3.72-3.67(\mathrm{~m}, 2 \mathrm{H})$, $3.65-3.62(\mathrm{~m}, 1 \mathrm{H}), 3.59-3.52(\mathrm{~m}, 4 \mathrm{H}), 3.27(\mathrm{dd}, J=6,8 \mathrm{~Hz}, 1 \mathrm{H}), 3.22(\mathrm{dd}, J=1.5,12.5$ $\mathrm{Hz}, 1 \mathrm{H}), 3.16$ (s, 3H), 2.38 (app dd, $J=9.5,16 \mathrm{~Hz}, 1 \mathrm{H}), 2.29$ (dd, $J=9,16.5 \mathrm{~Hz}, 1 \mathrm{H})$, 2.22 (dd, $J=3,16.5 \mathrm{~Hz}, 1 \mathrm{H}), 2.09$ (dd, $J=9,13.5 \mathrm{~Hz}, 1 \mathrm{H}), 2.04-1.97$ (m, 2H), 1.90-1.81 $(\mathrm{m}, 2 \mathrm{H}), 1.72-1.65(\mathrm{~m}, 2 \mathrm{H}), 1.55-1.39(\mathrm{~m}, 8 \mathrm{H}), 1.28(\mathrm{~d}, J=5.5 \mathrm{~Hz}, 3 \mathrm{H}), 1.19(\mathrm{~d}, J=6 \mathrm{~Hz}$, $3 \mathrm{H}), 1.11(\mathrm{~d}, J=6 \mathrm{~Hz}, 3 \mathrm{H}), 1.02(\mathrm{~d}, J=6.5 \mathrm{~Hz}, 3 \mathrm{H}), 1.01(\mathrm{~d}, J=7 \mathrm{~Hz}, 3 \mathrm{H})$. 


\section{Palacios, Anderson and Burke}

\section{${ }^{13} \mathrm{C}$ NMR (125 MHz, $\left.\mathrm{CD}_{3} \mathrm{OD}\right)$}

$\delta 171.5,157.6,144.2,144.1,141.4,136.2,135.8,133.9,133.5,133.4,133.3,133.0$, $132.6,132.4,132.0,130.9,127.6,127.0,125.1,125.0,119.8,107.7,101.3,98.4,76.4$, $74.7,73.7,71.4,71.2,70.6,70.3,70.0,69.7,69.1,67.7,67.5,67.1,66.7,57.1,43.6,42.7$, $42.0,41.8,41.4,40.2,35.0,29.6,28.9,17.8,17.0,16.2,12.1,11.1$.

\section{HRMS (ESI)}

calculated for $\mathrm{C}_{63} \mathrm{H}_{87} \mathrm{NO}_{17}(\mathrm{M}+\mathrm{Na})^{+}: \quad 1152.5872$

found:

1152.5852 

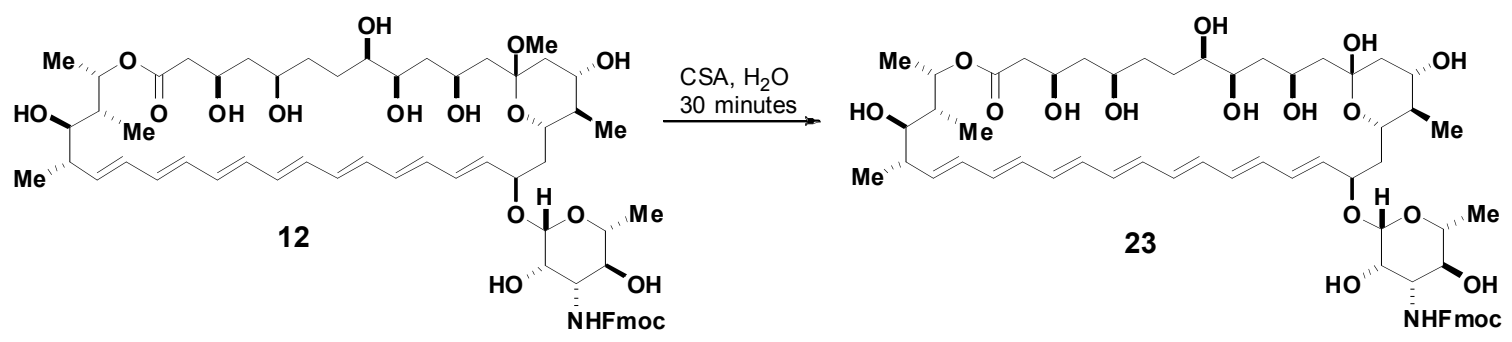

\section{N-Fmoc-41-methyl amphotericin B 23}

To a stirred solution of $12(9 \mathrm{mg}, 0.008 \mathrm{mmol})$ in THF: $\mathrm{H}_{2} \mathrm{O} 2: 1(1 \mathrm{~mL})$ at $23{ }^{\circ} \mathrm{C}$ was added camphorsulfonic acid $(0.6 \mathrm{mg}, 0.002 \mathrm{mmol}, 0.25 \mathrm{eq})$. The solution was stirred for 30 minutes and was then diluted with THF $(1 \mathrm{~mL})$ and quenched by the addition of solid sodium bicarbonate. The solids were removed by filtration through a pad of Celite and the filtrate was concentrated in vacuo to give $\mathbf{2 3}$ as a yellow solid (9 $\mathrm{mg}, 0.008 \mathrm{mmol}, \sim 100 \%$ ). This material was used in the next step without further purification. Alternatively, 23 was purified by preparative RP-HPLC (Waters SunFire Prep $\mathrm{C}_{18}$ OBD 5 micron 30 x $150 \mathrm{~mm} ; 300 \mu \mathrm{L}$ injection volume, $25 \mathrm{~mL} / \mathrm{min}$ flow rate 1:19 $\rightarrow$ 19:1 $\mathrm{MeCN}: 10 \mathrm{mM} \mathrm{NH}_{4} \mathrm{OAc}$, over 25 minutes) for use in NMR studies.

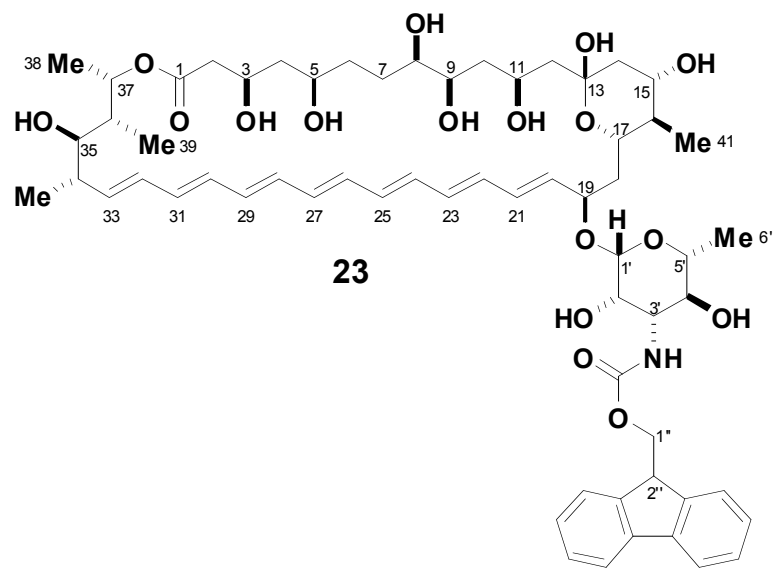

HPLC

$\mathrm{tR}=25.1$ minutes; flow rate $=25 \mathrm{~mL} / \mathrm{min}$, gradient of $5 \rightarrow 95 \% \mathrm{MeCN}$ in $5 \mathrm{mM}$ ammonium acetate over $25 \mathrm{~min}$. 
${ }^{1} \mathrm{H}$ NMR (600 MHz, pyridine $\left.d-5: \mathrm{CD}_{3} \mathrm{OD} 10: 1\right)$

$\delta 7.85(\mathrm{~d}, J=7.2 \mathrm{~Hz}, 2 \mathrm{H}), 7.71(\mathrm{dd}, J=6,8.5 \mathrm{~Hz}, 2 \mathrm{H}), 7.41(\mathrm{t}, J=7.2 \mathrm{~Hz}, 2 \mathrm{H}), 6.74(\mathrm{~m}$, $2 \mathrm{H}), 6.60-6.34(\mathrm{~m}, 11 \mathrm{H}), 5.77\left(\right.$ app d, $\left.J_{36,37}=1.8 \mathrm{~Hz}, 1 \mathrm{H}, \mathbf{H - 3 7}\right), 5.54\left(\mathrm{dd}, J_{32,33}=15 \mathrm{~Hz}\right.$ $\left.J_{33,34}=10.0,1 \mathrm{H}, \mathbf{H}-33\right), 4.97$ (app s, $\left.J_{1^{\prime}, 2^{\prime}}=1.6 \mathrm{~Hz}, 1 \mathrm{H}, \mathbf{H}-\mathbf{1}^{\prime}\right), 4.82-4.78\left(\mathrm{~m}, J_{10 \mathrm{e}, 11}=10.4\right.$ $\left.\mathrm{Hz}, J_{11,12 \mathrm{e}}=11.0 \mathrm{~Hz}, J_{18 \mathrm{a}, 19}=2.5 \mathrm{~Hz}, J_{18 \mathrm{e}, 19}=4.6 \mathrm{~Hz}, J_{19,20}=8.0 \mathrm{~Hz}, 2 \mathrm{H}, \mathbf{H - 1 1}, \mathbf{H}-\mathbf{1 9}\right)$, $4.62\left(\right.$ app t, $\left.J_{2 \mathrm{a}, 3}=1.8 \mathrm{~Hz}, J_{2 \mathrm{e}, 3}=9.1 \mathrm{~Hz}, J_{3,4 \mathrm{a}}=2.0 \mathrm{~Hz}, J_{3,4 \mathrm{e}}=10.1 \mathrm{~Hz}, 1 \mathrm{H}, \mathbf{H}-3\right), 4.51-$ $4.43\left(\mathrm{~m}, J_{16,17}=10.4 \mathrm{~Hz}, J_{17,18 \mathrm{a}}=7.5 \mathrm{~Hz}, 3 \mathrm{H}, \mathbf{H - 1 7}, \mathbf{H - 1}\right.$ '’ (2)), $4.39\left(\operatorname{app~d}, J_{1^{\prime}, 2^{\prime}}=1.6 \mathrm{~Hz}\right.$, $\left.1 \mathrm{H}, \mathbf{H}-\mathbf{2}^{\prime}\right), 4.34$ (dd, $\left.J_{2}, 3^{\prime}=3 \mathrm{~Hz}, J_{3^{\prime}, 4^{\prime}}=9.7 \mathrm{~Hz}, 1 \mathrm{H}, \mathbf{H}-\mathbf{3}^{\prime}\right), 4.29$ (t, $J=7.2 \mathrm{~Hz}, 1 \mathrm{H}, \mathbf{H}-$ 2'), 4.12-4.07 (m, $J_{4 \mathrm{a}, 5}=1.0 \mathrm{~Hz}, J_{4 \mathrm{e}, 5}=9.6 \mathrm{~Hz}, J_{5,6 \mathrm{a}}=1.8 \mathrm{~Hz}, J_{5,6 \mathrm{e}}=10.7 \mathrm{~Hz}, J_{14 \mathrm{e}, 15}=2.6$ $\left.\mathrm{Hz}, J_{14 \mathrm{a}, 15}=11.8 \mathrm{~Hz}, J_{15,16}=11.2 \mathrm{~Hz}, 2 \mathrm{H}, \mathbf{H - 5}, \mathbf{H}-15\right), 4.02-3.99$ (m, $J_{8,9}=3.4 \mathrm{~Hz}, J_{9,10 \mathrm{a}}=$ $2.6 \mathrm{~Hz}, J_{9,10 \mathrm{e}}=10.7 \mathrm{~Hz}, J_{3^{\prime}, 4^{\prime}}=9.7 \mathrm{~Hz}, J_{4^{\prime}, 5^{\prime}}=9.1 \mathrm{~Hz}, 2 \mathrm{H}, \mathbf{H - 9}, \mathbf{H}-4^{\prime}$ ), 3.73 (app dd, $J_{4^{\prime}, 5^{\prime}}$ ' $\left.\left.=9.1 \mathrm{~Hz}, J_{5}, 6^{\prime}=6.6 \mathrm{~Hz}, 1 \mathrm{H}, \mathbf{H - 5}\right)^{\prime}\right), 3.58\left(\operatorname{app~d}, J_{7 \mathrm{e}, 8}=2.5 \mathrm{~Hz}, J_{\mathrm{7a}, 8}=10.6 \mathrm{~Hz}, J_{8,9}=3.4\right.$ $\mathrm{Hz}, 1 \mathrm{H}, \mathbf{H - 8}), 3.43\left(\operatorname{app~d}, J_{34,35}=9.6 \mathrm{~Hz}, J_{35,36}=2.5 \mathrm{~Hz}, 1 \mathrm{H}, \mathbf{H}-35\right), 2.67\left(\operatorname{app~dd}, J_{33,34}=\right.$ $\left.10.0 \mathrm{~Hz}, J_{34,35}=9.6 \mathrm{~Hz}, 1 \mathrm{H}, \mathbf{H - 3 4}\right), 2.60\left(\mathrm{dd}, J_{2 \mathrm{a}, 2 \mathrm{e}}=16.8 \mathrm{~Hz}, J_{2 \mathrm{e}, 3}=9.1 \mathrm{~Hz}, 1 \mathrm{H}, \mathbf{H - 2 e}\right)$, 2.46 (app dd, $\left.J_{18 \mathrm{a}, 18 \mathrm{e}}=16.8 \mathrm{~Hz}, J_{18 \mathrm{e}, 19}=4.6 \mathrm{~Hz}, 1 \mathrm{H}, \mathbf{H - 1 8 e}\right), 2.44-2.40\left(\mathrm{~m}, J_{2 \mathrm{a}, 3}=1.8 \mathrm{~Hz}\right.$, $\left.J_{14 \mathrm{e}, 15}=2.6 \mathrm{~Hz}, 2 \mathrm{H}, \mathbf{H - 2 a}, \mathbf{H}-\mathbf{1 4 e}\right), 2.36-2.33\left(\mathrm{~m}, J_{6 \mathrm{e}, 7 \mathrm{e}}=13.4 \mathrm{~Hz}, J_{7 \mathrm{e}, 8}=2.5 \mathrm{~Hz}, 1 \mathrm{H}, \mathbf{H}-\right.$ 7e), $2.17-2.07\left(\mathrm{~m}, J_{9,10 \mathrm{e}}=10.7 \mathrm{~Hz}, J_{10 \mathrm{e}, 11}=10.4 \mathrm{~Hz}, J_{35,36}=2.5 \mathrm{~Hz}, J_{36,37}=1.8 \mathrm{~Hz}, 2 \mathrm{H}\right.$, H-10e, H-36), 2.02-1.90 (m, $J_{5,6 \mathrm{e}}=10.7 \mathrm{~Hz}, J_{6 \mathrm{e}, 7 \mathrm{a}}=4.4 \mathrm{~Hz}, J_{6 \mathrm{e}, 7 \mathrm{e}}=13.4 \mathrm{~Hz}, J_{11,12 \mathrm{e}}=11.0$ $\left.\mathrm{Hz}, J_{17,18 \mathrm{a}}=7.5 \mathrm{~Hz}, J_{18 \mathrm{a}, 19}=2.5 \mathrm{~Hz}, 3 \mathrm{H}, \mathbf{H}-6 \mathbf{e}, \mathbf{H - 1 2 e}, \mathbf{H - 1 8 a}\right), 1.81-1.76\left(\mathrm{~m}, J_{3,4 \mathrm{e}}=10.1\right.$ $\left.\mathrm{Hz}, J_{4 \mathrm{e}, 5}=9.6 \mathrm{~Hz}, J_{6 \mathrm{e}, 7 \mathrm{a}}=4.4 \mathrm{~Hz}, J_{6 \mathrm{a}, 7 \mathrm{a}}=12.7 \mathrm{~Hz}, J_{7 \mathrm{a}, 8}=10.6 \mathrm{~Hz}, 3 \mathrm{H}, \mathbf{H}-4 \mathbf{e}, \mathbf{H}-7 \mathbf{a}, \mathbf{H 1 2 a}\right)$, $1.73-1.69\left(\mathrm{~m}, J_{5,6 \mathrm{a}}=1.8 \mathrm{~Hz}, J_{6 \mathrm{a}, 7 \mathrm{a}}=12.7 \mathrm{~Hz}, J_{14 \mathrm{a}, 15}=11.8 \mathrm{~Hz}, 2 \mathrm{H}, \mathbf{H - 6 a}, \mathbf{H - 1 4 a}\right), 1.62-$ $1.60\left(\mathrm{~m}, J_{3,4 \mathrm{a}}=2.0 \mathrm{~Hz}, J_{4 \mathrm{a}, 5}=1.0 \mathrm{~Hz}, J_{15,16}=11.2 \mathrm{~Hz}, J_{16,17}=10.4 \mathrm{~Hz}, 2 \mathrm{H}, \mathbf{H - 4 a}, \mathbf{H - 1 6}\right)$, $1.56\left(\mathrm{~d}, J_{5^{\prime}, 6^{\prime}}=6.6 \mathrm{~Hz}, 3 \mathrm{H}, \mathbf{H - 6} \mathbf{6}^{\prime}\right), 1.55-1.52\left(\mathrm{~m}, J_{9,10 \mathrm{a}}=2.6 \mathrm{~Hz}, 1 \mathrm{H}, \mathbf{H - 1 0 a}\right), 1.44\left(\mathrm{~d}, J_{37,38}\right.$ $=6.6 \mathrm{~Hz}, 3 \mathrm{H}, \mathbf{H}-\mathbf{3 8}), 1.30\left(\mathrm{~d}, J_{34,40}=6.6 \mathrm{~Hz}, 3 \mathrm{H}, \mathbf{H}-\mathbf{4 0}\right), 1.24\left(\mathrm{~d}, J_{36,39}=7 \mathrm{~Hz}, 3 \mathrm{H}, \mathbf{H}-\mathbf{3 9}\right)$, $1.23\left(\mathrm{~d}, J_{16,41}=5.2 \mathrm{~Hz}, 3 \mathrm{H}, \mathbf{H}-\mathbf{4 1}\right){ }^{9}$

${ }^{13} \mathrm{C}$ NMR (150 MHz, pyridine $\left.d-5: \mathrm{CD}_{3} \mathrm{OD} 10: 1\right)$

$\delta 172.2,158.0,145.1,144.9,142.0,141.9,138.2,137.6,134.9,134.8,134.5,134.1$, 133.7, 133.5, 133.4, 133.2, 132.9, 130.3, 128.3, 127.8, 126.1, 123.6, 126.0, 120.7, 108.6, 99.6, 98.3, 78.8, 78.1, 76.3, 75.3, 75.0, 72.2, 71.9, 71.5, 70.4, 69.7, 69.5, 68.5, 67.6, 67.1, $58.7,48.1,45.1,44.2,43.1,41.1,36.6,30.3,19.1,18.8,17.5,14.1,12.8$.

HRMS (ESI)

calculated for $\mathrm{C}_{62} \mathrm{H}_{85} \mathrm{NO}_{17}(\mathrm{M}+\mathrm{Na})^{+}: \quad 1138.5715$

found: $\quad 1138.5734$

\footnotetext{
${ }^{9}$ Two of the Fmoc protons were obscured by the pyridine solvent peak.
} 

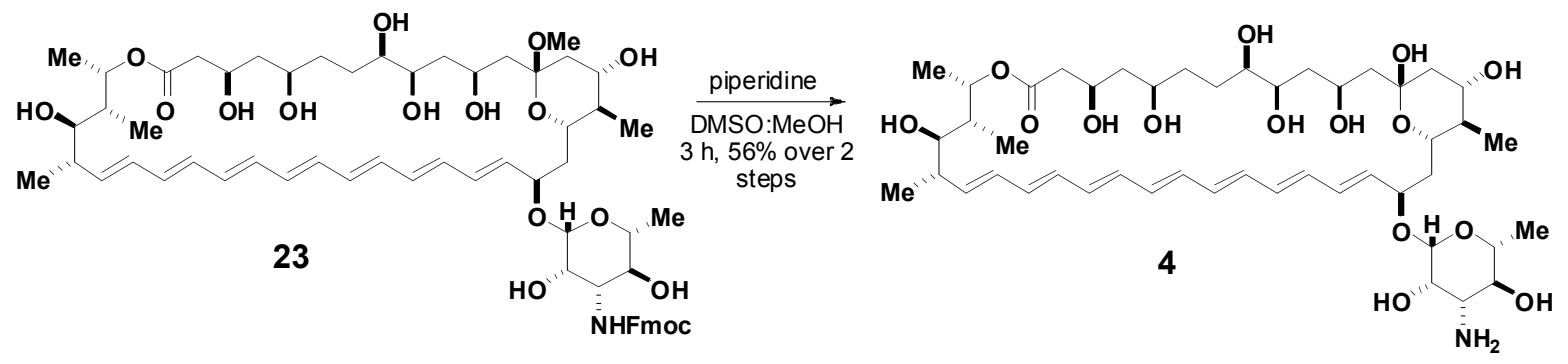

\section{C(41)-Methyl amphotericin B 4}

To a stirred solution of 23 (9 mg, $0.008 \mathrm{mmol})$ in DMSO:MeOH 4:1 (380 $\mu \mathrm{L})$ was added piperidine $(0.02 \mathrm{mmol}, 2 \mu \mathrm{L}, 2 \mathrm{eq})$. The solution was stirred for 3 hours and was then diluted with THF ( $1 \mathrm{~mL}$ ) and purified by prep RP-HPLC (Waters SunFire Prep $\mathrm{C}_{18}$ OBD 5 micron $30 \mathrm{x}$ $150 \mathrm{~mm} ; 300 \mu \mathrm{L}$ injection volume, $25 \mathrm{~mL} / \mathrm{min}$ flow rate 1:19 $\rightarrow$ 19:1 MeCN:10mM NH $4 \mathrm{OAc}$, over 25 minutes) to afford C(41)-methyl amphotericin B (4) as a yellow powder (4 mg, 0.0045 mmol, $56 \%$ over 2 steps).

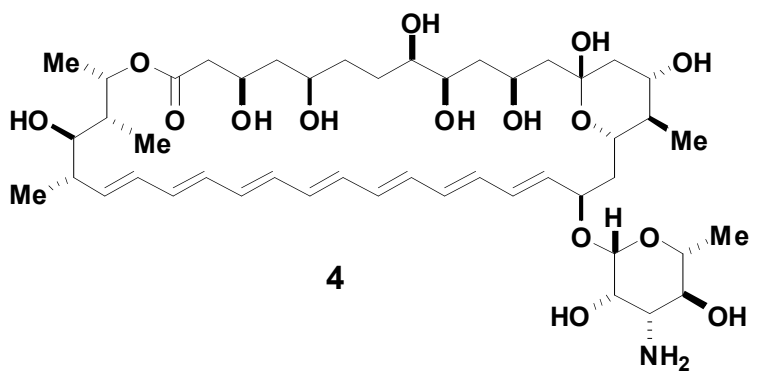

HPLC

$\mathrm{tR}=21.7$ minutes; flow rate $=25 \mathrm{~mL} / \mathrm{min}$, gradient of $5 \rightarrow 95 \% \mathrm{MeCN}$ in $5 \mathrm{mM}$ ammonium acetate over $25 \mathrm{~min}$.

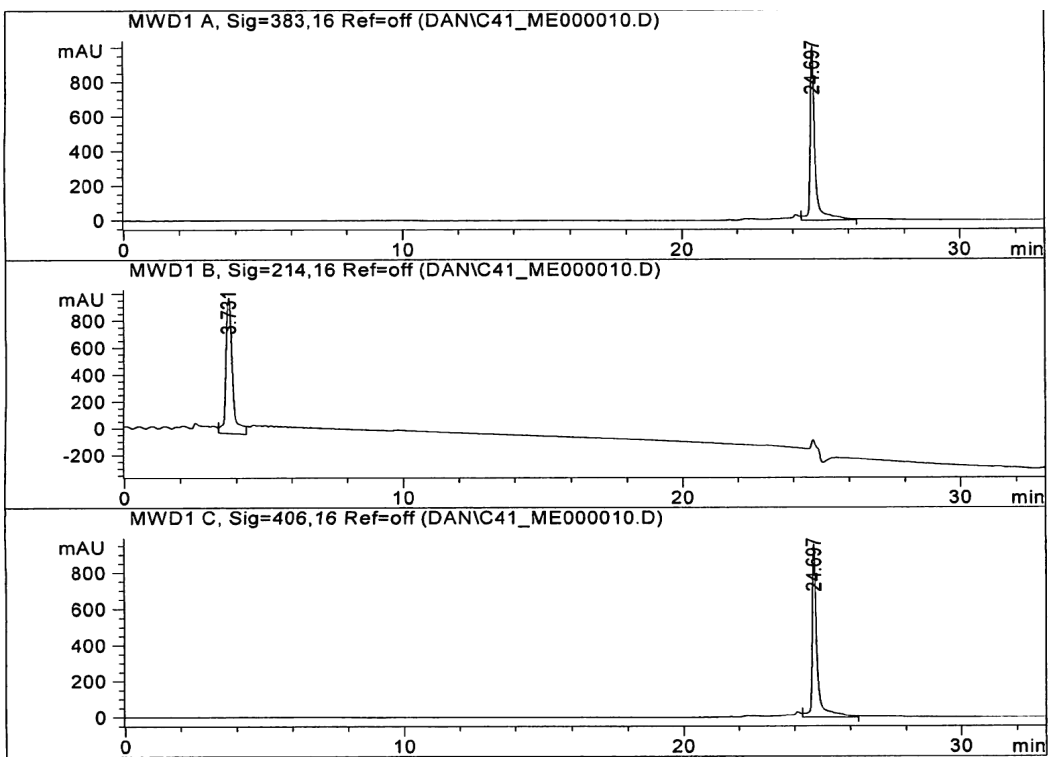


${ }^{1} \mathrm{H}$ NMR (500 MHz, pyridine $\left.d-5: \mathrm{CD}_{2} \mathrm{OD} 10: 1\right)$ $\delta$ 6.78-6.71 (m, 2H), 6.58-6.37 (m, 9H), 6.43-6.35 (m, 2H), $5.77($ app d, $J=5.5 \mathrm{~Hz}, 1 \mathrm{H})$, $5.54(\mathrm{dd}, J=10,15 \mathrm{~Hz}, 1 \mathrm{H}), 4.95(\mathrm{~s}, 1 \mathrm{H}), 4.81-4.77(\mathrm{~m}, 2 \mathrm{H}), 4.61(\mathrm{dt}, J=3,12.5 \mathrm{~Hz}$, $1 \mathrm{H}), 4.45-4.40(\mathrm{~m}, 2 \mathrm{H}), 4.35(\mathrm{~d}, J=2.5 \mathrm{~Hz}, 1 \mathrm{H}), 4.11-4.03(\mathrm{~m}, 2 \mathrm{H}), 4.00$ (app d, $J=11$ $\mathrm{Hz}, 1 \mathrm{H}), 3.77$ (t, $J=9 \mathrm{~Hz}, 1 \mathrm{H}), 3.66-3.58(\mathrm{~m}, 2 \mathrm{H}), 3.57$ (app d, $J=11 \mathrm{~Hz}, 1 \mathrm{H}) 3.42$ (app d, $J=9.5 \mathrm{~Hz}, 1 \mathrm{H}$ ), 2.66 (app dd, $J=7,9.5 \mathrm{~Hz}, 1 \mathrm{H}), 2.60$ (dd, $J=9.5,16.5 \mathrm{~Hz}, 1 \mathrm{H}), 2.49$ (dd, $J=5.5,14.5 \mathrm{~Hz}, 1 \mathrm{H}$ ), 2.41 (app dd, $J=7.5,12 \mathrm{~Hz}, 2 \mathrm{H}), 2.39-2.35(\mathrm{~m}, 1 \mathrm{H}), 2.10$ (app dd, $J=7.5,15.5,2 \mathrm{H}), 1.95-1.88(\mathrm{~m}, 3 \mathrm{H}), 1.81-1.72(\mathrm{~m}, 3 \mathrm{H}), 1.70-1.67(\mathrm{~m}, 2 \mathrm{H})$, $1.66-1.59(\mathrm{~m}, 2 \mathrm{H}), 1.52(\mathrm{~d}, J=6 \mathrm{~Hz}, 3 \mathrm{H}), 1.44(\mathrm{~d}, J=6.5 \mathrm{~Hz}, 3 \mathrm{H}), 1.30(\mathrm{~d}, J=6.5 \mathrm{~Hz}$, $3 \mathrm{H}), 1.24(\mathrm{~d}, J=7 \mathrm{~Hz}, 3 \mathrm{H}), 1.22(\mathrm{~d}, J=6.5 \mathrm{~Hz}, 3 \mathrm{H})$.

HRMS (ESI)

calculated for $\mathrm{C}_{47} \mathrm{H}_{75} \mathrm{NO}_{15}(\mathrm{M}+\mathrm{Na})^{+}: \quad 894.5191$

found:

894.5182 


\section{NMR studies}

Selection of compounds for NMR analysis. MeAmdeB 2 was used directly for NMR studies. Compounds 1, 3, and 4 were not amenable to high resolution NMR analysis due to their poor solubilities in appropriate NMR solvents. However, it has been demonstrated that AmB derivatives having covalent modifications of the carboxylic acid or amine functional groups have the same ground state conformation as judged by $\mathrm{NMR}^{10}$ or X-ray crystallographic analysis, ${ }^{11}$ respectively. Therefore, we chose suitably protected analogs AmB N-acyl methyl ester 17, AmdeB allyl ester 21, and N-Fmoc MeAmB 23 for the conformational analysis of 1, 3, and 4, respectively.

gCOSY NMR spectra. $500 \mathrm{MHz}$ and $600 \mathrm{MHz}$ gCOSY NMR spectra were acquired at $30{ }^{\circ} \mathrm{C}$ with 2048 points, 256 or 512 increments and 1, 4, or 8 transients. Spectra were processed on a SUN Microsystems SPARCstation Ultra 5 computer using Varian VNMR software, version 6.1, revision $\mathrm{C}$, with zero-filling to $4096 \times 4096$ and sine bell apodization such that $\mathrm{sb}=\mathrm{at} / 2$ and $\mathrm{sb} 1$ $=\mathrm{ni} /(2 * \mathrm{sw} 1)$.

H-H NOESY NMR spectra. Samples for NOESY NMR experiments were prepared in an Innovative Technologies, Inc. glove box using a NMR tube sealed with a PTFE screw cap. Sealed ampules of pyridine $d-5$ and $\mathrm{CD}_{3} \mathrm{OD}$ with $0.03 \%$ tetramethylsilane were used as solvents for these experiments. $600 \mathrm{MHz}$ NOESY spectra were acquired at $30{ }^{\circ} \mathrm{C}$ with 2048 points, 256 increments, 8 transients per increment, $\tau_{\text {mix }}=0.7 \mathrm{~s}$, and an interscan delay $(\mathrm{d} 1)$ of $3 * \mathrm{~T} 1$ (standard T1 relaxation experiments were performed for each compound). Spectra were processed using nmrPipe ${ }^{12}$ as follows: 1) 4 points back prediction, 2) $90^{\circ}$ shifted sinebell apodization, 3) zerofilling to 8192 points, 4) Fourier transformation and phasing, 5) linear prediction to 512 points, 6) $90^{\circ}$ shifted sinebell apodization, 7) zero-filling to 2048 points, and 8) Fourier transformation and phasing. The Sparky program, ${ }^{13}$ version 3.113 was used for peak-picking and integration of crosspeaks.

Phase-sensitive COSY (COSYPS) NMR spectra. $500 \mathrm{MHz}$ COSYPS spectra were acquired at $30{ }^{\circ} \mathrm{C}$ with 2048 points, 256 increments, and 4 transients per increment. $600 \mathrm{MHz}$ COSYPS spectra were acquired at $30{ }^{\circ} \mathrm{C}$ with 2458 points, 308 increments and 8 transients per increment. All COSYPS spectra were acquired with sufficient interscan delay to allow for full spinrelaxation $(\mathrm{d} 1=23.2$ seconds, as determined by $\mathrm{T} 1$ relaxation experiments, was sufficient for all compounds).

Gradient HMBC NMR spectrum. A gradient HMBC spectrum of 17 was acquired at $23{ }^{\circ} \mathrm{C}$ with 2048 points, 280 increments, and 128 transients. Parameters for $\mathrm{C}-\mathrm{H}$ coupling were set such that $\mathrm{j} 1 \mathrm{xh}=140 \mathrm{~Hz}$ and $\mathrm{jnxh}=8 \mathrm{~Hz}$. The spectrum was processed on a SUN Microsystems SPARCstation Ultra 5 computer using Varian VNMR software, version 6.1 revision C, with zero-filling to 1024 points in the indirect dimension and sinebell apodization such that $s b=a t / 2$ and $\mathrm{sb} 1=\mathrm{ni} /(2 * \mathrm{sw} 1)$.

\footnotetext{
${ }^{10}$ Sowinski, P.; Pawlak, J.; Borowski, E.; Gariboldi, P. Magn. Res. Chem. 1992, 30, 275-279.

${ }^{11}$ Ganis, P.; Avitabile, G.; Mechliński, W.; Schaffner, C.P. J. Am. Chem. Soc. 1971, 93, 4560-4564.

${ }^{12}$ Delaglio, F.; Grzesiek, S.; Vuister, G. W.; Zhu, G.; Pfeifer, J.; Bax, A. J. Biomol. NMR, 1995, 6, $277-293$.

${ }^{13}$ Goddard, T. D.; Kneller, D. G. SPARKY 3, University of California, San Francisco, http://www.cgl.ucsf.edu/home/sparky/
} 
COSYPS processing and ${ }^{3} \boldsymbol{J}$ determination. Raw COSYPS data were processed as described by Bax and coworkers ${ }^{14}$ to produce a diagonal-suppressed spectrum and a diagonal-only spectrum (Figures S4A and S4B, respectively show representative spectra for the AmdeB allyl ester 21). Amplitude-constrained multiplet evaluation (ACME), ${ }^{14}$ was used to determine ${ }^{3} J \mathrm{H}-\mathrm{H}$ coupling constants (see Table S1 for all coupling constants calculated by ACME).

${ }^{14}$ Delaglio, F.; Wu, Z.; Bax, A. J. Magn. Reson. 2001, 149, 276-281 
Palacios, Anderson and Burke

A
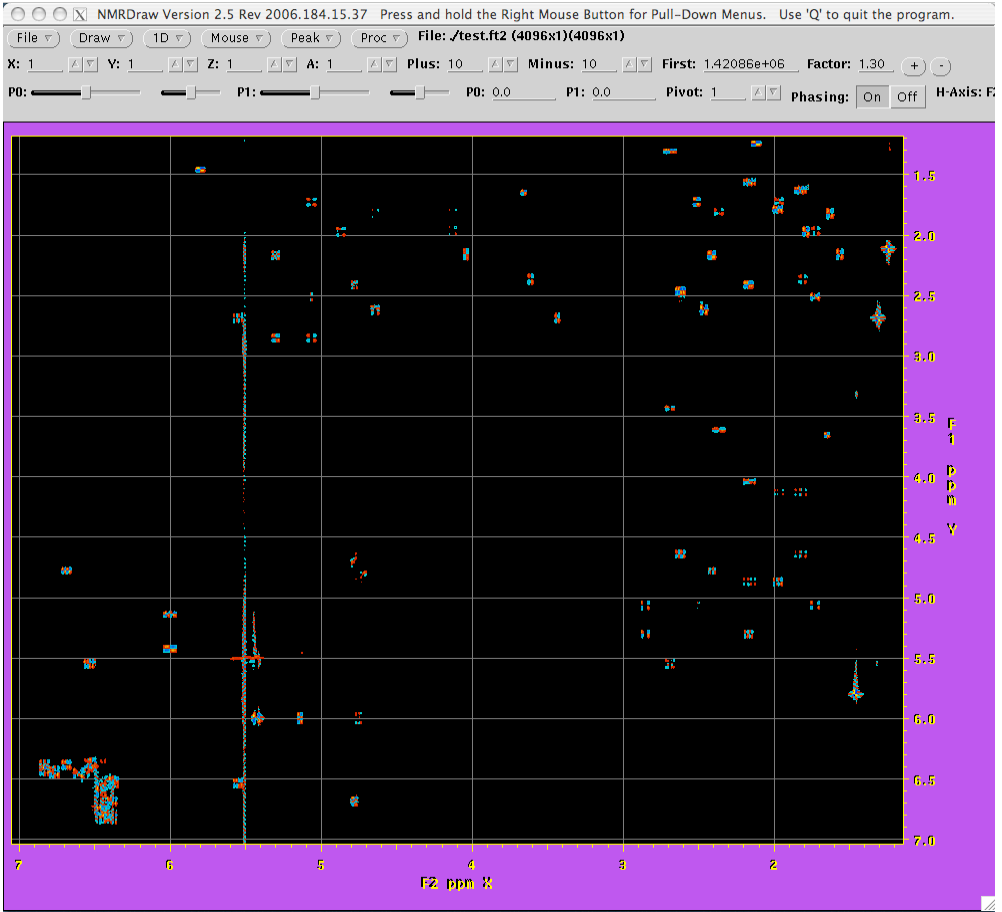

B

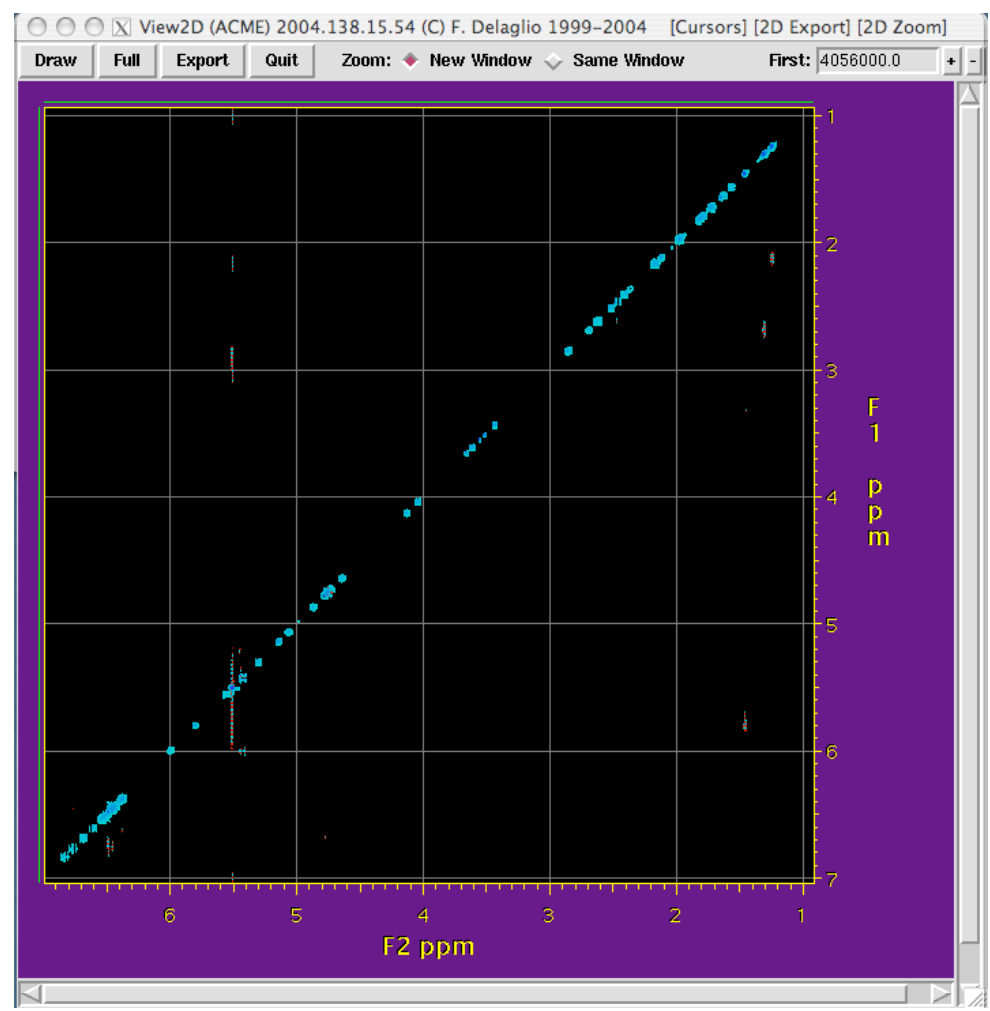

Figure S4. A. Diagonal-suppressed COSYPS spectrum of AmdeB allyl ester 21. B. Diagonal-only COSYPS spectrum of Amde B allyl ester 21. 
Crosspeak Fitting. The ACME method for determining $J$ values from COSYPS spectra is described in detail by Delaglio et al. ${ }^{14}$ Briefly, the ACME program can accurately integrate the crosspeaks of a COSYPS spectrum provided the experiment is run with interscan delay time sufficient for the spins to fully relax. ACME integrates selected peaks from the diagonal-only spectrum and the resulting integration values are used to integrate crosspeaks in the diagonalsuppressed spectrum. Figure S5 shows the results of fitting two peaks from the COSYPS diagonal of AmdeB allyl ester 21. Panels A, B, and C contain; A) the selected region of the spectrum (with peaks for fitting labeled 1 and 2), B) simulated peaks calculated in the fitting process, C) the residual between the experimental and calculated peaks. Therefore, in an accurate simulation, no residual is present for the selected peaks. Through this process, the average integration of selected peaks may be used to integrate crosspeaks from the diagonal-suppressed spectrum.

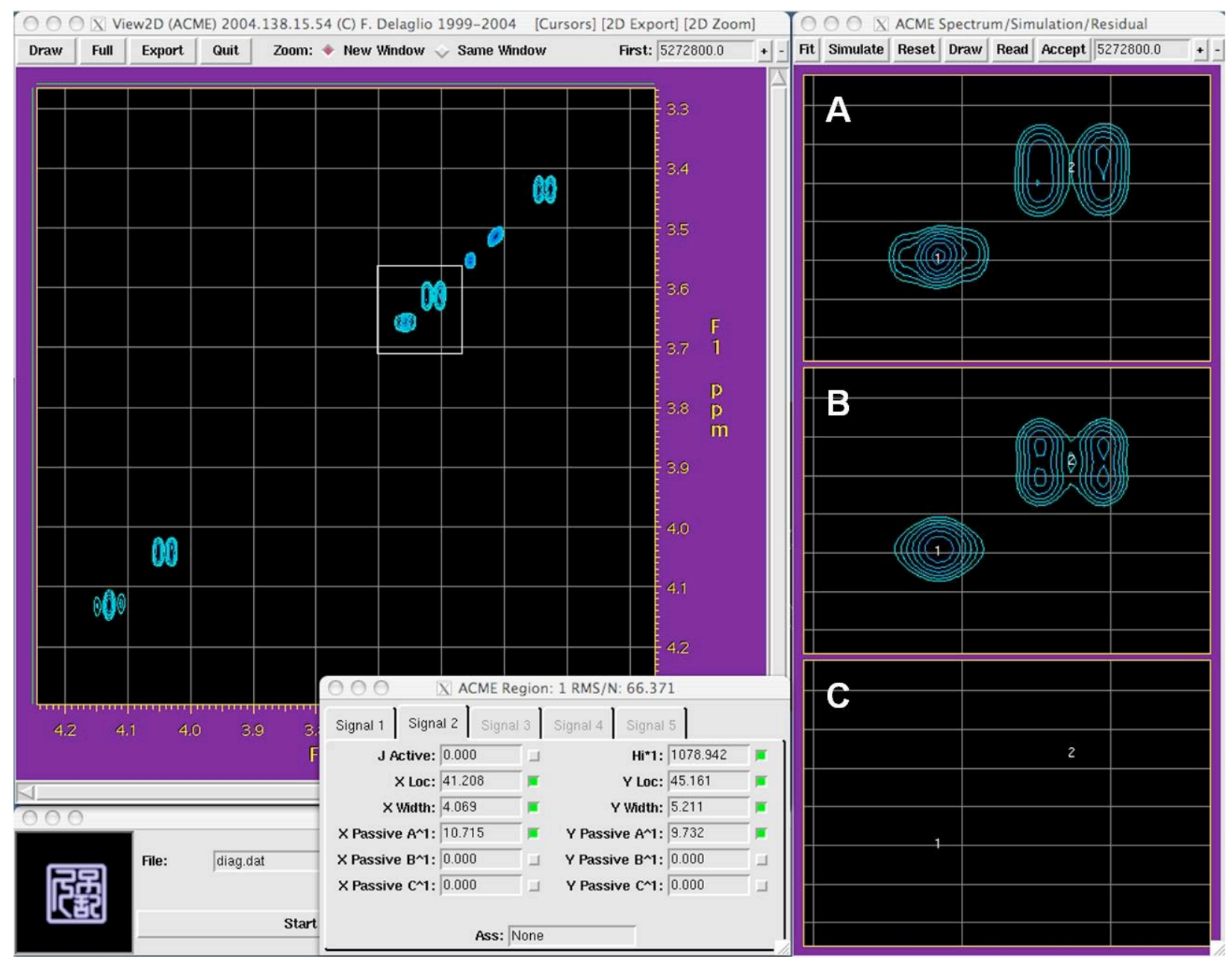

Figure S5. ACME results for fitting the AmdeB allyl ester 21 diagonal. A) The selected spectral region with peaks for fitting labeled 1 and 2. B) Simulated peaks calculated in fitting process. C) Residual between panels A) and B).

The fine structure of crosspeaks in a COSYPS spectrum can be used to obtain coupling constants in a manner analogous to obtaining coupling constants from a one-dimensional multiplet. In a two-dimensional crosspeak, the spacing between antiphase portions of the crosspeak correspond 
to the $J$ value for the associated spins. The ACME method employs the reference integration from the diagonal in a peak-fitting algorithm that integrates selected crosspeaks and calculates coupling constants. Figure S6 shows the results from the fitting algorithm applied to the crosspeak corresponding to protons $\mathrm{H}-18 \mathrm{a}$ and $\mathrm{H}-17$ in AmdeB allyl ester 21. Panel A again contains the selected peak from the spectrum. Panel B depicts the simulated crosspeak, and Panel C displays the residual. The lack of any significant residual is consistent with accurate reproduction of the multiplet fine structure in the fitting process. Similar analysis for each crosspeak in the spectra of compounds 17, 2, 21 and 23 was used to derive the coupling constants from which dihedral constraints were calculated.

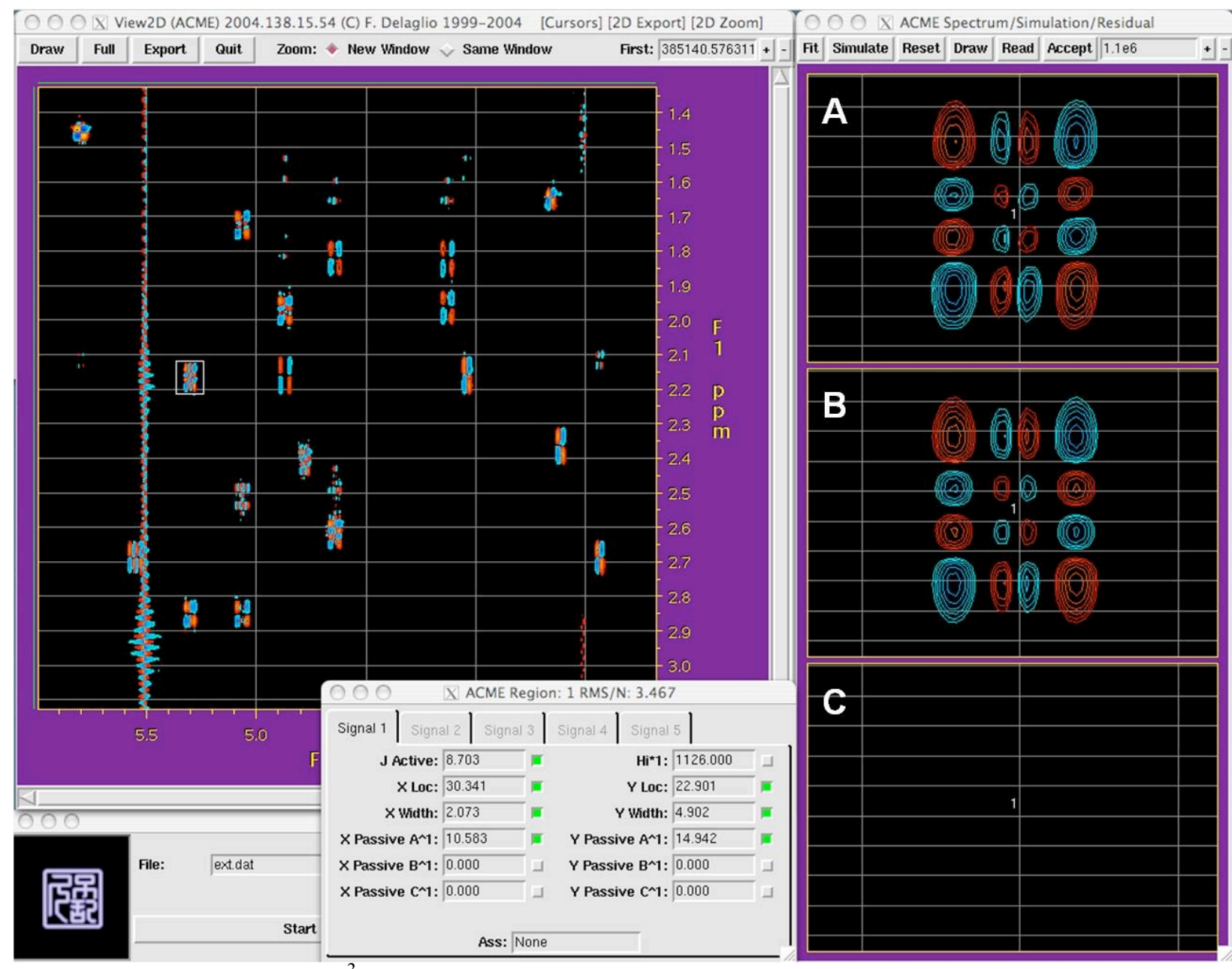

Figure S6. Calculation of ${ }^{3} J$ for H-18a (pseudoaxial) and H-17 for AmdeB allyl ester 21. ACME accurately reproduces the fine structure of the multiplet with no residual between the experimental and calculated peaks.

Dihedral angles were calculated from $\mathrm{H}-\mathrm{H}^{3} \mathrm{~J}$ values according to Altona's extended Karplus equation ${ }^{15}$ using the "HLA (4 substituents)" setting in the MestReJ software. ${ }^{16}$ However, each ${ }^{3} J$ gives rise to 4 possible solutions to the Karplus equation. Methods for choosing the appropriate

\footnotetext{
${ }^{15}$ Haasnoot, C. A. G.; de Leeuw, F. A. A. M.; Altona, C. Tetrahedron, 1980, 36, 2783-2792.

${ }^{16} \mathrm{http}: / / \mathrm{www} . \mathrm{mestrec} . \mathrm{com} /$ producto.php?id=8
} 
value are well-precedented. For example, in the context of conformational analysis of the erythronolide B lactone, Aurichio ${ }^{17}$ and Egan $^{18}$ chose dihedral values consistent with NOE data and the erythronolide B crystal structure, respectively. For our analyses, we chose angles consistent with both NOESY data and the AmB crystal structure. ${ }^{19}$ In some cases, two solutions to the Karplus equation were consistent with both NOESY and crystal structure data, and both solutions were included. The selected dihedral angles $\left( \pm 30^{\circ}\right)$ were used as constraints in Monte Carlo conformational searches (see Section IV).

\section{Energy Minimization Calculations}

NMR-Restrained Model Structures. Monte Carlo conformational searches were performed using the Molecular Operating Environment program (MOE), Version 2006.08, ${ }^{20}$ with the empirical MMFF94x force field and a Born solvation model with no distance cutoffs for nonbonded interactions. Initial atomic coordinates and structure files were generated from the AmB crystal structure using MOE. NMR-derived distance and dihedral constraints were set with a weighting factor of 200. 3500 random conformations were generated and minimized with Gaussian distribution of dihedrals biased towards multiples of $30^{\circ}$, dihedral minimization (RMS = 100), 0.001 Cartesian minimization RMS gradient, 0.0001 Cartesian perturbation, 0.1 RMS tolerance, a maximum of 2000 energy minimization steps for each minimization, a failure limit of 5000, no chiral inversion, no rotation about $\pi$ bonds or amide bonds, and an energy cutoff of 5 $\mathrm{kcal} / \mathrm{mol}$. Force field partial charges were calculated before each minimization. Default values were used for all other parameters.

Consistent with protein structural analysis techniques, ${ }^{21}$ each $\mathrm{H}-\mathrm{H}$ dihedral was constrained to the selected value $\pm 30^{\circ}$. When two solutions to the Karplus equation were selected, both values $\left( \pm 30^{\circ}\right)$ were allowed. Table S1 lists the dihedral constraints used in the conformational searching. Consistent with the standard convention for dihedral angles, values for the dihedral, $\theta$, were defined over the range $-180^{\circ}<\theta \leq 180^{\circ}$. Consistent with the known trans-configuration of the seven double bonds of the polyene moiety, the $\pi$-bonds were constrained to $180 \pm 10^{\circ}$.

Interproton distances were constrained for proton pairs exhibiting NOE correlations, with the lower limit set at $1.8 \AA$ (twice the hydrogen van der Waals radius), and the upper limit set at 5.0 $\AA$. Table S2 lists the NOE correlations used for conformational searching, and Figures S7 - S10 depict these correlations (red lines indicate NOE correlations, see Section VII for NOESY spectra). Notably, all four compounds contain a diagnostic series transannular NOEs between protons of the polyol and those of the polyene.

The Monte Carlo conformational search explores conformational space by randomly perturbing all dihedral angles in the molecule and then minimizing the resulting structures (taking into

\footnotetext{
${ }^{17}$ Auricchio, S.; Fronza, G.; Mele, A. J. Org. Chem. 1992, 57 (2), 452-455.

${ }^{18}$ Egan, R. S.; Martin, J. R.; Perun, T. J.; Mitscher, L. A. J. Am. Chem. Soc. 1975, 97 (16), 4578- 4583.

${ }^{19}$ Ganis, P.; Avitabile, G.; Mechliński, W.; Schaffner, C.P. J. Am. Chem. Soc. 1971, 93, 4560-4564.

${ }^{20}$ Molecular Operating Environment, version 2006.08; Chemical Computing Group: Montreal, Quebec, Canada.

${ }^{21}$ Cavanagh, J.; Fairbrother, W. J.; Palmer, A. G. III; Rance, M.; Skelton, N. J. Protein NMR Spectroscopy:

Principles and Practices, $2^{\text {nd }}$ Ed.; Academic Press: San Diego, 2006; p. 802.
} 
account the restraints as described above). MOE repeated this process 3500 times, and the lowest energy conformation of each compound was used in rigid root mean square (RMS) atom alignment (see below).

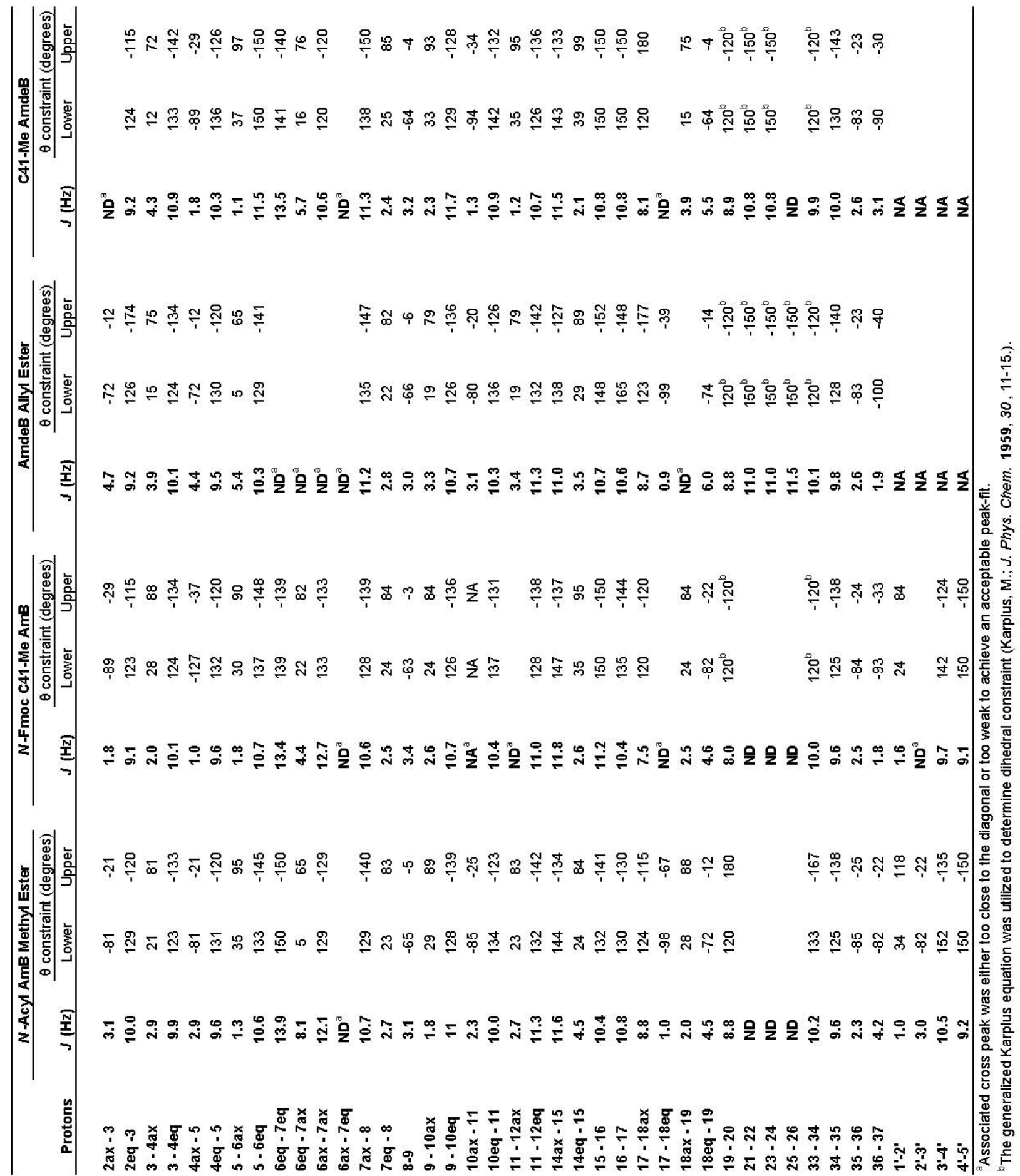

Table S1. Dihedral constraints used in conformational searches using MOE. Also shown are the coupling constants (calculated by ACME) from which the dihedral constraints were derived. 


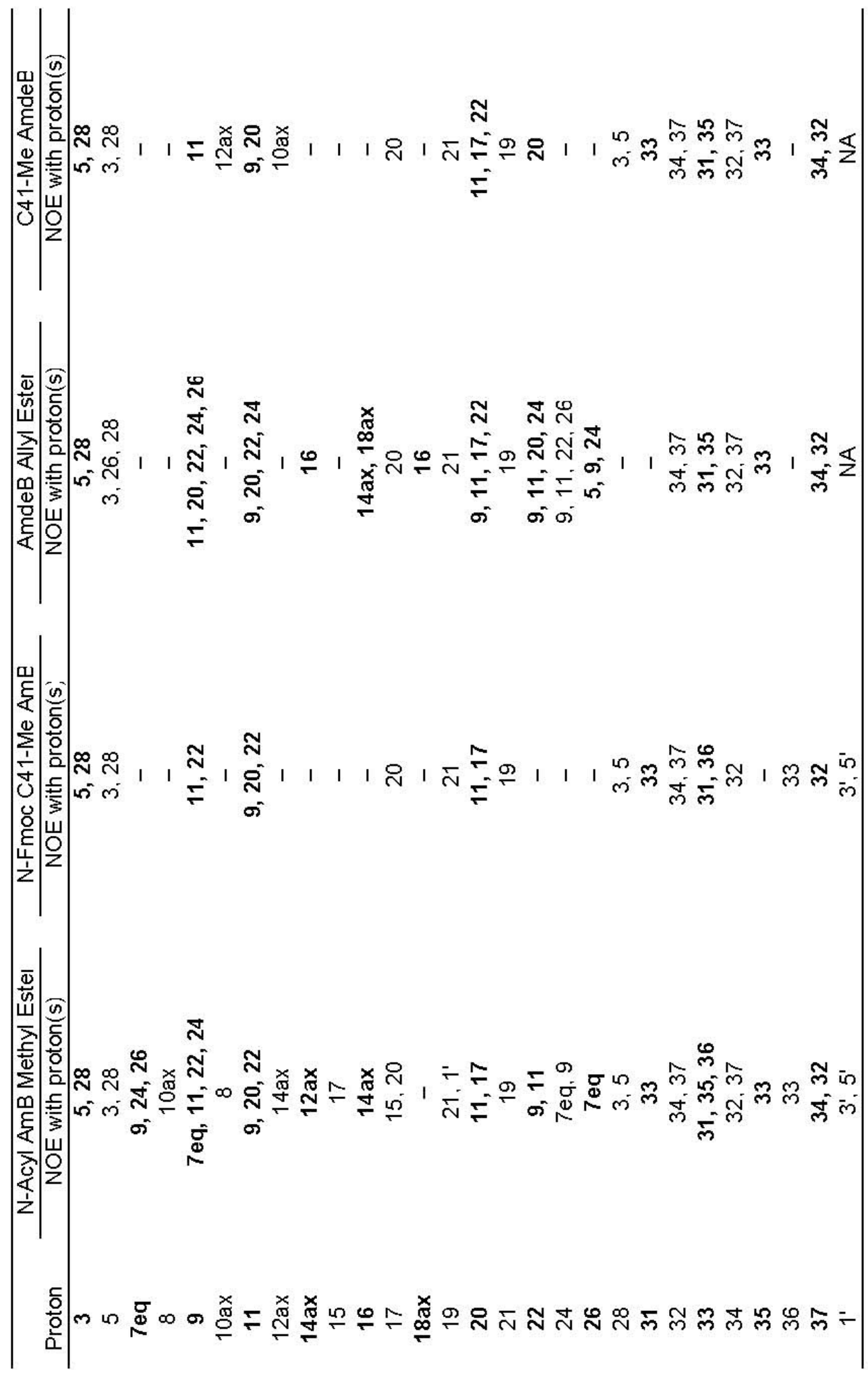

Table S2. Observed NOE correlations used to derive distance constraints in conformational searches using MOE. 


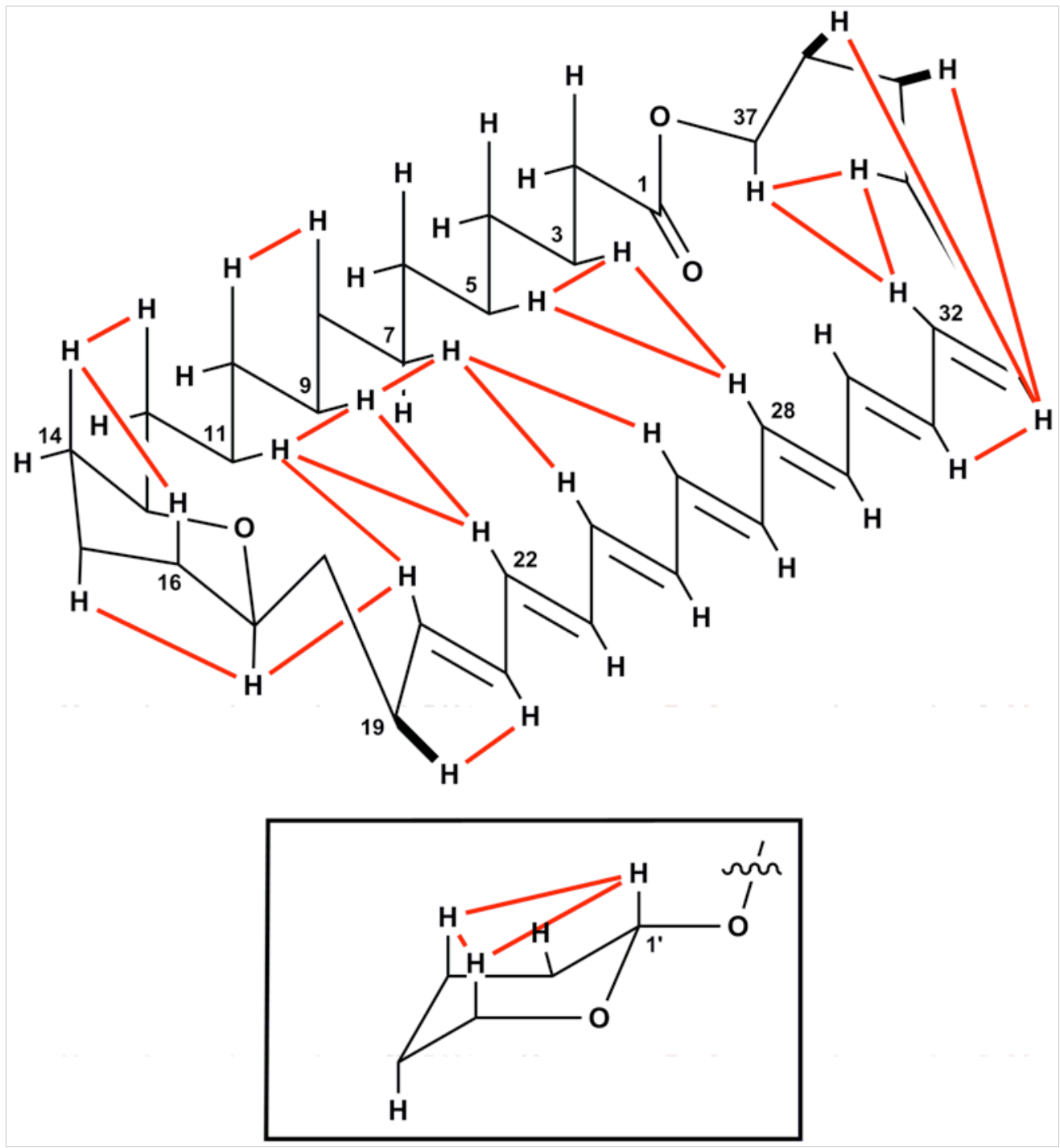

Figure S7. NOE correlations for N-acyl AmB Methyl ester 17. For clarity, appendages other than protons have been removed from the macrolide skeleton. Selected carbon atoms are numbered. 


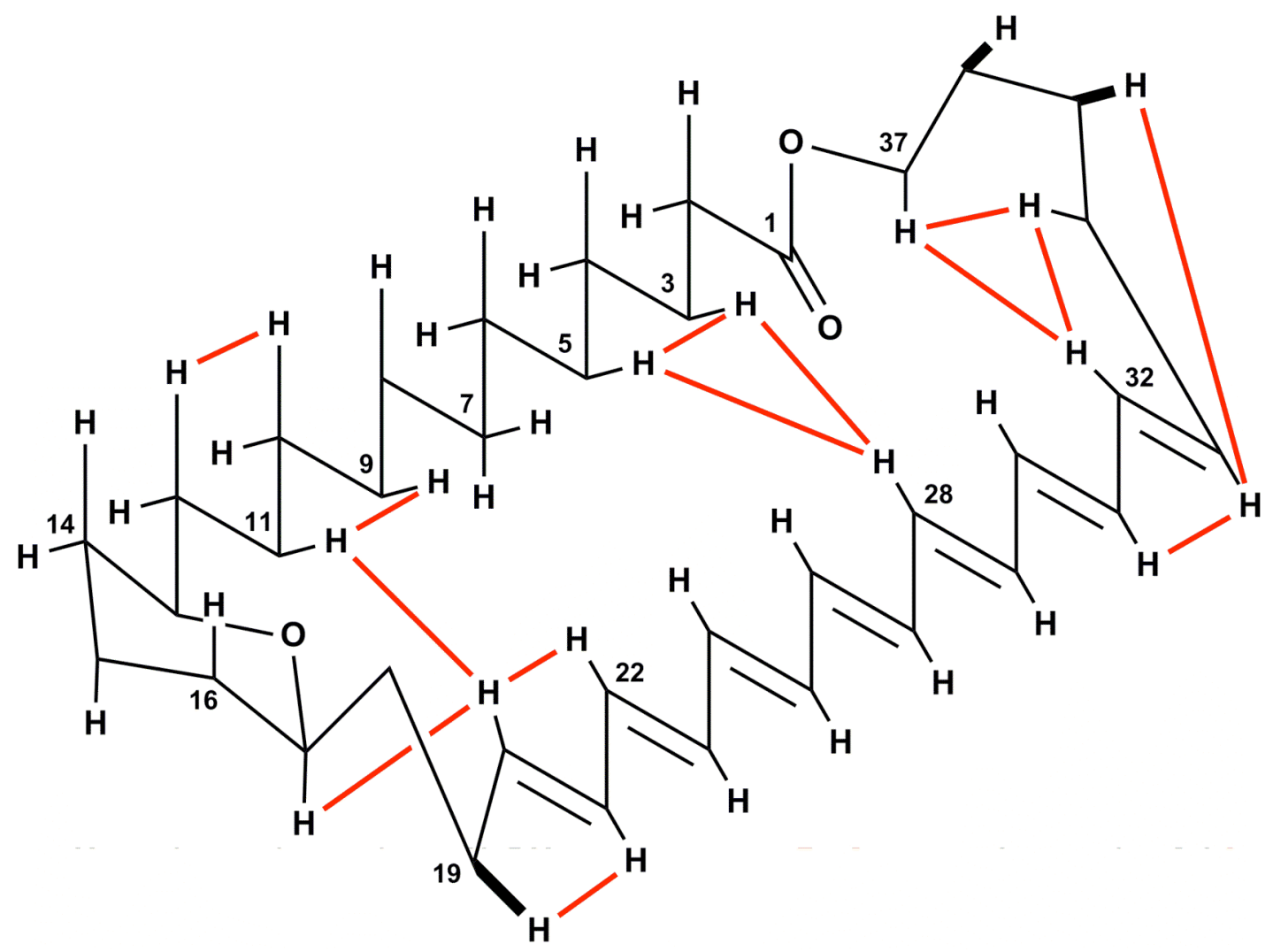

Figure S8. NOE correlations for MeAmdeB 2. For clarity, appendages other than protons have been removed from the macrolide skeleton. Selected carbon atoms are numbered. 


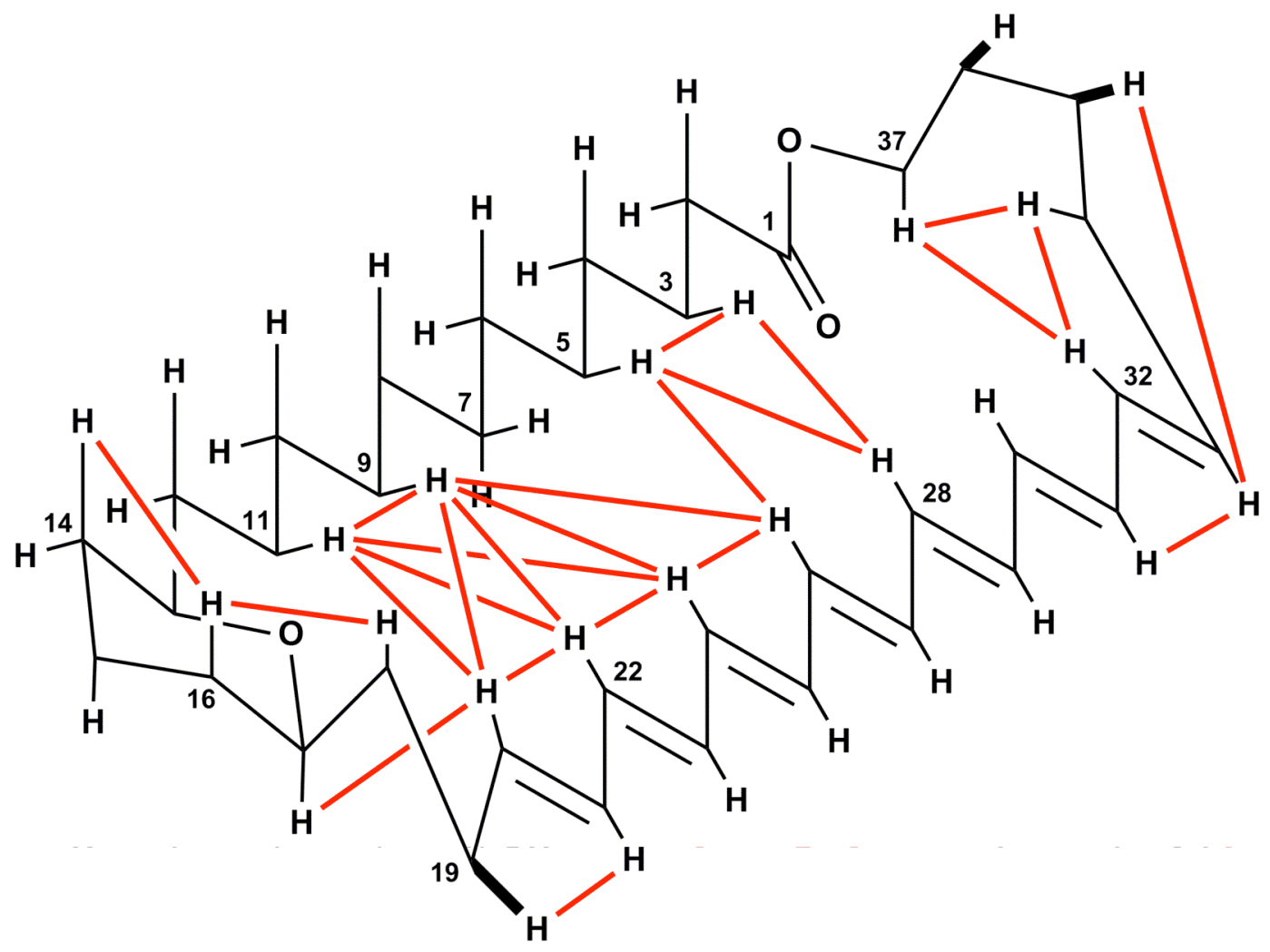

Figure S9. NOE correlations for AmdeB allyl ester 21. For clarity, appendages other than protons have been removed from the macrolide skeleton. Selected carbon atoms are numbered. 

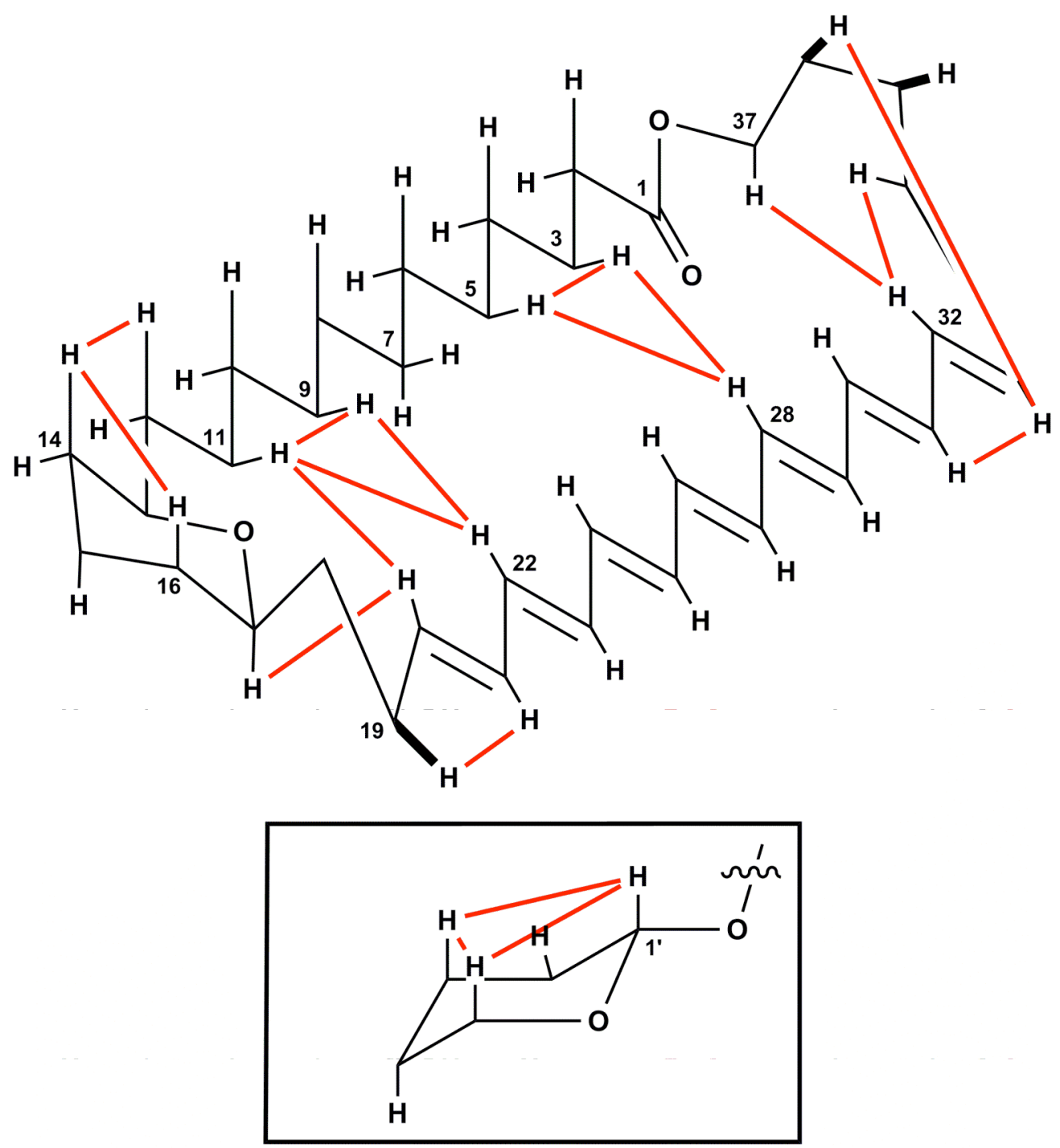

Figure S10. NOE correlations for $N$-Fmoc MeAmB 23. For clarity, appendages other than protons have been removed from the macrolide skeleton. Selected carbon atoms are numbered. 
Rigid RMS atom alignment for NMR-restrained model structures. Only the atoms of the macrolactone ring and the cyclic hemiketal were used for RMS alignment. All other atoms were deleted from the lowest-energy conformers of $\mathbf{1 7}, \mathbf{2}, \mathbf{2 1}$, and $\mathbf{2 3}$, and the resulting skeletons representing the ground-state conformations of AmB 1, MeAmB 2, AmdeB 3, and MeAmdeB 4, respectively were saved as MDL MOL files (*.mol) and imported into the Cerius ${ }^{2}$ program, Version $4.11,{ }^{22}$ with no energy minimization or calculation of charges. Rigid RMS atom alignment revealed RMSD $=0.081 \AA$ for the four structures. The aligned structures were saved as PDB files (*.pdb), and the overlay image (Figure 2 in the text and Figure S11) was generated using Visual Molecular Dynamics (VMD). ${ }^{23}$

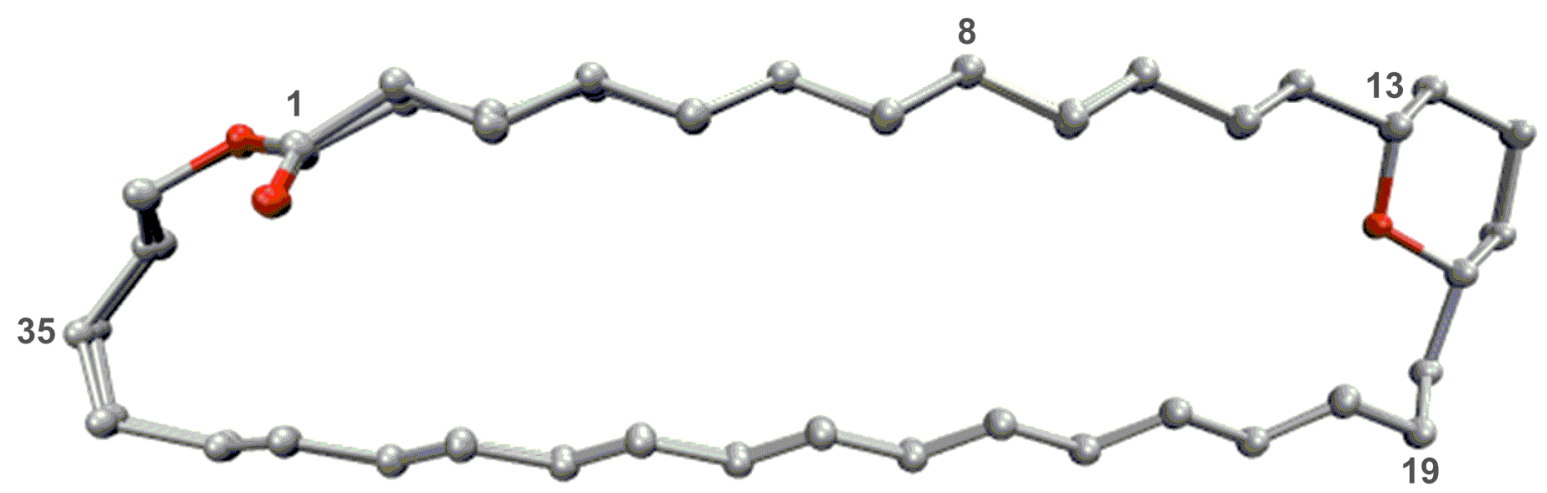

Figure S11. Superposition of the ground state conformation of the macrolactone skeletons of compounds 1-4 (or their more soluble analogs). Rigid RMS atom alignment revealed $\mathrm{RMSD}=0.081 \AA$ for the four structures.

${ }^{22}$ AccelRys Software, Inc. http://www.accelrys.com/products/cerius2/

${ }^{23}$ Humphrey, W.; Dalke, A; and Schulten, K., J. Molec. Graphics 1996, 14, 33-38. 


\section{Antifungal Assays}

General procedure for extinction coefficient determination. A sample of dried compound was massed in a tared vial using a Mettler Toledo MT5 microbalance. This sample was then dissolved in DMSO to create a concentrated stock solution. A portion of this concentrated stock solution was diluted by a factor of five with DMSO to create a dilute stock solution. To achieve the final concentration for UV/Vis experiments, a volume of the dilute stock solution was diluted to $0.5 \mathrm{~mL}$ with $\mathrm{MeOH}$. For each compound, UV/vis experiments were performed using five different final concentrations and each concentration was prepared three times to obtain an average absorbance. The average absorbance was plotted against the concentration. The data was fitted with a linear least squares fit using Excel and the slope of the fitted line was used as the extinction coefficient. ${ }^{24}$
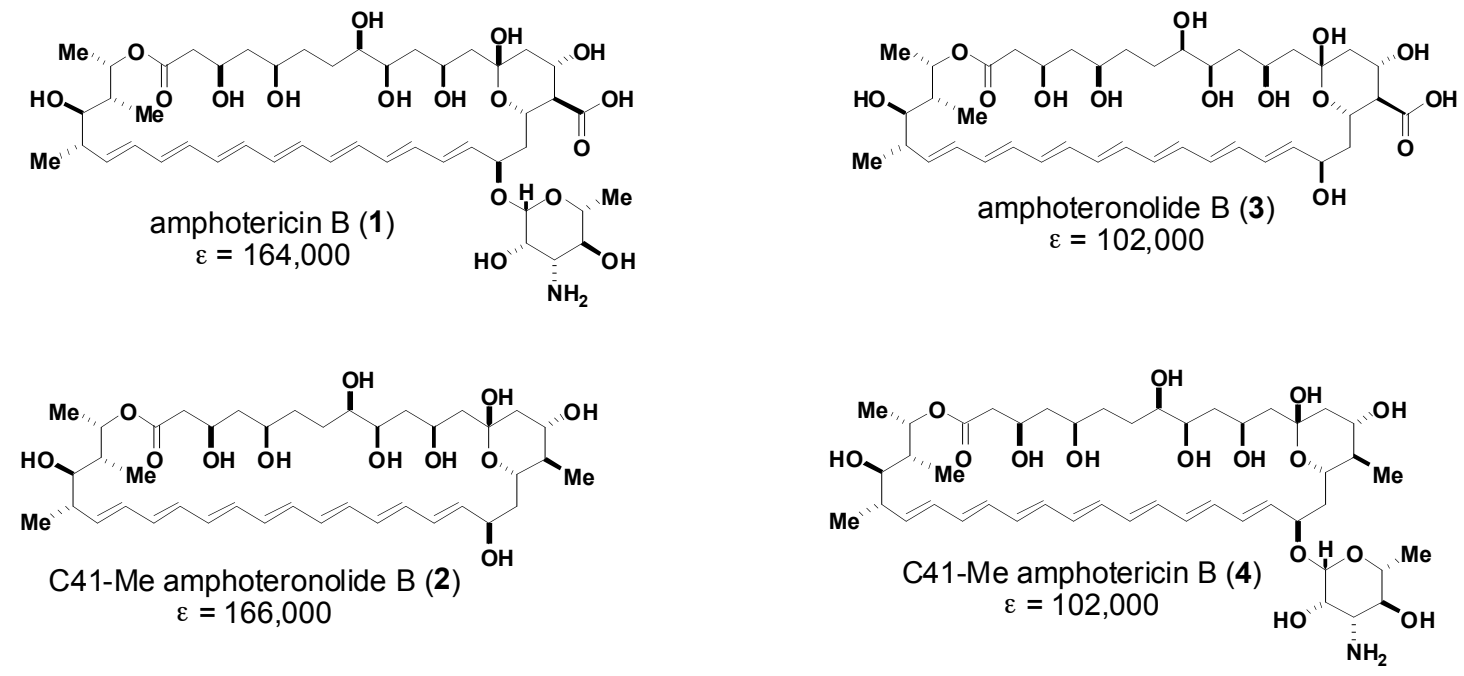

Figure S12. Extinction coefficients for compounds 1-4.

Growth conditions for Saccharomyces cerevisiae. S. cerevisiae (ATCC 9763) cultures were incubated at $30{ }^{\circ} \mathrm{C}$ on yeast peptone dextrose (YPD) agar plates or in YPD liquid cultures with rotary shaking. For liquid YPD medium, yeast extract $(5 \mathrm{~g})$, Bacto peptone $(10 \mathrm{~g})$, and MilliQ $\mathrm{H}_{2} \mathrm{O}(475 \mathrm{~mL})$ were combined and autoclaved at $250{ }^{\circ} \mathrm{C}$ for 15 minutes. Sterile $40 \% \mathrm{w} / \mathrm{v}$ aqueous glucose $(25 \mathrm{~mL})$ was subsequently added (sterile glucose solutions were prepared by dissolving glucose in MilliQ water and autoclaving at $250{ }^{\circ} \mathrm{C}$ for $12 \mathrm{~min}$ ). For agar plates, the same procedure was used except using only $225 \mathrm{~mL}$ of water and combining with $250 \mathrm{~mL}$ sterile $4 \%$ $\mathrm{w} / \mathrm{v}$ aqueous agar solution (sterile $4 \% \mathrm{w} / \mathrm{v}$ agar was prepared by adding agar to MilliQ water and autoclaving at $250{ }^{\circ} \mathrm{C}$ for $15 \mathrm{~min}$ ). Agar plates were prepared by pouring the hot YPD/agar mixture into sterile $15 \mathrm{~mm} \times 100 \mathrm{~mm}$ culture dishes. The plates were allowed to cool at room temperature until the agar had solidified.

Growth conditions for Candida albicans. C.albicans (ATCC 90028) were cultured in the same manner as $S$. cerevisiae except that the cells were incubated at $37^{\circ} \mathrm{C}$ rather than $30^{\circ} \mathrm{C}$.

\footnotetext{
${ }^{24}$ The value obtained for AmB in this manner agrees with the previously reported value; see McNamara, C.M.; Box, S.; Crawforth, J.M.; Hickman, B.S.; Norwood, T.J.; Rawlings, B.J. J. Chem. Soc. Perkin Trans. I 1998, 83-87.
} 
Disk Diffusion Assay. Protocols for disk diffusion assays were adapted from the National Committee of Clinical Laboratory Standards document M2-A8. ${ }^{25}$ Yeast were streaked on YPD agar plates with a sterile toothpick and incubated at $30^{\circ} \mathrm{C}(\mathrm{S}$. cerevisiae $)$ or $37{ }^{\circ} \mathrm{C}(\mathrm{C}$. albicans $)$ until individual colonies could be identified by eye $(\sim 24 \mathrm{~h})$. A single colony was suspended in 150-200 uL YPD liquid medium, and this suspension was added to $\sim 50 \mathrm{~mL}$ YPD liquid medium. The liquid culture was incubated overnight at $30^{\circ} \mathrm{C}(\mathrm{S}$. cerevisiae $)$ or $37^{\circ} \mathrm{C}(\mathrm{C}$. albicans $)$ in a shaker incubator $(200 \mathrm{rpm})$. The saturated cell culture was diluted with YPD medium to an $\mathrm{OD}_{600}$ of $0.1\left(\sim 3 \times 10^{7}\right.$ cells $\left./ \mathrm{mL}\right)$ as measured on a Shimadzu PharmaSpec UV-1700 UV/Visible spectrophotometer. This culture was used to inoculate a YPD plate by streaking the entire plate with a sterile cotton tip applicator three times, turning the plate approximately $60^{\circ}$ after each application and finishing by swabbing the rim of the agar. The plate was allowed to dry for approximately 2 to 3 minutes before application of paper disks impregnated with compounds 14. The disks were prepared in the following manner: 10 microliters of a $4 \mathrm{mg} / \mathrm{ml}$ (S. cerevisiae) or a $2 \mathrm{mg} / \mathrm{mL}$ (C. albicans) solution of each compound in DMSO was added to an $8 \mathrm{~mm}$ disk of Whatman 4 filter paper. Controls were prepared in a similar manner using only DMSO. The disks were then placed on the agar and gently pressed with forceps. All disks, including DMSO controls, were added within 15 minutes of inoculation. After disks were added to the plate the plate was inverted and incubated at $30{ }^{\circ} \mathrm{C}($ S. cerevisiae $)$ or $37{ }^{\circ} \mathrm{C}$ (C. albicans) for 36 to 48 hours prior to assessment. Those compounds which showed a visible zone of growth inhibition were judged to be active (Figure S13). This experiment was repeated for each yeast strain and yielded the same results.

A.

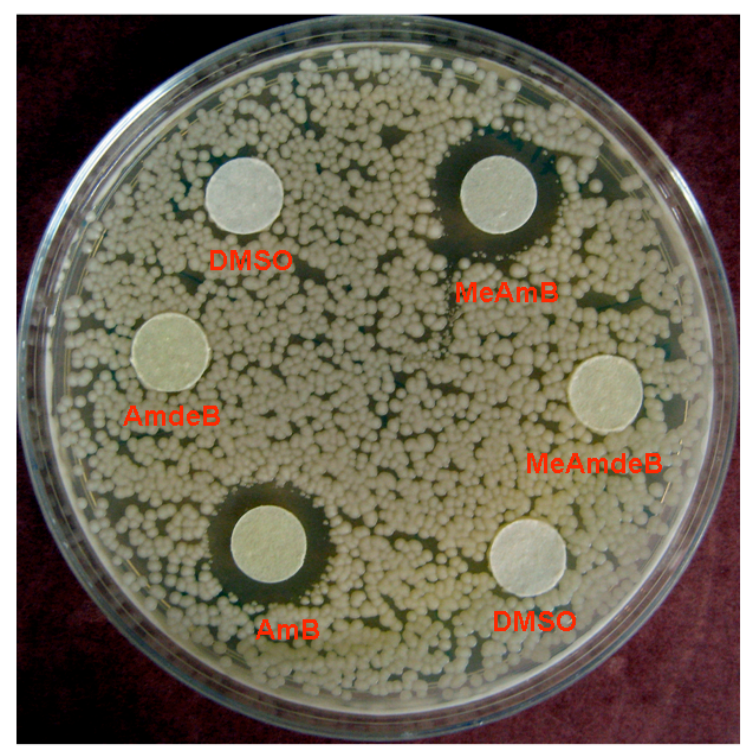

B.

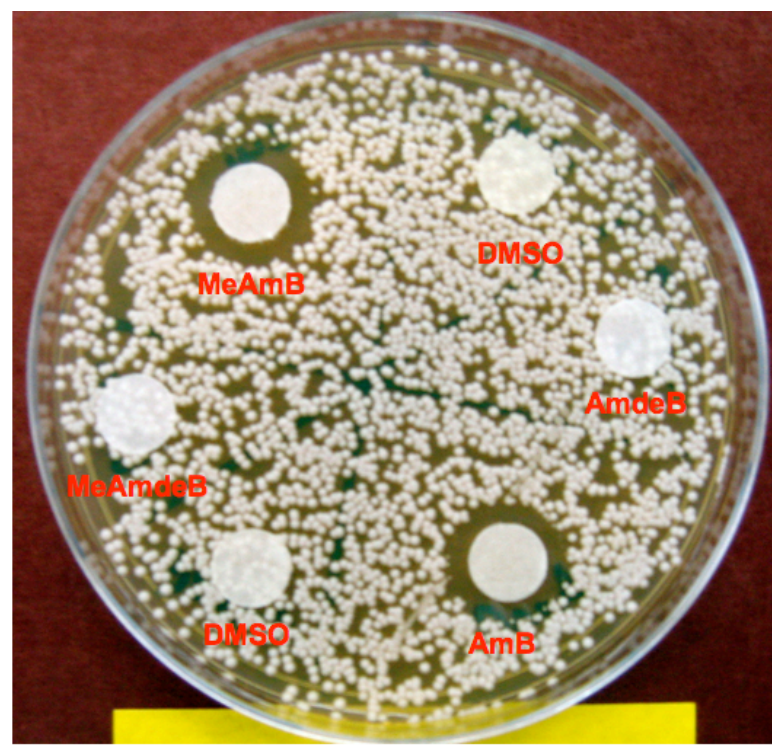

Figure S13. Representative results of disk diffusion assay for A. S. cerevisae and B. C. albicans.

\footnotetext{
${ }^{25}$ National Committee of Clinical Laboratory Standards. Performance Standards for Antimicrobial Disk Susceptibility Tests, M2-A8 Approved Standard- $8^{\text {th }}$ Ed. Vol. 23, Number 1, 2003.
} 
Broth microdilution minimum inhibitory concentration (MIC) assays. Protocols for broth microdilution assays were adapted from the National Committee of Clinical Laboratory Standards document M27-A2 ${ }^{26}$ and by the protocol reported by Paquet and Carreira. ${ }^{27}$ Yeast were streaked on YPD agar plates with a sterile toothpick and incubated at $30{ }^{\circ} \mathrm{C}(\mathrm{S}$. cerevisiae $)$ or $37{ }^{\circ} \mathrm{C}$ (C. albicans) until individual colonies could be identified by eye $(\sim 24 \mathrm{~h})$. A single colony was suspended in 150-200 $\mu \mathrm{L}$ YPD liquid medium, and this suspension was added to $\sim 50$ $\mathrm{mL}$ YPD liquid medium. The liquid culture was incubated overnight at $30{ }^{\circ} \mathrm{C}(\mathrm{S}$. cerevisiae $)$ or $37^{\circ} \mathrm{C}(C$. albicans $)$ in a shaker incubator $(200 \mathrm{rpm})$. The saturated cell culture was diluted with YPD medium to an $\mathrm{OD}_{600}$ of $0.1\left(\sim 3 \times 10^{7}\right.$ cells $\left./ \mathrm{mL}\right)$ as measured on a Shimadzu PharmaSpec UV-1700 UV/Visible spectrophotometer. Aliquots $(195 \mu \mathrm{L})$ of the resulting cell suspension were added to a 96-well plate. Compounds for testing were prepared as $400 \mu \mathrm{M}$ solution in DMSO and this stock solution was serially diluted to concentrations of $320,240,200,160,120,80,40$, 20,10 , and $5 \mu \mathrm{M}$. Aliquots $(5 \mu \mathrm{L})$ of each DMSO solution were added to the 96 -well plate, with each row of the plate containing a different concentration. This 40 -fold dilution resulted in final compound concentrations of $10,8,6,5,4,3,2,1,0.5,0.25$, and $0.125 \mu \mathrm{M}$. DMSO $(5 \mu \mathrm{L})$ was added as a control to each well of the final row. Each concentration was tested in triplicate. Plates were covered with Corning Thermowell aluminum sealing tape and incubated at $30{ }^{\circ} \mathrm{C}(S$. cerevisiae) or $37^{\circ} \mathrm{C}$ (C. albicans) for 18 hours. MIC values were determined as concentration corresponding to the row which showed no visible growth. The assay was repeated three times and the reported values represent the average of these three experiments.

\section{Liposome Studies}

\section{Preparation of pyranine-containing liposomes}

Liposomes were prepared using a modification of the protocol reported by Fujii and coworkers. ${ }^{28}$ Hydrogenated soy phosphatidylcholine (HSPC) ergosterol (erg) and distearoyl phosphatidylcholine (DSPG) were dissolved in chloroform $(0.1 \mathrm{M}, 0.01 \mathrm{M}$ and $0.01 \mathrm{M}$ respectively). To a 13 x $100 \mathrm{~mm}$ glass test tube was added 303 microliters of the HSPC solution, 750 microliters of the erg solution and 1.21 millilters of the DSPG solution. Samples were incubated at $65{ }^{\circ} \mathrm{C}$ for approximately five minutes and the solvent was evaporated with a stream of $\mathrm{N}_{2}$ at $65^{\circ} \mathrm{C}$. The samples were left under vacuum for at least eight hours prior to hydration. The sample was hydrated with $2 \mathrm{~mL}$ pyranine SSB buffer $[0.1 \mathrm{mM}$ pyranine dye, 9\% (w/w) sucrose $10 \mathrm{mM}$ sodium succinate $\mathrm{pH} 5.5$ ] and incubated at $65^{\circ} \mathrm{C}$ for approximately five minutes. The samples were then vortexed vigorously to create a homogenous suspension. The homogenous suspension was probe sonicated 5 minutes ( 5 output watts, $2 \mathrm{~mm}$ probe) with a Sonics and Materials (Danbury, CT) Vibracell Sonicator model VC 130 keeping the internal temperature of the sample at $65^{\circ} \mathrm{C}$ with a vigorously stirred water bath. The samples were then cooled to room temperature and passed through a $0.22 \mu \mathrm{m}$ syringe tip filter (Millipore, Billerica MA). Unencapsulated pyranine was removed by gel exclusion chromatography with a Sephadex G50-150 column $(1.5 \times 25 \mathrm{~cm})$ and SSB as the eluent. The liposome containing fractions were visualized with UV light $\left(\lambda_{366}\right)$.

\footnotetext{
${ }^{26}$ National Committee of Clinical Laboratory Standards. Reference Method for Broth Dilution Antifungal Susceptibility Testing, M27-A2, Approved standard-2 ${ }^{\text {nd }}$ Ed. Vol. 22, Number 15, 2002.

${ }^{27}$ Paquet, V.; Carreira, E. M. Org. Lett. 2006, 8, 1807.

28 a) Fujii, G.; Chang, J.-E.; Coley, T.; Steere, B. Biochemistry 1997, 36, 4959-4968. b) Weakliem, C.L.; Fujii, G.; Chang, J.; Ben-Shaul, A.; Gelbart, W.A. J. Phys. Chem. 1995, 99, 7694-7697.
} 


\section{Liposome permeability assay}

To prepare compounds 1 and $\mathbf{4}$ for the assay, a stock solution of $8 \times 10^{-3} \mathrm{M}$ was prepared. The stock solution was then serially dilute to the following concentrations: $6 \times 10^{-3}, 4 \times 10^{-3}, 2 \times 10^{-3}$, $1 \times 10^{-3}, 8 \times 10^{-4}, 6 \times 10^{-4}, 4 \times 10^{-4}, 2 \times 10^{-4}, 1 \times 10^{-4}, 8 \times 10^{-5}, 6 \times 10^{-5}, 4 \times 10^{-5}, 2 \times 10^{-5}$, and $1 \times$ $10^{-5}$. The liposome suspension was prepared as described above and diluted by a factor of 10with SSB buffer prior to the experiment. A sample was then prepared for analysis by diluting $100 \mu \mathrm{L}$ of the dilute liposome solution to $1.90 \mathrm{~mL}$ with phosphate buffer [ $9 \%$ sucrose, $10 \mathrm{mM}$ (sodium) phosphate $\mathrm{pH}$ 7.4]. To this sample was added $2 \mu \mathrm{L}$ of one of the drug containing solutions and time dependent emission spectra were observed over 300 seconds in 2 second increments. The excitation slitwidth was set at $4 \mathrm{~nm}$ and the emission slitwidth at $6.0 \mathrm{~nm}$. The excitation wavelength was $454 \mathrm{~nm}$ and the emission wavelength was $513 \mathrm{~nm}$.

This liposome permeability assay uses the $\mathrm{pH}$ dependent fluorescent dye pyranine to measure ion flux across the lipid bilayer. ${ }^{28}$ As described above, this dye was trapped within small unilamellar vesicles (SUV's) having an internal $\mathrm{pH}$ of 5.5. The external buffer was then adjusted to $\mathrm{pH} 7.4$ and increasing amounts of $\mathrm{AmB}$ or $\mathrm{MeAmB}$ were added to the exterior solution. Equilibration of the $\mathrm{pH}$ across the lipid bilayer, indicated by an increase in the fluorescence of the pyranineimpregnated liposome sample, signifies an increase in membrane permeability caused by the added compound. The negative log of the concentration of the compound was plotted against $\mathrm{F}_{0} / \mathrm{F}_{5}$ (the fluorescence intensity of the liposome suspension at time $=0$ divided by the fluorescence intensity at time $=5 \mathrm{~min}$.) to generate the plot shown in Figure S14.

\section{Change in fluorescence versus concentration of compound}

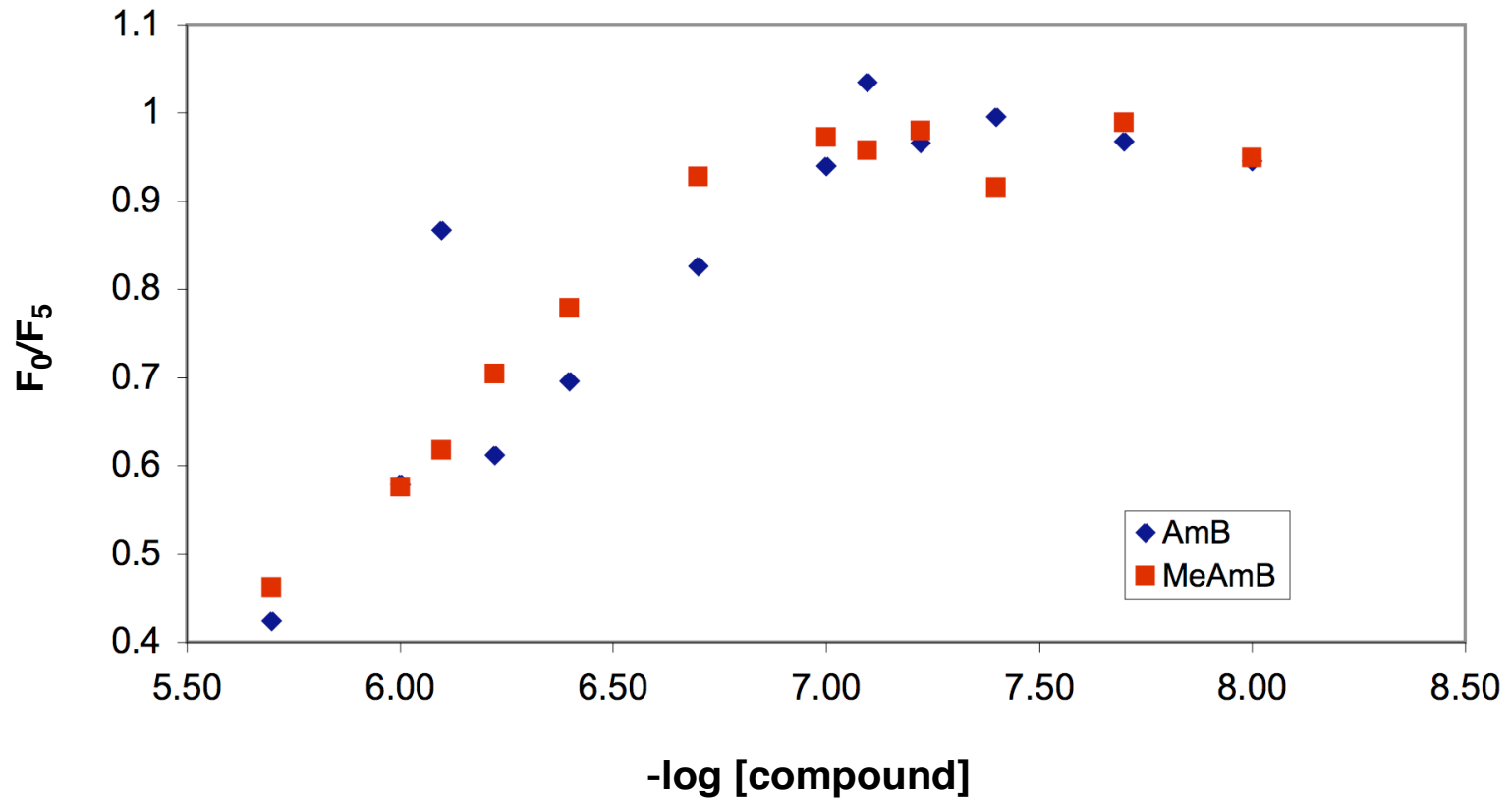

Figure S14. Change in fluorescence versus concentration of compound. $F_{0} / F_{5}$ represents the fluorescence intensity of the pyranine-impregnated liposome suspension at time $=0$ divided by the fluorescence intensity at time $=5 \mathrm{~min}$. A reduction in this ratio indicates the permeabilization of liposomes. ${ }^{28}$ Data represent the average of two experiments. 